Christopher Joseph Ulishney

West Virginia University, cjulishney@mix.wvu.edu

Follow this and additional works at: https://researchrepository.wvu.edu/etd

Part of the Heat Transfer, Combustion Commons

\author{
Recommended Citation \\ Ulishney, Christopher Joseph, "Experimental Design, Testing, and Evaluation of Methods to Improve the \\ Efficiency and Reduce Emissions from a Small Two-stroke Natural Gas Engine" (2018). Graduate Theses, \\ Dissertations, and Problem Reports. 3707. \\ https://researchrepository.wvu.edu/etd/3707
}

This Thesis is protected by copyright and/or related rights. It has been brought to you by the The Research Repository @ WVU with permission from the rights-holder(s). You are free to use this Thesis in any way that is permitted by the copyright and related rights legislation that applies to your use. For other uses you must obtain permission from the rights-holder(s) directly, unless additional rights are indicated by a Creative Commons license in the record and/ or on the work itself. This Thesis has been accepted for inclusion in WVU Graduate Theses, Dissertations, and Problem Reports collection by an authorized administrator of The Research Repository @ WVU. For more information, please contact researchrepository@mail.wvu.edu. 


\title{
Experimental Design, Testing, and Evaluation of Methods to Improve the Efficiency and Reduce Emissions from a Small Two- Stroke Natural Gas Engine
}

Christopher J. Ulishney

Thesis submitted to the Benjamin M. Statler College of Engineering and Mineral Resources at West Virginia University in partial fulfillment of the requirements for the degree of

Master of Science in

Mechanical Engineering

\author{
Derek Johnson, Ph.D., Chair \\ Cosmin Dumitrescu, Ph.D. \\ Hailin Li, Ph.D. \\ Department of Mechanical and Aerospace Engineering \\ Morgantown, West Virginia
}

2018

Keywords: small two-stroke, natural gas, efficiency, injection, emissions, tuning Copyright 2018 Christopher J. Ulishney 


\section{Abstract \\ Experimental Design, Testing, and Evaluation of Methods to Improve the Efficiency and Reduce Emissions from a Small Two-Stroke Natural Gas Engine}

\section{Christopher J. Ulishney}

Decentralized power generation is a research area of interest due to possible improvements in electrical generation efficiency and grid resilience. Two-stroke engines are simple, inexpensive, power dense systems that could serve as the prime-movers for combined heat and power (CHP) systems. In addition, such systems could be fueled on natural gas (NG) that is readily available to serve as a reliable fuel source in most households. However, most two-stroke engines are inefficient and produce excessive emissions. This research focused on methods to simultaneously improve engine efficiency and decrease emissions from a $34 \mathrm{cc}$ air-cooled, two-stroke engine retrofitted to operate on NG. The engine type and size were selected for decentralized household power generation at the 1-kilowatt $(\mathrm{kW})$ level. The engine utilized resonant intake and exhaust systems designed for operation at a fixed frequency of $90 \mathrm{~Hz}$ (5400 RPM) using Helmholtz resonance theory. Testing was conducted at wide open throttle (WOT) with electronic injection timing and ignition timing set for maximum brake torque (MBT). Two different fueling strategies and two variations in resonant exhaust systems were examined. The engine was first tested with port injection (PI) of NG with a near optimum baseline exhaust, then using low pressure direct injection (LPDI) with the near optimum exhaust, and finally with LPDI and an optimized resonant exhaust. Maximum indicated efficiency was $31.2 \%$ for the optimized LPDI system. Using PI as a baseline, LPDI increased efficiency by a relative $81 \%$ and $70 \%$ for the optimized and near optimum exhausts, respectively. Brake specific fuel consumption (BSFC) decreased by $33 \%$ and $32 \%$, while indicated power increased by $46 \%$ and $25 \%$, respectively. Emission levels met EPA standards for non-methane hydrocarbon plus nitrogen oxides $\left(\mathrm{NMHC}+\mathrm{NO}_{\mathrm{x}}\right)$ and carbonmonoxide (CO) under all test configurations. At the most efficient points LPDI operation decreased $\mathrm{NMHC}+\mathrm{NO}_{\mathrm{x}}$ by $46 \%$ for both exhausts as compared to PI, while $\mathrm{CO}$ increased under LPDI. This research validates that a resonance tuned, LPDI, NG, two-stroke engine could be incorporated into an emissions compliant decentralized power generation system with high efficiency at the $1 \mathrm{~kW}$ level. The findings will support future efforts in designing efficient, economically competitive, and clean CHP systems. 


\section{Acknowledgements}

I would like to thank Dr. Thompson for having selected me as an undergraduate applied thermodynamics grader, since this position led me on a direct path for graduate school. I would also like to thank Dr. Thompson for his recommending me to the new thermodynamics instructor, Dr. Derek Johnson. My utmost thanks go to Dr. Johnson for all his efforts in taking me under his wing as a new graduate student and aiming me toward success. Dr. Johnson orchestrated the engine team research, aiding in selection of components, designs, and technologies used for engine efficiency improvement.

I would like to thank all the members of the WVU ARPA-E GENSETS project. Mehar Bade performed engine simulation and assisted in experimental engine testing. Matt Robinson, who created a linear engine model foundation. Greg Heiskell, Jay Subramanian, and Fereshteh Mamoudzade who designed the linear alternator and created a working prototype. Nima Zimani Meymian, who designed the spring system for the linear alternator. Al Yasin, who created Solidworks models of all the alternator components. Dr. Musho performed Ansys simulation of alternator designs. Mr. Dale Dzielski, tech to market leader for work in product marketability and cost analysis. Dr. Clark who guided the engine team in selection of the research engine and improvement pathways. Dr. Thompson, for his aid in spring selection and design, as well as machining key components for the alternator prototype. Dr. Famouri, project principle investigator, for his continuous efforts in linear alternator design which allowed WVU to receive the project funding. Most importantly, engine team leader Mr. Mahdi Darzi for his influential guidance along the way. Without his background research, initial laboratory testing setup, cocollecting of data, and assistance in data analysis this work would not have been possible. Mr. Darzi, a PhD colleague, also conducted engine simulation in GT Power which created the optimized exhaust design used in testing.

I would also like to give special thanks to my committee members Dr. Cosmin Dumitrescu and Dr. Hailin Li for their constructive criticism in editing. Without criticism, there is limited intellectual development. Dr. Dumitrescu's ICE class provided a strong background for engine data analysis and introduction to "the Bible of engines", (aka Heywood's Fundamentals of Internal Combustion Engines). Dr. Li was a professor on the ARPA-E project who supplied two-stroke expertise. 
Additional thanks go to Mr. Kelsey Crawford of the MAE tech shop and Dr. Thompson for providing me with hands-on training in machining. Without strong machining skills, much of this work would have not been possible. I also thank Precision Machining, LLC. in Granville, WV for custom machining pressure transducer ports, injector ports, and spark plug ports in the cylinders used in this research. I would also like to thank Mr. Zac Luzader, Mr. David McKain, Mr. Richard Atkinson, and Mr. Robert Heltzel. Mr. Luzader provided the engine team with his time series data collection software, Scimitar. Mr. Heltzel also provided help with Scimitar data collection. Mr. McKain explained CFR emissions calculations and provided me with insight on their calculations prior to my taking the graduate course. Lastly, Mr. Richard Atkinson helped in troubleshooting injector issues.

This work would not have possible without ARPA-E for supplying my graduate school funding in conjunction with the WVU GENSETS project. 


\section{Table of Contents}

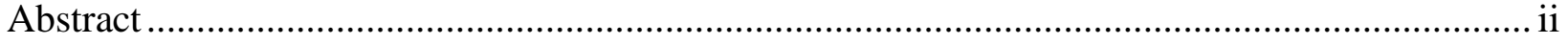

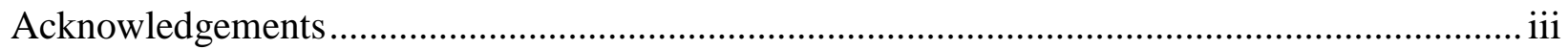

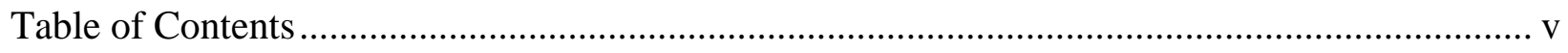

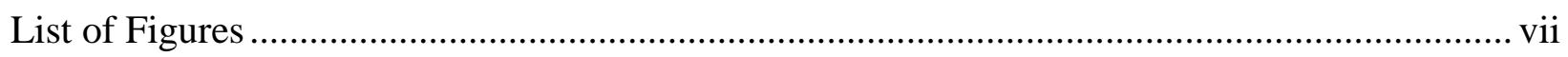

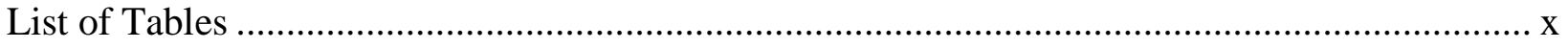

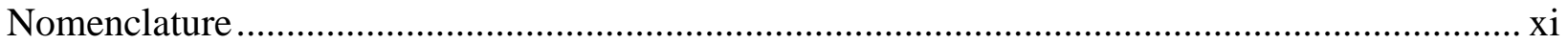

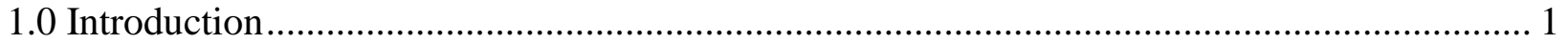

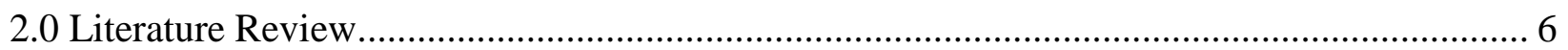

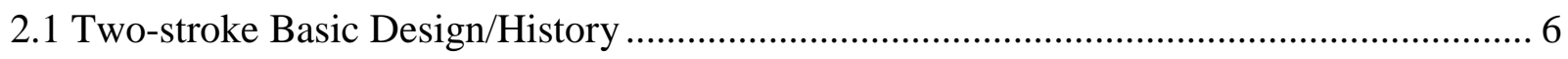

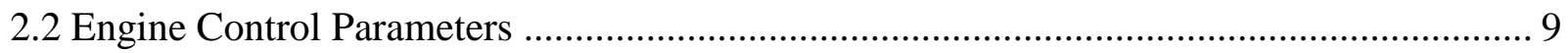

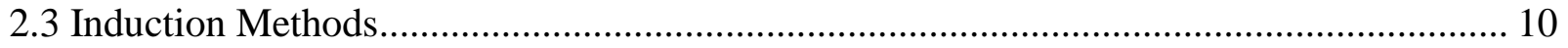

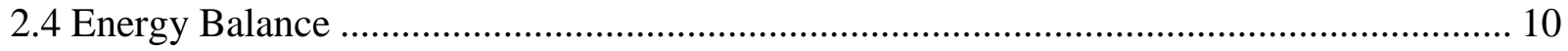

2.5 State of the Art Technologies......................................................................................... 11

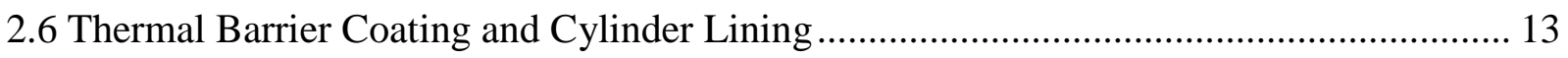

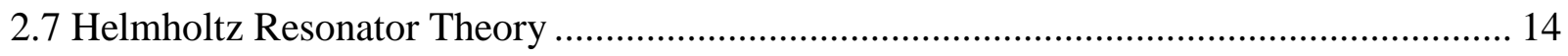

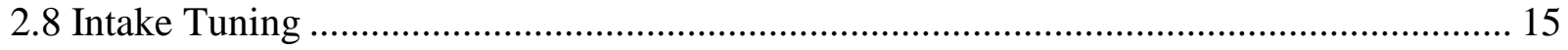

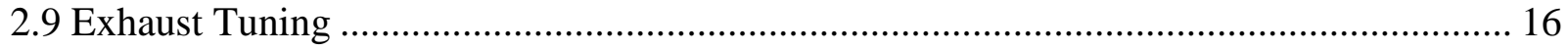

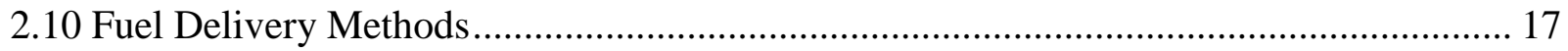

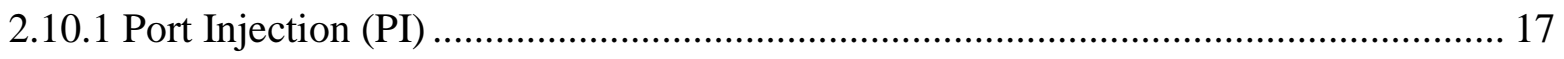

2.10.2 Low Pressure Direct Injection (LPDI) …………................................................... 18

2.10.3 High Pressure Direct Injection (HPDI) ........................................................... 19

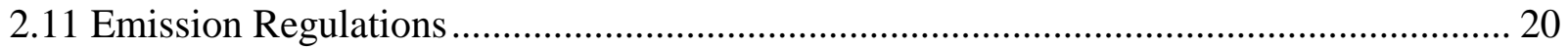

2.12 Background/ Development of Problem - Natural gas accessibility and use as a power

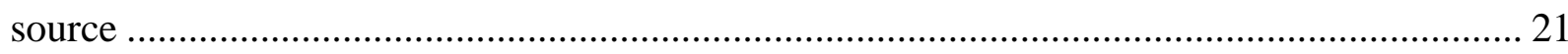

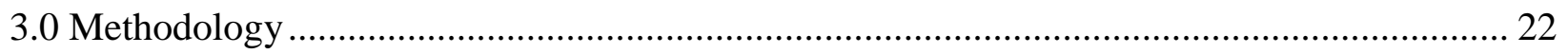

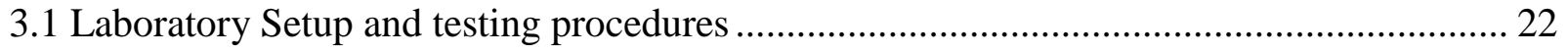

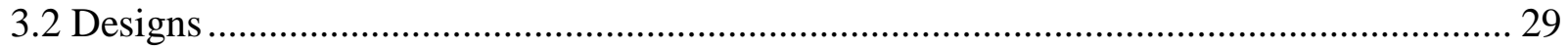

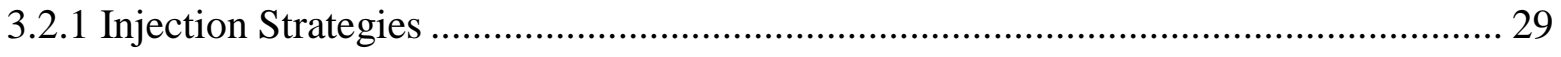

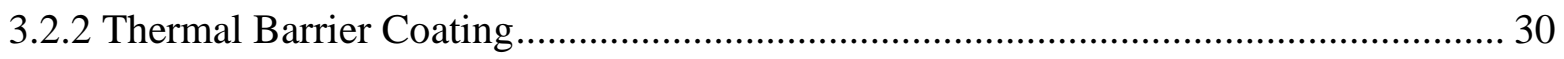

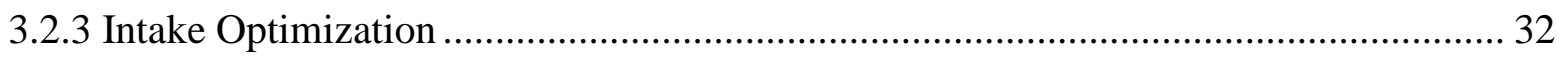

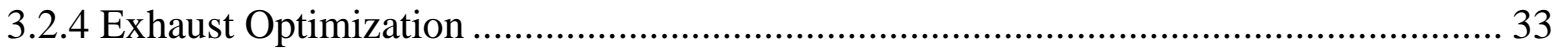

3.3 Data Processing ……………………………………...................................................... 39 


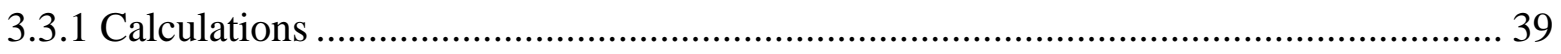

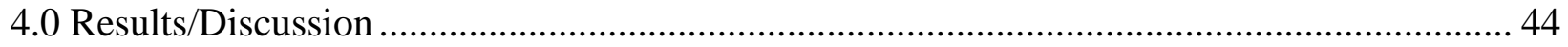

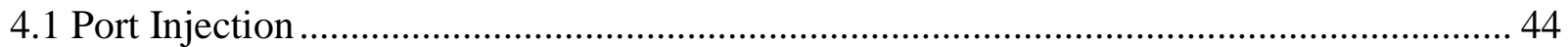

4.2 LPDI with Beta Exhaust Resonator ..................................................................... 47

4.3 LPDI with Optimized Exhaust Resonator.............................................................. 51

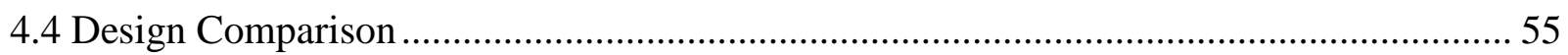

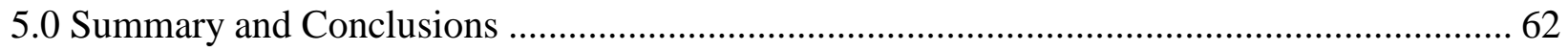

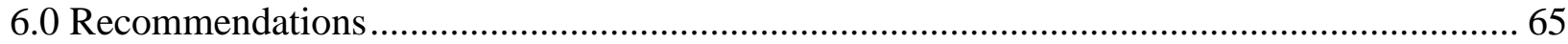

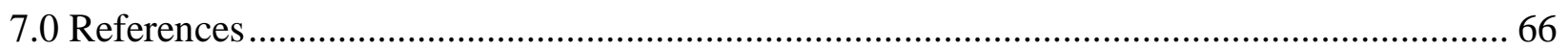

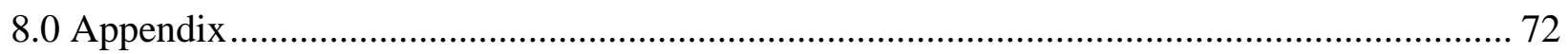




\section{List of Figures}

Figure 1 - Current U.S. NG consumption [11] ...................................................... 3

Figure 2 - Schematic of two-stroke engine cycle with CCC and direct injection. a.) compression stroke once the exhaust port is closed, b.) fuel injection and spark near TDC, c.) power/expansion stroke after combustion initiation, d.) scavenging process as transport

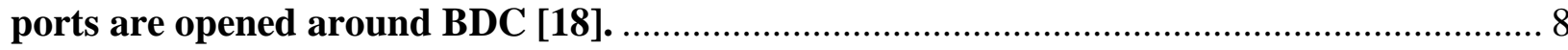

Figure 3 - Scavenge flow patterns for the four basic scavenging approaches. Note the uniflow approach is the only one that uses an exhaust valve as opposed to an exhaust port [22].

Figure 4 - Helmholtz resonator schematic showing the basic length, area, and volume elements of a tuned intake [36] .................................................................................... 14 Figure 5 - Exhaust pressure wave travel schematic for a basic tuned resonator. a.) initial positive pressure expansion as the export port opens, b.) once the flow expands in the divergent cone, a negative pressure (suction wave) is created, c.) as the flow passes through the convergent cone a positive pressure wave is created in the direction opposite of flow, and d.) when tuned correctly this positive pressure waive will arrive just prior to exhaust port closure [12].

Figure 6 - Schematic of the laboratory setup including major measurement components [62].

Figure 7 - Laboratory photograph showing the Zenoah research engine outfitted for LPDI operation. Note the white tube entering from the right provided forced cooling air to the cylinder.

Figure 8 - CAD schematic of LPDI engine setup showing the centrally located injector at the top and center of the combustion chamber [62]................................................ 26 Figure 9 - Cylinder schematics for different fuel delivery methods. LPDI (left), PI (right) showing original spark plug location [62]....

Figure 10 - Porting schematic to highlight the addition of the custom boost port at the rear of the cylinder [62]. 27

Figure 11 - Basic conical injector flow schematic [64]................................................ 29

Figure 12 - Ceramic TBC applied to piston and dome of the original CY engine............... 31 Figure 13 - Effect of TBC coating on indicated efficiency for CY engine at various lambda values.

Figure 14 - Effect of intake length on indicated efficiency for CY engine at lambda of 0.95.

Figure 15 - Tuner's Handbook exhaust design schematic with key dimensions and their naming convention used in experimental designs [12] [66] ....................................... 34

Figure 16 - Actual location of the design length for the reflected wave [12]..................... 35 Figure 17 - Beta exhaust schematic using a modified naming convention which starts from the exhaust port on the right and travels to the exhaust tailpipe exit at the left end of L5 [62]. 36

Figure 18 - Photograph of during testing of the beta exhaust with all major measurement and components labeled. 
Figure 19 - (Top) Exhaust tuning effect on indicated power of CY engine for constant lambda of 0.95, (Bottom) exhaust tuning effect on indicated efficiency of CY engine for constant lambda of 0.95 . 38

Figure 20 - (Top) DR at various lambda values under PI with the beta exhaust, (Bottom) indicated power at various lambda values under PI with the beta exhaust. 44 Figure 21 - (Top) BSFC at various lambda values under PI with the beta exhaust, (Bottom) indicated efficiency at various lambda values under PI with the beta exhaust. ................. 45 Figure 22 - Indicated power as a function of input energy under PI with the beta exhaust.45 Figure 23 - (Top) bsTHC at various lambda values under PI with beta exhaust, (Bottom) bsNO $_{x}$ at various lambda values under PI with beta exhaust. 46 Figure 24 - (Top) $\mathrm{CO}_{2}$ equivalent emissions at various lambda values under PI with the beta exhaust, (Bottom) CA5-CA90 duration at various lambda values under PI with the beta exhaust. .

Figure 25 - (Top) DR at various lambda values with the beta exhaust, (Bottom) indicated power at various lambda values with the beta exhaust............................................... 48 Figure 26 - (Top) BSFC at various lambda values with the beta exhaust, (Bottom) indicated power at various lambda values with the beta exhaust................................................. 48 Figure 27 - Indicated power as a function of input energy with the beta exhaust............. 49 Figure 28 - (Top) bsTHC at various lambda values with the beta exhaust, (Bottom) bsNO $_{x}$

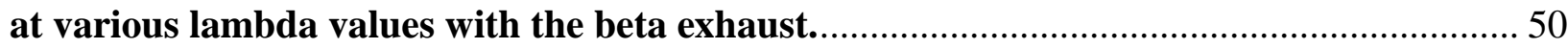
Figure 29 - (Top) CA5-CA90 duration at various lambda values with beta exhaust, (Bottom) $\mathrm{CO}_{2}$ equivalent at various lambda values with beta exhaust............................ 51 Figure 30 - (Top) DR at various lambda values under LPDI, (Bottom) indicated power at

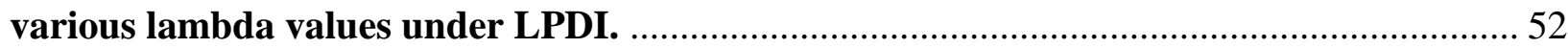
Figure 31 - (Top) BSFC at various lambda values under LPDI, (Bottom) indicated efficiency at various lambda values under LPDI.................................................... 53 Figure 32 - Indicated power as a function of input energy under LPDI. ........................... 53 Figure 33 - (Top) bsTHC at various lambda values with under LPDI, (Bottom) bsNOx at

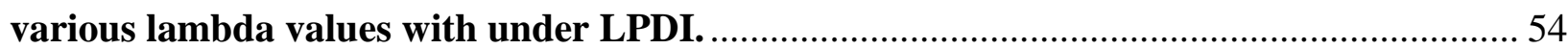
Figure 34 - (Top) CA5-CA90 duration at various lambda values under LPDI, (Bottom) $\mathrm{CO}_{2}$ equivalent at various lambda values with under LPDI. ........................................ 55 Figure 35 - Normalized distribution of indicated efficiency, fuel consumption, emissions,

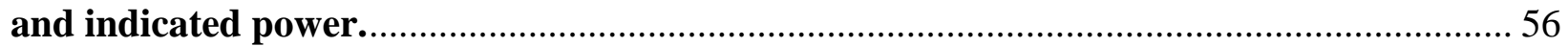
Figure 36 - Average pressure at most efficient point of operation over 200 cycles. ............ 56 Figure 37 - (Top) injection gauge pressure requirements at various lambda values, (Bottom) average peak cylinder pressures over 200 cycles at various lambda values........ 58 Figure 38 - (Top) average LPDI exhaust pressure with respect to CAD over 200 cycles for different exhausts, (Bottom) average LPDI returning pressure wave near EPC over 200 cycles.

Figure 39 - (Top) average heat release per cycle at various lambda values, (Bottom) COV of

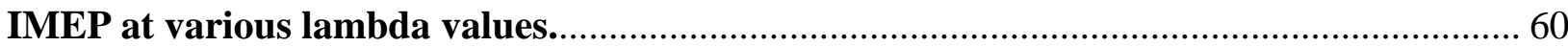

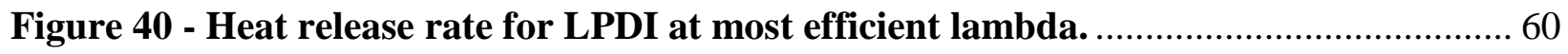


Figure 41 - (Top) Emission attainment plot brake specific CO for different configurations at various lambda values, (Bottom) emission attainment plot of brake specific $\mathrm{NMHC} \mathrm{NO}_{\mathrm{x}}$

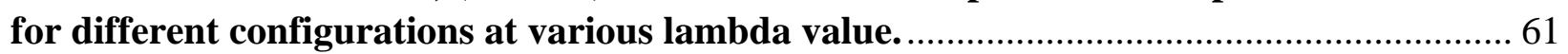




\section{List of Tables}

Table 1 - Regulated gaseous emission limits for small engine classes in units of $\mathrm{g} / \mathrm{kW}$-hr with this engine class highlighted [55].

Table 2 - Engine specifications for the 34 cc Zenoah engine with custom rear boost port. . 24

Table 3 - Specifications of the natural gas used for these research efforts........................ 28

Table 4 - List of constant parameters for configuration variations. ................................. 28

Table 5 - Dimensions of the beta exhaust, corresponding with sections of Figure 17......... 37

Table 6 - Dimensions of the optimized exhaust, corresponding with sections of Figure 17. 39

Table 7 - Peak pressure and location for most efficient point (200 cycle average)............. 57

Table 8 - Change in key parameters at most efficiency point compared to PI baseline....... 64 


\section{Nomenclature}

\section{Definitions / Abbreviations}

\begin{tabular}{|l|l|}
\hline Acronym & \\
\hline AFR & Air-Fuel Ratio \\
\hline ARPA-E & $\begin{array}{l}\text { Advanced Research } \\
\text { Projects Agency- Energy }\end{array}$ \\
\hline ATDC & After Top Dead Center \\
\hline BBDC & $\begin{array}{l}\text { Before Bottom Dead } \\
\text { Center }\end{array}$ \\
\hline BDC & Bottom Dead Center \\
\hline BS & Brake Specific \\
\hline BSFC & $\begin{array}{l}\text { Brake Specific } \\
\text { Consumption }\end{array}$ \\
\hline BTDC & Before Top Dead Center \\
\hline BTE & Brake Thermal Efficiency \\
\hline${ }^{\circ} \mathrm{C}$ & Degrees Celsius \\
\hline CAD & Crank Angle in Degrees \\
\hline cc & Cubic Centimeters \\
\hline CCC & Crankcase Compression \\
\hline CFD & $\begin{array}{l}\text { Computational } \\
\text { Dynamics }\end{array}$ \\
\hline CFR & $\begin{array}{l}\text { Code of } \\
\text { Regulation }\end{array}$ \\
\hline CHP & Combined Heat and Power \\
\hline CH ${ }_{4}$ & Methane \\
\hline cm & Centimeters \\
\hline CNG & Compressed Natural Gas \\
\hline
\end{tabular}

\begin{tabular}{|l|l|}
\hline $\mathrm{CO}$ & Carbon Monoxide \\
\hline $\mathrm{CO}_{2}$ & Carbon Dioxide \\
\hline $\mathrm{COV}$ & Coefficient of Variation \\
\hline $\mathrm{CR}$ & Compression Ratio \\
\hline $\mathrm{CY}$ & Chung Yang \\
\hline $\mathrm{D}$ & Diameter \\
\hline DCR & $\begin{array}{l}\text { Dynamic Compression } \\
\text { Ratio }\end{array}$ \\
\hline DI & Direct Injection \\
\hline DR & Delivery Ratio \\
\hline ECU & Engine Control Unit \\
\hline EPA & Environmental Protection \\
Agency
\end{tabular}




\begin{tabular}{|c|c|}
\hline GWP & Global Warming Potential \\
\hline $\mathrm{g} / \mathrm{kW}-\mathrm{hr}$ & Grams Per Kilowatt Hour \\
\hline $\mathrm{HC}$ & Hydrocarbon \\
\hline HPDI & $\begin{array}{l}\text { High Pressure Direct } \\
\text { Injection }\end{array}$ \\
\hline $\mathrm{Hz}$ & Hertz (1/seconds) \\
\hline ICE & $\begin{array}{l}\text { Internal Combustion } \\
\text { Engine }\end{array}$ \\
\hline IMEP & $\begin{array}{l}\text { Indicated Mean Effective } \\
\text { Pressure }\end{array}$ \\
\hline $\mathrm{J}$ & Joules \\
\hline $\mathrm{kW}$ & Kilowatt \\
\hline $\mathrm{kPa}$ & kilopascal \\
\hline $\mathrm{L}$ & Length \\
\hline LFE & Laminar Flow Element \\
\hline LHV & Lower Heating Value \\
\hline LPDI & $\begin{array}{l}\text { Low Pressure Direct } \\
\text { Injection }\end{array}$ \\
\hline LPG & Liquefied Petroleum Gas \\
\hline $\mathrm{m}$ & Meters \\
\hline $\mathrm{mm}$ & Millimeter \\
\hline MBT & Maximum Brake Torque \\
\hline MFC & Mass Flow Controller \\
\hline $\mathrm{MJ} / \mathrm{kg}$ & Mega joules per Kilogram \\
\hline MN & Methane Number \\
\hline NG & Natural Gas \\
\hline NMHC & $\begin{array}{l}\text { Non-Methane } \\
\text { Hydrocarbon }\end{array}$ \\
\hline
\end{tabular}

\begin{tabular}{|l|l|}
\hline $\mathrm{NO}_{\mathrm{x}}$ & Nitrogen Oxides \\
\hline OBR & O'Neil Brothers Racing \\
\hline OLEA & Oscillating Linear Engine \\
Alternator
\end{tabular}




\begin{tabular}{|l|l|}
\hline $\mathrm{A}_{2}$ & $\begin{array}{l}\text { Half Angle of the Baffle } \\
\text { Cone }\end{array}$ \\
\hline $\mathrm{A}_{\text {eff }}$ & Effective port area \\
\hline $\mathrm{A}_{\text {port }}$ & Exhaust Port Area \\
\hline $\mathrm{B}$ & Bore \\
\hline $\mathrm{bmep}$ & $\begin{array}{l}\text { Brake Mean Effective } \\
\text { Pressure }\end{array}$ \\
\hline $\mathrm{CNG}_{\text {slpm }}$ & Fuel flow \\
\hline $\mathrm{E}_{\mathrm{o}}$ & $\begin{array}{l}\text { Exhaust } \\
\text { Duration }\end{array}$ \\
\hline$\dot{E}_{\text {in }}$ & Fuel Energy Input \\
\hline $\mathrm{FTIR}$ & Open \\
\hline $\mathrm{K}_{\mathrm{EQ}}$ & $\begin{array}{l}\text { NOx } \\
\text { FTIR }\end{array}$ \\
\hline $\mathrm{k}_{\text {factor }}$ & MFC Concentration from \\
\hline $\mathrm{K}_{\mathrm{h}}$ & Gas Correction Factor \\
\hline $\mathrm{L}$ & NOctor \\
\hline $\mathrm{L}_{\mathrm{T}}$ & Stroke Length \\
\hline $\mathrm{M}$ & Tuned Length Factor \\
\hline $\mathrm{MAF}_{\text {slpm }}$ & Aolar Mass \\
\hline$\dot{m}$ & Air flow \\
\hline $\mathrm{N}$ & Mass Flow \\
\hline$\dot{n}_{\text {exh }}$ & Operating Speed \\
\hline $\mathrm{P}_{\mathrm{b}}$ & Exhaust Molar Flow Rate \\
\hline $\mathrm{P}_{\mathrm{i}}$ & Indicated Power \\
\hline
\end{tabular}

\begin{tabular}{|l|l|}
\hline $\mathrm{P}_{\text {crit }}$ & Critical Injection Pressure \\
\hline $\mathrm{P}_{\text {cyl }}$ & Cylinder Pressure \\
\hline $\mathrm{P}_{\text {inj }}$ & Injection Pressure \\
\hline $\mathrm{r}$ & Radius \\
\hline $\mathrm{r}_{\mathrm{c}}$ & $\begin{array}{l}\text { Geometric Compression } \\
\text { Ratio }\end{array}$ \\
\hline $\mathrm{R}$ & $\begin{array}{l}\text { Connecting rod to crank } \\
\text { rod length ratio }\end{array}$ \\
\hline $\mathrm{R}_{\mathrm{i}}$ & Ideal gas constant \\
\hline $\mathrm{T}$ & Temperature \\
\hline $\mathrm{T}$ & Torque \\
\hline $\mathrm{V}$ & Volume \\
\hline $\mathrm{V}_{\mathrm{c}}$ & Clearance Volume \\
\hline $\mathrm{V}_{\mathrm{d}}$ & Displacement Volume \\
\hline $\mathrm{V}_{\mathrm{s}}$ & Sonic Wave Velocity \\
\hline $\mathrm{V}_{\mathrm{i}}$ & Component Mole Fraction \\
\hline $\mathrm{x}_{\mathrm{i}}$ & Component Mass Fraction \\
\hline$\lambda$ & Cambda \\
\hline$\gamma$ & Gamma \\
\hline$\rho$ & Density \\
\hline$\eta_{\text {th,brake }}$ & Brake Thermal Efficiency \\
\hline$\eta_{\text {th,ind }}$ & Efficiency \\
\hline
\end{tabular}




\subsection{Introduction}

This research was conducted as a part of the Advanced Research Projects Agency- Energy (ARPAE) generators for small electrical and thermal systems (GENSETS) project at West Virginia University (WVU). The project goal was to design a 1 kilowatt $(\mathrm{kW})$ natural gas combined heat and power (CHP) system with high fuel to electric conversion efficiency [1]. The WVU team selected a resonant oscillating linear engine alternator (OLEA) design utilizing a two-stroke prime mover and custom springs. Research was separated into team efforts for system simulation, creating Solidworks drawings of the system, alternator design, spring design, and engine research.

Mr. Mahdi Darzi and I were tasked to lead the engine design research team. For experimental testing of designs, engine research was conducted on a traditional slider crank configuration operating at the system design resonant operating frequency. My research focused on experimental testing to validate the efficiency improvement of technologies that were implemented on the research engine. I focused on the following research areas:

- Building the research engine testing platform

- Examination of various engine selections

- Collection of data with Mr. Darzi (running experimental tests)

- Validation of intake resonator theory

- Validation of literature-based exhaust resonator theory

- Experimental validation of a GT Power designed exhaust resonator

- Examination of the effects of port injection (PI) and low pressure direct injection (LPDI) fueling strategies

- Evaluation the impacts of injection strategies, and resonant exhaust design on indicated efficiency, indicated power, emissions, and other engine parameters.

Studying the literature surrounding small displacement two-stroke engines showed a wide range of applications for the engine, as well as technologies used for improvement. Modern regulations and clean energy activism have caused researchers to re-explore the world of two-stroke engines using various types of alternative fuels and advanced technologies. This research aims to improve the overall efficiency and lower exhaust emissions of a resonant tuned small two-stroke engine operating at a fixed frequency fueled with natural gas (NG). There are numerous restrictions that 
limit the efficiency of small two-stroke engines such as undesirable stroke to bore ratio, excessive heat loss, combustion instabilities, and increased fuel slip with decreasing engine displacement [2]. It is evident that two-stroke engines have generally been left out of the technological boom that four-stroke engines have undergone for the automotive industry. For handheld two-stroke engines to remain inexpensive carburetors are the fuel delivery method of choice. Engine out emissions are typically untreated on small gasoline two-stroke engines due to the space requirement and high temperature needed for an effective catalyst. Only recently have dirt bike manufacturers released 125 cubic centimeters (cc) and larger gasoline direct injection two-stroke engines. However, these engines still consider power density as the primary design target. For power density, their lightweight structure, and simplicity, two-stroke engines are still dominant for small displacement equipment.

The conversion of a small displacement two-stroke engine to operate on NG, required background knowledge of fuel chemistry and distribution infrastructure. Pipeline NG is primarily composed of methane $\left(\mathrm{CH}_{4}\right)$, along with variable amounts of ethane, propane, butanes, pentanes, carbondioxide $\left(\mathrm{CO}_{2}\right)$, and nitrogen [3]. Raw NG pulled from the ground is generally processed to remove water, solids, and any undesirable non-hydrocarbon species. The refined gas is then odorized for safety purposes before being distributed to customers. Theoretical combustion of NG offers a $25 \%$ lower carbon release rate than traditional gasoline or diesel fuel for the same heat release, making it a desirable fuel source for internal combustion engines (ICE). NG also exhibits a high knock resistance, allowing it to be used under higher compression ratios than gasoline. The flammability limits of NG are nearly twice as wide as gasoline, allowing for leaner operation [4] [5]. Lean operation allows for reductions in both carbon-monoxide $(\mathrm{CO})$ and nitrogen oxides $\left(\mathrm{NO}_{\mathrm{x}}\right)$ [5] [6]. NG combustion is also benefited by low particulate matter concentrations in the burnt products due to the absence of fuel rich pockets and strong carbon bonds [5] [6]. For natural gas combustion particulate matter observed almost exclusively comes from the combustion of lubrication oil which has escaped the crankcase [6].

NG is a prominent energy source utilized in the United States (U.S.) and around the world. Only in the past decades has it been widely incorporated into the world of ICEs as an alternative fuel source. In 2012, it was stated by the ARPA-E MOVE program that 65 million U.S. households and businesses currently have NG accessibility [7]. The gradual expansion of infrastructure has 
enabled NG to be readily available to most of the U.S. and the cost to decrease [8]. Projected lower prices of NG are a result of increased production with a near constant annual consumption [8]. CHP systems are of special concern due to the possible benefits in energy savings. If a NG supply line is already available to a household, it would be energy efficient to create electric power locally if such a CHP could achieve around 35\% fuel to electricity power conversion. This assumption takes into account a $95 \%$ alternator efficiency, which requires the engine to be at or above $37 \%$ efficiency. The power savings occur when the prime-mover (i.e. engine) approaches efficiencies near that of large power plants, but saves energy traditionally lost in electrical power transmission (transformers and long supply cables with resistive losses). When the overall fuel to electric conversion rate is cheaper, the consumer will save money.

NG has been the dominant energy source for electricity generation since 2015, surpassing coal fired electrical generation [9]. With the low carbon to energy ratio of NG, it releases only 55\% of the $\mathrm{CO}_{2}$ that an equal energy content of coal would produce [10]. Figure 1 below shows the current distribution of NG to different energy sectors, with electrical generation already in place as the primary consumer.

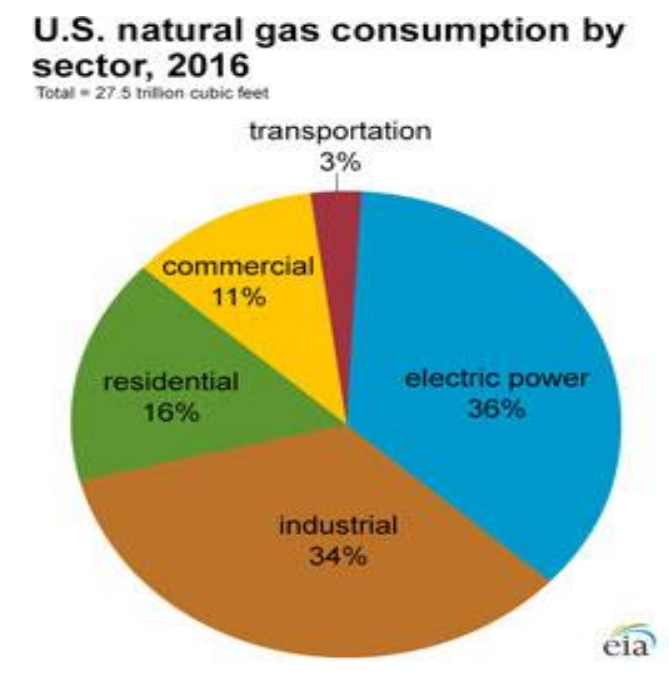

Figure 1 - Current U.S. NG consumption [11].

Primary research was conducted on a $34 \mathrm{cc}$ Zenoah boost ported two-stroke engine operating at 5400 revolutions per minute (RPM) under port injection (PI) and low-pressure direct injection (LPDI). The effects of each injection strategy on engine efficiency, power, and emission characteristics were investigated. After the most efficient operating point was found, two 
variations in tuned exhaust designs were compared. An intake tuning strategy verified on a similar Chung Yang (CY) engine was implemented on the Zenoah engine for all tests.

A variety of two-stroke engines were examined for use in a linear alternator aimed at efficiently producing 1 kilowatt $(\mathrm{kW})$ electrical output under NG fueling at a fixed frequency of $90 \mathrm{~Hz}$ (equivalent to $5400 \mathrm{RPM}$ ). Thus, an engine capable of producing $1.1 \mathrm{~kW}$ brake power was required to overcome electrical conversion losses expected in the alternator design. Due to the alternator being a stationary device operating at a fixed frequency, intake and exhaust tuning may be implemented with little concern for space requirements. While engine efficiency decreases with decreasing displacement due to a number of factors, a modestly efficient engine can be beneficial for home CHP systems by running at full load and utilizing recovered waste heat for home heating needs (domestic water, space heating, etc.).

Initial research was conducted on a CY 29 cc engine. Exhaust and intake tuning were explored, different compression ratios tested, fuel types tested, fueling strategies of PI and fumigation tested, and thermal barrier coating (TBC) applied. After key efficiency gaining strategies produced little net gains and a maximum indicated thermal efficiency of near $16 \%$, further engine options were explored. Research was then conducted on a Stihl MS 261 chainsaw engine. The engine was found to produce too much power at wide open throttle (WOT) to efficiently operate at the $1.1 \mathrm{~kW}$ level. Finally, the custom ported boosted Zenoah engine currently used was selected based on a review of collected data and available engine options. The engine was referred to as boosted because of the custom boost port design. The engine was stock from Zenoah and customized by engineers at O’Neil Brothers Racing (OBR). The original intake port was blocked off and a reed valve installed affording the use of reed-induction crankcase compression. Modifications were made to the transfer ports and exhaust port, and a boost port was added to the cylinder with a matching boost port window machined into the piston. The combustion chamber was also cut and reshaped to be hemispherical which improves combustion as suggested by literature [12]. The 34 cc engine was able to produce promising baseline efficiencies of up to $18 \%$ when operated with PI.

The boost ported Zenoah engine was then retrofitted to operate on the NG LPDI test platform. The implementation LPDI in an engine of this displacement proved difficult. The original spark plug port was the only space large enough with existing clamp areas that could be used for injection. This required the usage of a smaller $6.35 \mathrm{~mm}$ spark plug placed on the side of the combustion 
dome. The pressure transducer port was also custom machined to fit the cylinder. Placement of both the spark plug and pressure transducer was at $40^{\circ}$ with respect to the injector. 


\subsection{Literature Review}

\subsection{Two-stroke Basic Design/History}

Two-stroke engines have held a primary role in small vehicle transportation, marine engines, handheld equipment, and numerous minor applications over the past 13 decades. The advantages of two-stroke engines include higher power density than four-stroke engines, higher engine operating speeds, and the capability to fit in smaller, lightweight packages due to lack of valve assemblies. The primary disadvantages of the two-stroke engine include short circuiting (or the direct slippage of fresh air/fuel mixture into the exhaust stream), lower efficiencies than four-strokes, and overall increased exhaust emissions. There was a brief surge in automotive two-stroke interest during the 1980's-90's by numerous manufacturers with the emergence of direct injection and electronic control, however none of these engines made it to market [13]. In the past decade, research efforts primarily focused on redesign of the two-stroke engine for alternative fuel usages as well as to achieve higher efficiency via more complex porting systems [14] [15] [16].

Two-stroke engines operate with one power stroke and one compression stroke per cycle. For this reason, both the intake and exhaust ports are simultaneously open for some duration. A cycle begins with the piston moving towards top dead center (TDC). During this movement, a negative pressure gradient is created on the underside of the piston to draw fresh charge from the intake into the crankcase. When the piston reaches TDC, combustion expansion pushes it downward until the exhaust port becomes exposed. Exhaust is expanded out of the port until cylinder pressure drops slightly above atmospheric, at the same time as fresh charge is being compressed beneath the piston. After the exhaust is partially expelled, transfer ports become exposed which deliver fresh fuel air charge that pushes additional exhaust out of the cylinder though in basic designs this action also loses some fuel air charge. Crankshaft inertia causes the piston to begin another upward stroke, which after the exhaust port is fully closed the piston compresses the remaining mixture for ignition on the next cycle [6].

\section{Two-stroke Advantages}

- Higher power density than four-stroke engines of the same displacement

- Valve train not required

- No oil pump or oil pumping losses, may operate in any orientation 
- Higher operating speeds versus four-stroke engine counterparts

- Less output torque fluctuation per cycle than four-stroke engines [13]

- More cost efficient to manufacture than four-stroke engines

\section{Two-stroke Disadvantages}

- Increased hydrocarbon (HC) emissions due to typical carbureted engines scavenging with an air-fuel mixture

- Higher heat flux near TDC causing increased heat losses

- Pumping losses in the case of crankcase compression

- Misfires at low speeds

- Incomplete combustion

The two-stroke engine was first designed by Sir Dugald Clerk of England in the year 1877, and he later patented it in 1881 [17]. Two-stroke design normally is differentiated by one of the various scavenging methods employed or by the porting style. Common scavenging methods include cross-scavenging, loop scavenging, reverse loop scavenging, and uniflow scavenging. Air may be inlet directly to the cylinder or compressed in the crankcase and delivered by transfer ports built into the cylinder walls. Most two-stroke engines use the crankcase as a mixing chamber for the fuel and air intake prior to passage into the cylinder via transfer ports near bottom dead center (BDC), this method is known as crankcase compression (CCC). The intake mixture will be drawn into the crankcase during the pistons upward motion and compressed during the subsequent downward motion that follows. It is common for engines to have a reed valve in the crankcase to allow flow only into the crankcase and seal under pressurization. With gasoline two-stroke engines, the air/fuel mixture contains the lubricating oil required for the crankcase components such as crank bearings, rod bearings, wrist pin bearings, piston, and piston rings. A schematic of direct injection two-stroke engine with a reed valve is displayed in Figure 2. 

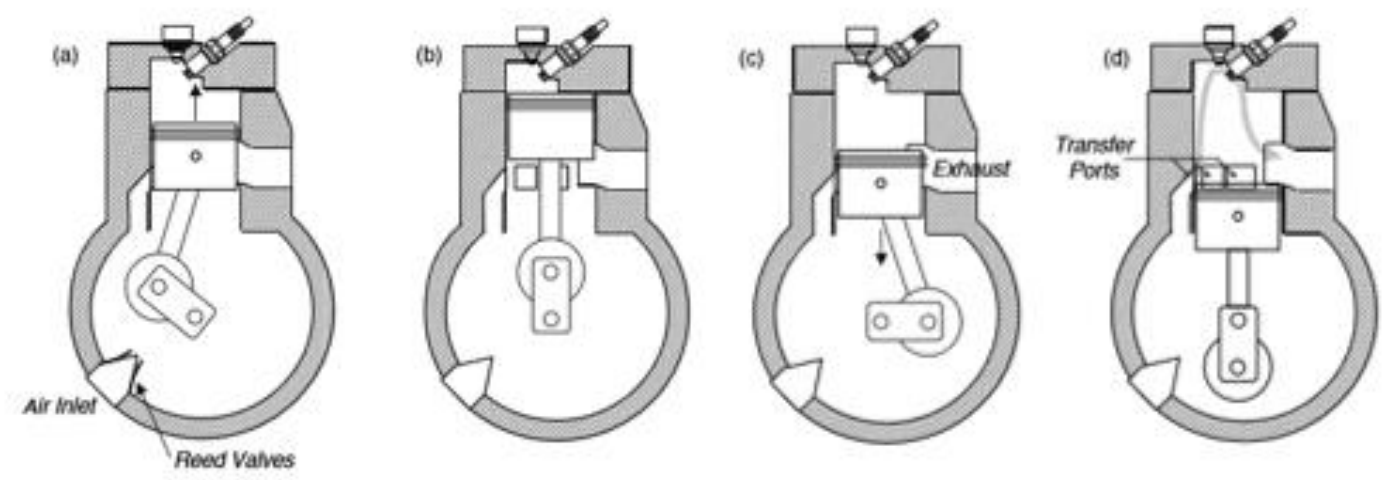

Figure 2 - Schematic of two-stroke engine cycle with CCC and direct injection. a.) compression stroke once the exhaust port is closed, b.) fuel injection and spark near TDC, $c$.) power/expansion stroke after combustion initiation, $d$.) scavenging process as transport ports are opened around BDC [18].

All engines are characterized by their geometrical compression ratio (GCR), or the ratio between the maximum and minimum volumes (clearance volume) achieved in a cycle. The GCR is the ratio of position $\mathrm{d}$ to $\mathrm{b}$ in Figure 2 above. For two-stroke engines however, it is more useful to consider the dynamic compression ratio (DCR), or the ratio between the volume present at complete exhaust port closure to the clearance volume. The DCR is roughly the ratio of position $\mathrm{c}$ to $\mathrm{b}$ in Figure 2 above [18] [19].

The reed valve plays an important role on two-stroke performance, allowing for the intake process to occur in the cooler sections of the crankcase. The reed opens under negative crankcase pressure and is pressed shut under subsequent positive pressure buildup. A piston-controlled intake process is dictated by the time in which the piston uncovers the wall passage to the crankcase. For both cases, induction occurs on the upward motion of the piston; followed by compression and release of the fresh charge into the combustion chamber [6].

Other scavenge flow system schematics are shown below in Figure 3. The most difficult part of designing two-stroke engines is finding the best scavenging method for an engine. The difficulty lies within the randomness of cycle to cycle variations on in-cylinder gas flow motion [20]. The original paper was written on scavenging in 1914 by Hopkinson [20]. Large uniflow diesel twostroke engines have been the most thermally efficient engines ever constructed at over 50\% [20]. These scavenging methods shown in Figure 3 have benefits for different operation points and can be used with or without CCC [20]. The uniflow scavenged type is the only one which relies on an 
exhaust valve, while all others are port controlled. Uniflow is commonly acknowledged as the best method but optimized loop/cross scavenging can be made to be nearly as efficient [20].

CCC relies on air/fuel induction during the piston's upward movement and discharge via transfer ports during the downward stroke. However, pumping losses occur in the crankcase and transfer ports causing an added resistance to the power stroke. It is proven that CCC can reach brake specific fuel consumption of 450 grams per kilowatt hour ( $\mathrm{g} / \mathrm{kW}-\mathrm{hr}$ ) under gasoline operation for engines in the $50 \mathrm{cc}$ range manufactured by Stihl [21].
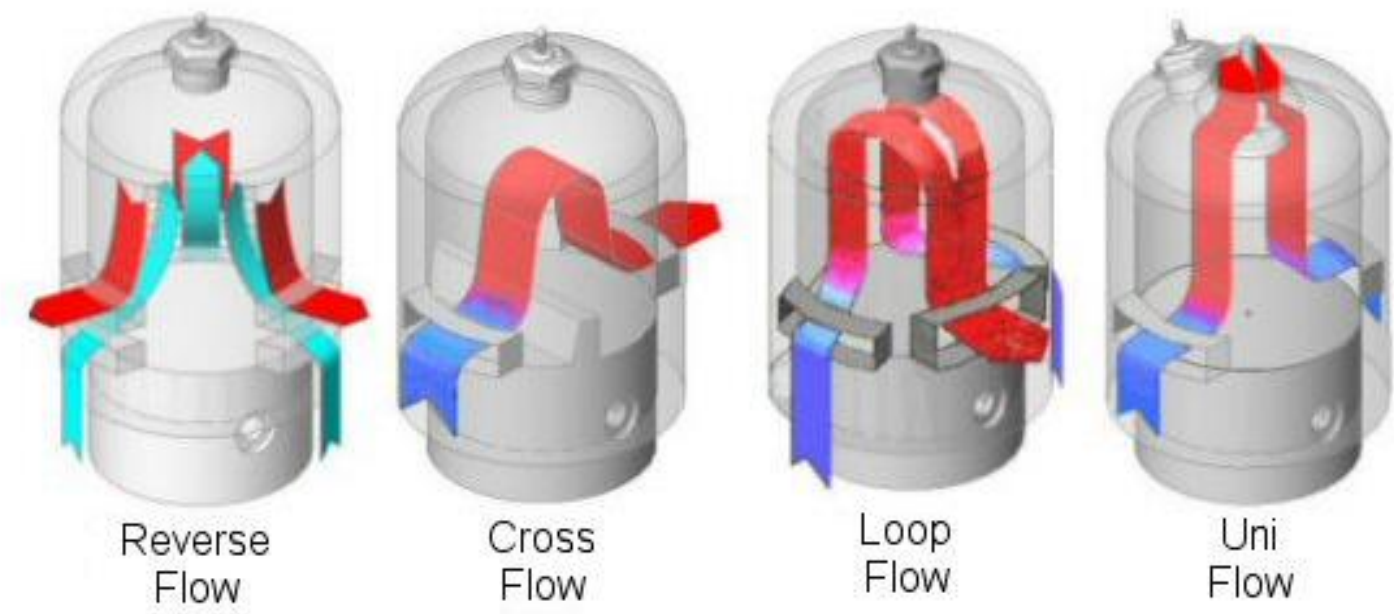

Figure 3 - Scavenge flow patterns for the four basic scavenging approaches. Note the uniflow approach is the only one that uses an exhaust valve as opposed to an exhaust port [22].

\subsection{Engine Control Parameters}

Mechanical control of speed or power of a single cylinder piston engine can be completed in several ways. The USPTO lists all patented ideas for such control. Single cylinder engines may be controlled by changing the air supplied, fuel supplied, or both [23]. The quality of this resulting mixture is commonly referred to as the air-fuel ratio (AFR). Single cylinder engines may also be controlled by throttling of the intake and exhaust flows. Exhaust and intake timings may be controlled with valves or with geometrical constraints of the piston cylinder system (i.e. port timing).

Engine parameters for engine control patented under this section include the following; engine temperature, lubricant temperature, fuel pressure, engine noise from knocking, throttle position, intake pressure, volumetric efficiency, ambient air temperature, ambient air humidity, fuel 
temperature, fuel type or quality, fuel mass used per cycle, fuel delivery timing, fuel consumption, porting or valve configuration, exhaust gas treatment, output torque, mechanical efficiency, and misfires [23].

\subsection{Induction Methods}

Since it is uncommon for two-stroke engines to utilize intake valves, the induction method is critical to engine performance. As previously discussed, induction styles can use reed valves, piston-skirts, or other methods. In addition, the inducted air may be atmospheric or pressurized.

Reed valves are thin sheets of carbon fiber, fiber glass, reinforced plastic, or steel which are positioned at the mouth of the intake to allow flow only in one direction. They are of paramount importance in the CCC operation of a two-stroke engine. The stiffness of the reeds has been observed to dictate the scavenging flow into an engine as well as the area difference between the inlet and outlet of the reeds. The use of different reed materials has been shown to have only a small effect on performance [6]. Other induction methods include piston skirt-controlled porting, rotary scavenging plates, and forced induction intake. Piston controlled porting relies on the piston skirt to control port exposure to the cylinder. This is the simplest form of porting and is common is small displacement handheld equipment. Rotary scavenge plates are designed to rotate with the crankshaft and allow asymmetric port openings [6].

Forced induction may occur with the use of turbo-charging or super-charging. Turbo-charging relies on exhaust enthalpy recovery via a turbine, while super-charging relies on an auxiliary driven compressor. Both systems provide a boost pressure to the intake which increases the scavenging flow magnitude. For small displacement engines, the power required for super-charging becomes a significant portion of the power produced. Also, with piston-controlled porting the effectiveness of forced induction is limited by port overlap [6].

\subsection{Energy Balance}

Research conducted by Ausserer et al. showed a decrease in thermal efficiency with decreasing engine sizes below $100 \mathrm{cc}$. The energy balance examined the sensible exhaust enthalpy, brake power, cooling load, incomplete combustion, and short-circuiting as the possible loss pathways in an attempt to quantify the main losses. The results consistently showed short-circuiting as the dominant factor accounting for about $40 \%$ of the losses, followed by incomplete combustion near 
$20 \%$. They reported $13 \%$ brake thermal efficiency (BTE) using a gasoline fueled $28 \mathrm{cc}$ two-stroke engine [2].

Piecha et al. completed a more detailed wall heat transfer analysis to the existing energy balance methods. In tests conducted on a $45.6 \mathrm{cc}$ two-stroke Stihl engine at $6000 \mathrm{RPM}$ it was found that the energy was split into 27\% thermal exhaust, 19\% unburned fuel, 19\% effective or useful, $18 \%$ scavenging losses, $14 \%$ wall heat transfer, and $3 \%$ friction. The engine was noted to have lower scavenging losses than normal due to excellent porting [24]. Also, energy balances conducted under the engine warm-up phase revealed increased miscellaneous losses partly attributed to the transient heating of metal components [25].

In a report by Pathak et al. the effect of "break in" time was investigated. The "break in" period of an engine is the required initial running to allow materials to rub off any imperfections from manufacturing and to allow the piston ring coating to absorb to the cylinder lining. They found that $\mathrm{NO}_{\mathrm{x}}$ remained stable during this 7-10 hour period, $\mathrm{HC}$ emissions increased during the first half and then stabilized; and the $\mathrm{CO}$ emissions decreased linearly during the 10 hours. Power output was found to approach a maximum output level at about five hours run time, then stabilized slightly below the maximum for the engine's primary life [26].

A study by Trattner et al. on small spark ignition (SI) two-stroke and four-stroke engines up to 150 $\mathrm{cc}$ addressed further possible loss pathways. The losses were measured relative to the ideal engine efficiency. Imperfect combustion, real combustion loss, wall heat transfer, gas exchange loss, scavenging loss, and mechanical loss were all subtracted from the ideal efficiency to produce the effective efficiency. Key results of this study highlighted the relative increase of heat transfer losses at part load as compared to WOT [27].

\subsection{State of the Art Technologies}

With the emergence of modern injection technologies, many automotive companies scrambled during the 1980's-90's to develop an efficient and power dense two-stroke engine for passenger vehicle use. The dawning of feedback electronic control for direct injection allowed engineers to redesign the "dirty" carbureted two-stroke engines previously known. This was accomplished through control of the fuel quantity delivered to the cylinder, dependent on fuel type, pressure, timing and duration of which it is injected. The direct injection method significantly reduces 
scavenging losses of unburned hydrocarbon fuel which has plagued the carbureted counterpart. While two-stroke direct injection (DI) was the primary driver of this automotive exploration, there were many other emerging technologies which were employed to aid in the design process. Engine simulation, computational fluid dynamics (CFD), water visualization apparatus, laser-doppler velocimetry, combustion photography, laser light-sheet visualization diagnostics, real-time incylinder and crankcase pressure analysis, cycle heat release analysis, fast-response flame ionization detector exhaust HC sampling, and scavenging measurement methods were all employed in the design work by manufacturing groups [13]. The research efforts however were never successful in creating an efficient and emissions compliant engine that was capable of competing with the four-stroke market.

At the University of Chiba in Japan, studies were conducted by Xiong et al. with pre-chamber combustion. Pre-chamber combustion allowed for increased thermal efficiency over conventional spark plugs by increasing activation energy supplied to the main mixture. It was found that too much jet penetration from the injector caused the flame to move too far down in the chamber leading to excessive heat losses. They found that injectors with 4-7 orifices worked the best because they decreased the overall jet flame penetration into the walls and allowed for increased flame propagation area. They were able to achieve over $35 \%$ thermal efficiency on their large bore engine [16]. Boretti and Scalzo at RMIT investigated the use of a complex piston motion (rotating and translating) in order to improve scavenge efficiency in a 1 liter two-stroke engine. The complex piston is coupled with a jet ignition system for an optimal combustion process. The design claimed to achieve above $36 \%$ brake thermal efficiency operating with gasoline. This efficiency was reported at $35.8 \%$ while running pure methane. Power density over $100 \mathrm{~kW} /$ liter was also reported [14].

A report by Bergman and Berneklev pointed out the necessity of pushing for stratified charging of the cylinder, or even sequentially stratified. They investigated the Husqvarna/Stihl separated air and air/fuel intake method. This method allowed firstly for pure air scavenging of the cylinder to expel residual gases which reduces unburned hydrocarbon slippage of the second scavenge flow consisting of fuel/air mixture. Sequentially scavenged engines exhibit much lower HC emissions due to this process. They showed that longer scavenging ducts also created a possibility of tuning the pressure pulses within it to benefit the scavenging process [28]. This separated intake process 
design still constitutes one of the best carbureted two-stroke engines in current production. Further investigations on Stihl chainsaw engines include a detailed analysis of low friction piston coatings. The results of the study show small reductions in friction with the application of tungsten doped diamond like carbon coating [29].

NG controlled auto-ignition has been investigated in four-stroke engines. Results of the study show thermal efficiency of $39.1 \%$ with $40 \mathrm{ppm}$ (parts per million) $\mathrm{NO}_{\mathrm{x}}$. The use of $\mathrm{NG}$ in a compression ignition manner requires compression ratios of 12 to 35 , but such compression ratios were not afforded in this research [30]. Current large displacement four-stroke engines for automotive and industrial purposes created by Cummins offer excellent emission qualities under NG operation. The Cummins ISL G Near Zero 239 kW engine produces $0.02 \mathrm{~g} / \mathrm{bhp}$-hr or $0.027 \mathrm{~g} / \mathrm{kW}$-hr, which is $90 \%$ less $\mathrm{NO}_{\mathrm{x}}$ than current Environmental Protection Agency (EPA) standards and has a $9 \%$ greenhouse gas $(\mathrm{GHG})$ decrease [31].

\subsection{Thermal Barrier Coating and Cylinder Lining}

Studies conducted by Toyota Motor researchers showed a decrease in heat losses from engines with "Thermal Swing" coatings applied to the cylinder liner of DI diesel engines. Thermal Swing coatings offered a superior heat transfer mode to traditional ceramic barriers due to their ability to fluctuate with the gas temperature. This allowed for less heat transfer at TDC with normal heat rejection occurring near BDC. The coating manufactured by Toyota is better known as SiRPA liner. Thermal swing barriers reduce thermal conductivity through a surface by more than 100 times as compared to iron or aluminum surfaces. Thermal swing coatings also had a low volumetric heat capacity, so they do not store nearly as much heat as their ceramic counterparts. This technology was specifically intended for use in the cylinder walls, but with manufacturing costs this application remains out of reach [32].

The main types of two-stroke engine cylinder linings on the market are standard chrome plated or Nickasil (nickel alloy) plated [33]. Chrome was used extensively until the 1970's when research into other materials led to the invention of Nickasil'TM [33]. Chrome was used for its' low coefficient of friction, however it also is "oil-phobic" allowing oil to run off the walls easily [33]. Nickasil offers both better oil retention and the same low friction quality [33]. The comparison testing of Nickasil in the laboratory was unsuccessful due to the poor quality of the 3-D printed 
cylinders on which it was applied. The CY cylinders originally used for testing had too sharp of transfer port edges to be honed conventionally.

\subsection{Helmholtz Resonator Theory}

Any closed end chamber constitutes a Helmholtz resonator. Such a chamber with known volume and runner geometry will have a characteristic natural frequency of pressure pulse oscillation. Helmholtz theory may be used for both intake and exhaust tuning purposes. The frequency may be utilized in the exhaust as a means of extracting more exhaust from the cylinder during the suction phase, as well as pushing slipped mixture back into the exhaust port on the returning positive pressure wave. When used with the intake process, tuning the positive pressure wave frequency acts as an extra final push for the fresh intake charge to clear the intake port or reed valve. For a fixed frequency of operation (which is standard for electrical power generation engines) an optimized intake geometry may be determined. The tuned length used to construct the intake corresponds to the value of effective length $\left(\mathrm{L}_{\text {eff }}\right)$ calculated which takes the diameter into account. The Helmholtz frequency, $f_{h}$, is twice that of the engine operating frequency [34] [35]. Figure 4 below shows a schematic of design parameters for construction of a tuned Helmholtz resonator chamber. Note the calculation used the fixed engine geometry to determine $V_{\text {eff }}$, from which a set of possible area and length values may be determined. For CCC the effective volume should consider the crankcase volume as well as the displacement volume at half stroke.

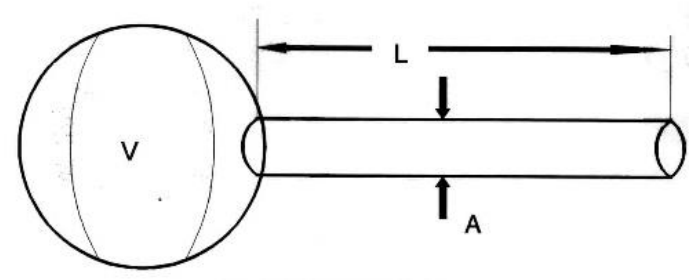

Figure 4 - Helmholtz resonator schematic showing the basic length, area, and volume elements of a tuned intake [36].

Equations 1-3 can be used once the engine operating frequency is defined since the Helmholtz frequency is approximately two times the operating frequency. 


$$
\begin{array}{r}
f_{h}=\frac{c}{2 \pi} \sqrt{\frac{A}{L_{e f f} \times V_{e f f}}} \\
L_{e f f}=L+0.3 d \\
V_{e f f}=\frac{V_{d}}{2}+V_{\text {crankcase }}
\end{array}
$$

Where $A$ is the effective cross-sectional area of the resonator tube, $V_{\text {crankcase }}$ is the volume of the crankcase, and $V_{d}$ is the displacement volume, and $c$ is the speed of sound in air at intake conditions.

Traditionally, tuning has been applied with the goal of peak power density. Intake and exhaust tuning have both been shown to increase power density, however in this research efficiency was the primary concern over power density. Typically, the most efficient operating point occurs at a slightly lean mixture [35]. As the mixture becomes slightly rich, power density increases along with more stable combustion [35]. Traditionally, tuners did not care about having to run rich for the increased power density while emission went heavily unregulated. With more stringent regulations in today's market, this research has focused on tuning for peak efficiency. The peak tuning point would be expected to change with this primary goal in mind.

\subsection{Intake Tuning}

Tuned intakes are an appropriate design methodology on all quality production engines, especially two-stroke engines. This process however is typically overlooked on smaller handheld engines due to space constraints and desire to keep manufacturing costs low. Intake tuning of two-stroke engines is based on Helmholtz resonator theory. The base geometry of the intake may be characterized by overall length, volume, and taper angles of any Helmholtz resonator chambers. Wladyslaw's experiment showed that varying intake length and diameter independently effect the delivery ratio (DR). The DR is the ratio between the actual mass delivered to the cylinder and the theoretical mass that would perfectly fill the cylinder volume. The addition of a side volume in the

intake system was also shown to improve DR [37]. The intake pipe has a direct purpose of increasing the compression pressure. By varying only the length of inlet pipe at constant engine speed, a $17 \%$ gain in compression pressure was achieved by Matthews and Gardiner due to increased DR. It may also be mentioned that wave velocity increases with increased pipe diameter [38]. Additional improvements to the intake process occur by adding Helmholtz resonator cones 
to the intake pipe. The reflected pressure waves can be timed properly to increase DR. Jawad showed that intake resonators which operate approximately twice the frequency of the piston can increase power and induction [39] [34]. The main pressure pulse is formed by the final closing of the intake valve or reed, which will be reflected at such a time that assists the next intake process. Overall, intake tuning must be tailored for each specific type and size of engine [12].

\subsection{Exhaust Tuning}

Tuned exhaust systems are critical for two-stroke engine breathing and scavenging. An exhaust may be fine-tuned for a very specific power output and speed, or more broadly tuned for a range of power and speeds. This tuned region of the engine operating speed scale is commonly referred to as the power-band of the engine. The exhaust mass flow is influenced by the timing of the pressure pulse traveling in the resonator [12]. The pressure pulse causes a suction pressure on the cylinder to help pull the scavenging flow through the transfer ports and clear residual gases from the combustion chamber [12]. After the pressure wave is reflected off the back-converging cone, it returns to the port pushing some of the escaped charge back into the cylinder [12]. Figure 5 shows the general travel scheme of tuned exhaust pressure pulses. Notice that the plus symbol represents a positive pressure wave while the negative symbol denotes a negative or suction pressure wave.
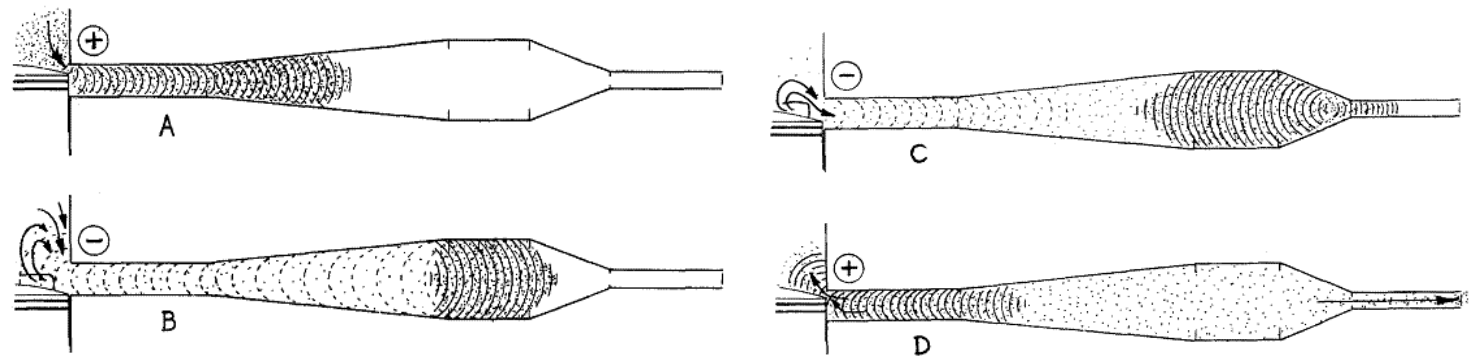

Figure 5 - Exhaust pressure wave travel schematic for a basic tuned resonator. a.) initial positive pressure expansion as the export port opens, $b$.) once the flow expands in the divergent cone, a negative pressure (suction wave) is created, $c$.) as the flow passes through the convergent cone a positive pressure wave is created in the direction opposite of flow, and d.) when tuned correctly this positive pressure waive will arrive just prior to exhaust port closure [12].

Zsiga et al. studied the effects of exhaust tuning on a $52 \mathrm{cc}$ small two-stroke leaf blower engine. The baseline testing was performed with the typical stock box silencer exhaust and compared to 
two different tuned resonator exhausts. At maximum brake torque (MBT) engine power increased by $40 \%$ while also lowering specific emissions of $\mathrm{HC}+\mathrm{NO}_{\mathrm{x}}$ by $34 \%$ [40]. At other operating points $\mathrm{HC}+\mathrm{NO}_{\mathrm{x}}$ was reduced by up to $62 \%$. Maximum trapping efficiency increased by $15 \%$ and brake specific fuel consumption (BSFC) decreased by 18\% [40]. The research showed the possible increases in power, however tuned exhausts are not practical for mobile power equipment due to package volume. This space consideration was not a concern for a stationary generator as the case in this research. Additionally, while power was the main consideration in their study, this paper examines the combined effects of exhaust tuning on power and efficiency.

\subsection{Fuel Delivery Methods}

Fuel may be delivered to the engine in a number of ways. For decades, carburetors were used to control fueling. The design utilizes a venturi in the intake pipe which causes a suction of fuel that mixes with the air stream. Carburetors cause inherent fuel slippage when used for two-stroke engines due to the scavenging process consisting of a homogeneous air-fuel mixture. Port injection, injecting fuel into the air stream prior to the intake port, was an advancement to carburetors [41]. PI allows for the electronic control of fueling, which eliminates the dictation of fueling by existing air-flow. Controlling fuel-flow independent of air-flow allows for precision fuel control, which enables better acceleration and deceleration fueling. LPDI consists of injecting fuel at pressures less than 5 bar directly into the cylinder or transfer port of the engine. This reduces the amount of fuel entrained with the scavenging air-flow which greatly improves fuel trapping efficiency. High pressure direct injection (HPDI) involves fuel injection directly into the cylinder at pressures greater than 5 bar. HPDI allows for maximum fuel trapping efficiency, since the cylinder is a closed chamber at the point of injection. HPDI is the current technology of choice for the automotive industry.

\subsubsection{Port Injection (PI)}

Port injection consists of delivering fuel into the air intake stream prior to the valve, reed, or port which supplies the intake charge. In the case of CCC engines that use reeds, this occurs prior to the reed valve which enters the crankcase. As a result of early mixing, the air fuel mixture becomes homogenous within the crankcase [42]. For gaseous fuel, PI and fumigated fueling have similar power, efficiency, and DR for this reason [42]. 
Experiments performed on a $300 \mathrm{cc}$ two-stroke engine outlined the possible gains in efficiency when moving from carbureted to PI and LPDI. Peak efficiency was recorded at $20.6 \%$ for carbureted fuel metering, $26.2 \%$ for PI, and $29.5 \%$ for LPDI. The fuel consumption decreased as compared to the carbureted model, by $15 \%$ for PI and $25 \%$ for LPDI. The power of this engine at 7500 RPM was noted to decrease slightly with the added technologies; from $22.2 \mathrm{~kW}$ carbureted, to $21.6 \mathrm{~kW}$ on PI and $21.3 \mathrm{~kW}$ on LPDI. The LPDI design was also noted to be above $20 \%$ efficient for the entire operating range [43].

\subsubsection{Low Pressure Direct Injection (LPDI)}

LPDI of compressed natural gas $(\mathrm{CNG})$ has been shown to increase efficiency and reduce emissions of $\mathrm{CO}$ and $\mathrm{HC}$ in two-stroke engines versus traditional carbureted gasoline fueling. Studies conducted on a $98 \mathrm{cc}$ Yamaha two-stroke engine operated with CNG LPDI at an injection pressure of 2 bar showed a $9 \%$ increase in efficiency over the traditional gasoline carbureted engine at 3500 RPM. Data also showed a $79.3 \%$ and $94.5 \%$ decrease in $\mathrm{HC}$ and CO, respectively. It was found that the most efficient start of injection (SOI) occurred at 123 crank angle degrees (CAD) before top dead center (BTDC). The rate of heat release of CNG LPDI was also shown to be 38\% faster than the carbureted gasoline counterpart [44].

Research conducted on transfer port injection (TPI) of CNG showed an extension of the lean burn limit and a relative $25 \%$ efficiency increase over fueling with a gas mixer (fumigation). Total hydrocarbon (THC) emissions were reduced by a maximum of $47 \%$ which was attributed to better fuel trapping [45]. With a move toward fuel injection over the traditional carburetors, oil delivery methods must be addressed. For KTM's new TPI 2018 series of $250 \mathrm{cc}$ dirt bikes, a separate oil pump system with engine control unit (ECU) controlled variable flow rates for various loads and speed was created. The new series of TPI bikes are said to reduce low speed fuel consumption by up to $40 \%$ with similar WOT fuel consumption [46]. A similar Husqvarna version of the $250 \mathrm{cc}$ fuel injected dirt bike was made slightly prior in 2018 which boasts 30-40\% improvement in fuel economy over the traditional carbureted model [47]. Studies conducted on TPI of liquefied petroleum gas (LPG) also showed considerable reductions in emission output; the conversion from carbureted to TPI resulted in a $87.6 \%$ reduction in $\mathrm{CO}, 59.3 \%$ reduction in $\mathrm{HC}$, and combined reduction of $80 \% \mathrm{CO}+\mathrm{HC}[48]$. 
Other LPDI research showed the impact of injection window on engine performance. It was shown that staged injections resulted in more stable combustion [49]. LPDI of gaseous LPG was shown to reduce $\mathrm{HC}$ emissions by up $93 \%$ as compared to PI. BTE was reported to increase from $20 \%$ to $28 \%$ when transitioning from PI to LPDI. Leaner mixtures were achievable under LPDI as compared to PI. LPDI also led to higher cylinder pressures and increased the rate of heat release [15]. Early work in the field also concluded significant reductions in HC emissions could be made by transitioning to LPDI of NG over PI [50]. Testing of a $50 \mathrm{cc}$ air cooled scooter under LPDI was shown to meet 2014 Euro emission standards while increasing idle stability and catalyst life [51].

\subsubsection{High Pressure Direct Injection (HPDI)}

The Bosch research and development group conducted an investigation on NG injected four-stroke engines for vehicles. It was found that by using two-stage injection split $90 \%$ early injection and $10 \%$ near ignition reduced $\mathrm{HC}$ emissions by $25 \%$ over the best single injection strategy. Injection pressure was found to have minimal effect on the emission levels of HC. Injection timing was paramount in forming the proper mixture formation to achieve a low HC emissions [52]. Numerical simulation of NG injector designs showed improvements in efficiency for injectors with more orifices, while keeping the injector tip net area approximately constant. It was found that an injector tip with 7 orifices as compared to 4 , with areas of $12.6 \mathrm{~mm}^{2}$ and $12.4 \mathrm{~mm}^{2}$ respectively increased indicated efficiency by over $10 \%$ [16].

A study on injection parameters by Dube and Ramesh examined HPDI of gasoline in a $200 \mathrm{cc}$ aircooled, single cylinder, reeded two-stroke engine. For the direct injection of gasoline at 3000 RPM, it was found that injection 150 CAD BTDC yielded the highest BTE. The highest MBT was achieved with injection at 165 CAD BTDC. Retarding the end of injection (EOI) resulted in higher trapped equivalence ratios and increased $\mathrm{CO}$ emissions. Variations in the injection pressure over the range of 100-150 bar showed negligible changes in BTE. The effect of spark plug location was also examined and found to have a negligible effect of the BTE or power output; however, the heat release rate shows a higher maximum value and a shift toward TDC from 20 CAD after top dead center (ATDC) to about 10 CAD ATDC. DI of gasoline was shown to reduce HC emissions by over 2000 ppm for any operation condition, reduce $\mathrm{NO}_{\mathrm{x}}$ by $1500 \mathrm{ppm}$ near stoichiometric conditions, and increase $\mathrm{CO}$ emissions at all operating points over PI [53]. 
For NG two-stroke operation in a residential power generator application, HPDI was excluded as a possibility due to the NG pressure occurring in distribution lines. Typical street distribution lines for NG operate at 410 kilopascals ( $\mathrm{kPa}$ ) gauge or less, or about 5 bar gauge [54]. The use of HPDI would then require a gas compressor, which would be costly in terms of energy at the $1 \mathrm{~kW}$ level. For this reason, research efforts focused on LPDI of NG at 5 bar and less.

\subsection{Emission Regulations}

The EPA dictates in the code of federal regulations (CFR) part 1054.103 that engines less than 80 cc in displacement are considered as handheld engines and are subject to the same standards regardless of being used in a stationary device or handheld equipment [55]. Class IV handheld equipment is described by displacements in the range of less than $50 \mathrm{cc}$ but greater than $20 \mathrm{cc}$ [56]. The useful life for heavy use is 300 hours for a typical engine of this size class under the CFR [55]. The EPA requires all new engines to fall at or below the standards of $50 \mathrm{~g} / \mathrm{kW}-\mathrm{hr} \mathrm{NMHC}+\mathrm{NO}_{\mathrm{x}}$ and $805 \mathrm{~g} / \mathrm{kW}$-hr CO [55]. NG engines use non-methane hydrocarbon (NMHC) emissions instead of THC, due to the reactivity in ozone production of double carbon and higher fuel components. Ozone is formed from the combination of $\mathrm{NO}_{\mathrm{x}}$ and volatile organic compounds in the presence of heat or sunlight [57]. The US EPA ranks propane and butane as very volatile organic compounds which occur primarily in gaseous form in the atmosphere and are highly reactive in ozone formation [58]. National ambient air quality standards have been placed on carbon monoxide, nitrogen dioxide, particulate matter, sulfur dioxide, lead, and ozone [59]. $\mathrm{CH}_{4}$ while unregulated toward $\mathrm{HC}$ content, contributes to the net $\mathrm{CO}_{2}$ equivalent and global warming potential. The California alternative limit for CO under Phase 3 test fuel is $536 \mathrm{~g} / \mathrm{kW}$-hr [55]. Note in Table 1 below that $\mathrm{HC}$ refers only to NMHC for NG engines.

Table 1 - Regulated gaseous emission limits for small engine classes in units of $\mathrm{g} / \mathrm{kW}$-hr with this engine class highlighted [55].

\begin{tabular}{|c|c|c|}
\hline Engine Displacement Class & HC+NO $_{\mathbf{x}}$ & $\mathbf{C O}$ \\
\hline Class III & 50 & 805 \\
\hline Class IV & 50 & 805 \\
\hline Class V & 72 & 603 \\
\hline
\end{tabular}




\subsection{Background/ Development of Problem - Natural gas accessibility and use as a power source}

Consequences of using NG include the issue of maintaining good volumetric efficiency with two gaseous intake constituents rather than air alone. This competition in breathing generally rules out PI of NG as an equivalent to gasoline operation power production. Lean burn SI NG combustion is also prone to erratic flame kernel formation observed as a result of cyclic turbulence variations [5]. NG has a higher GHG potential than traditional liquid fuels due to high amounts of $\mathrm{CH}_{4}$ present in the combustion products. NG also has limitations on storage for vehicle use, requiring bulky large tanks. However, this fuel is perfect for stationary power generation such as at a household already heated with NG or at drilling sites. For LPDI applications of NG, the gas line prior to the house's regulator would be under sufficient pressures.

$\mathrm{NG}$ composition varies continuously with time and location. The requirements for pipeline quality NG are minimum $75 \%$ methane, maximum $10 \%$ ethane, and maximum $5 \%$ propane by volume [3]. Methane exhibits the highest knock resistance of the natural gas components; however, this increases required activation energy for ignition in SI engines. Increased inert components of $\mathrm{CO}_{2}$ and $\mathrm{N}_{2}$ also make a gas mixture more difficult to ignite. As higher carbon components (propane and ethane) increase in the natural gas mixture the fuel becomes easier to ignite and burns slightly hotter which increases thermal $\mathrm{NO}_{\mathrm{x}}$ production [60]. Higher carbon components are less knock resistant, or easier to ignite than methane and increase the regulated NMHC content in the exhaust. The higher carbon components, especially propane, burn inherently richer than methane causing increased $\mathrm{CO}$ production [60].

Testing of various lean burn $\mathrm{NG}$ engines showed a trend of increasing $\mathrm{NO}_{\mathrm{x}}$ and $\mathrm{HC}$ emissions with decreasing methane number (MN) and increasing Wobbe index. NMHC emissions were shown to increase with decreased $\mathrm{MN}$ and were proportional to NMHC contents in the fuel. $\mathrm{CO}$ emissions were relatively constant for all fuel blends and well below standards. The stoichiometric ISL G engine did not follow any clear emission trends with regards to fuel composition. For all engines, higher Wobbe index resulted in decreased fuel consumption [61]. 


\subsection{Methodology}

\subsection{Laboratory Setup and testing procedures}

A data acquisition system was created to collect engine operating parameter data. The system utilized a Microsquirt open source ECU, used to control ignition timing, injection timing, and AFR. The Microsquirt was coupled with Tuner Studio MS software to control the parameters and create fuel tables which correlated throttle position to injection duration. A DSP6000 dynamometer controller coupled to a Magtrol 715-6 HD hysteresis load absorber set engine speed and measured the engine brake torque. The engine speed was set to 5400 RPM for all testing. PID controller setting of 5,13,2 were used for engine testing. An MKS multi-gas 2030 series FTIR continuous gas analyzer measured exhaust gas components. Measured components consisted of methane, ethane, propane, carbon monoxide, nitrogen oxides, water, and carbon dioxide. A Model 755-R Rosemount paramagnetic oxygen analyzer was used instead of typical zirconia-based sensors, due to excess hydrocarbons and overall leanness of the exhaust. Airflow was recorded with a HEISE PTE1 pressure calibrator and a 226.5 standard liter per minute (SLPM) laminar flow element (LFE). The LFE required intake piping greater than ten times the diameter on the inlet side. An MC-20 series Alicat Mass Flow Controller (MFC) measured fuel flow rate. The MFC flow was set to methane and corrected to specific blend properties using MFC correction factors. An Omega I-server environmental instrument monitored test room temperature, humidity, and barometric pressure. This served for density correction and water correction data. A Kistler Kibox instrument with a 6054A piezoelectric pressure transducer was utilized in measuring in-cylinder pressure, a 4007B piezoresistive pressure sensor for crankcase pressure measurements, and a 4049B piezoresistive pressure sensor for exhaust pressure measurement. Cylinder pressure was used to determine indicated parameters, while intake and exhaust pressure sensors served to validate tuning effects. The Kistler Kibox software performed calculations for combustion statistics such as burn duration, percentage mass fraction burned, heat release rates, peak pressures, and also determined indicated mean effective pressure (IMEP). An example screenshot of the Kibox software is shown in Figure A3. An ICP CON PET 7019Z was used to record thermocouple temperatures. Cylinder head and crankcase temperatures were used to assess cooling loads and avoid overheating, while exhaust port and exhaust tail temperatures were used to adjust tuning parameters. In-house Scimitar software recorded all low frequency time series data $(1-10 \mathrm{~Hz})$ 
while also performing power, efficiency, LFE flow, AFR, and density correction calculations. An example screenshot of the Scimitar software is shown in Figure A2. The setup is shown below in Figure 6.

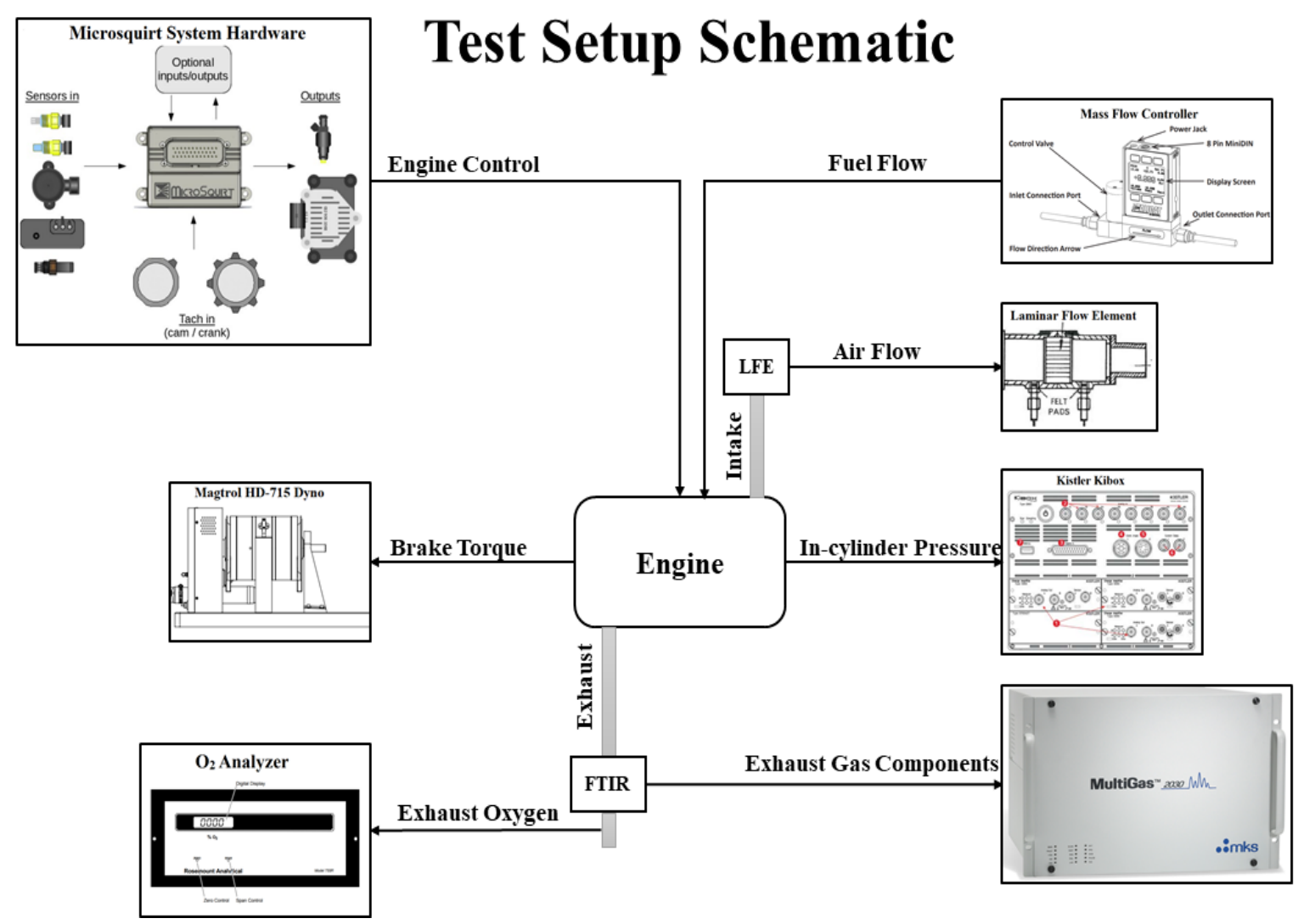

Figure 6 - Schematic of the laboratory setup including major measurement components [62].

All engine testing was conducted at WOT in steady state operation with AFR varied to examine operation of a number of points ranging from rich to lean. All testing was performed with spark timing and injection timing values which resulted in MBT. Pressure and volume-based data were logged using the Kistler Kibox and time-series measurements were collectively logged using the Scimitar software. Two different fueling methods, LPDI and PI, were tested to compare baseline efficiency and power output using the beta exhaust which served as the baseline exhaust. After validating the emission reduction and efficiency gains on the LPDI setup, a new GT-Power optimized exhaust was tested under this configuration. The custom Zenoah engine was the final research platform and its specifications are shown below in Table 2. 
Table 2 - Engine specifications for the 34 cc Zenoah engine with custom rear boost port.

\begin{tabular}{|c|c|}
\hline No. of Cylinder & 1 \\
\hline Type & Two-Stroke \\
\hline Bore & $38[\mathrm{~mm}]$ \\
\hline Stroke & $30[\mathrm{~mm}]$ \\
\hline Connecting Rod & $52[\mathrm{~mm}]$ \\
\hline Induction system & Naturally Aspirated \\
\hline Displaced volume & $34[\mathrm{cc}]$ \\
\hline Number of ports & 6 \\
\hline Boost Port & Yes \\
\hline Reed Valve & Yes \\
\hline GCR & 12.76 \\
\hline DCR & 8.15 \\
\hline Exhaust Port Open & 92 CA ATDC \\
\hline Transfer Port Open & 120 CA ATDC \\
\hline Scavenge Type & Loop with boost port \\
\hline Manufacturers & Zenoah \& OBR \\
\hline
\end{tabular}

The research engine required a starting mechanism as well as a means to motor the engine for top dead center correction. Originally, a one-way bearing was connected to an input shaft powered by a GE AF300-B drive and three phase industrial motor. The system was aligned using a T-slot pivot table with floating bearings supporting the shaft. However, small alignment issues caused frequent failure of the one-way bearings, which impacted brake efficiency measurements over time. A major upgrade was made to the test bench by introducing a T-slot table for all components to have common alignment. Precision machining was performed to create base plates for each component which fixed vertical alignment. After fixing alignment issues, a starter clutch was selected to replace the one-way bearing. The starter clutch allowed for clutch engagement only at speeds over 4000 RPM, thus when the motor was shut off there was no contact between moving parts. Power was output to the dynamometer via a flexible shaft, which acted as a sacrificial component to avoid overloading the dynamometer. In addition, the output side still used a clutch attached to the crankshaft output. Due to the use of the clutch and variable mechanical efficiency, it was determined that research should focus more on indicated engine performance rather than brake performance. The tuned exhausts were mounted on posts with $0.91 \mathrm{~mm}$ vertical resolution and had full freedom to move about the plane of the T-slot table surface. The engine was mounted on a 
vertical alignment plate as well. All vertical alignment was made to complement the dynamometer shaft center height.

The injection signal was controlled by the ECU, which was then sent to a solid-state relay. The relay was necessary for the high current injection pulse required to operate the injector. A MR2535L diode on the input side of the relay prevented fly back voltage due to inductance when stopping the injection current flow. An LS2 coil connected to the $6.35 \mathrm{~mm}$ VR2L spark plug was also controlled by the ECU for ignition. A 36-tooth trigger wheel with a missing tooth $60 \mathrm{CAD}$ BTDC and VR sensor synchronized to the ECU determined crank angle-based timings and recorded engine speed with resolution up to plus or minus 10 CAD. Figure 7 shows the experimental setup for LPDI testing.

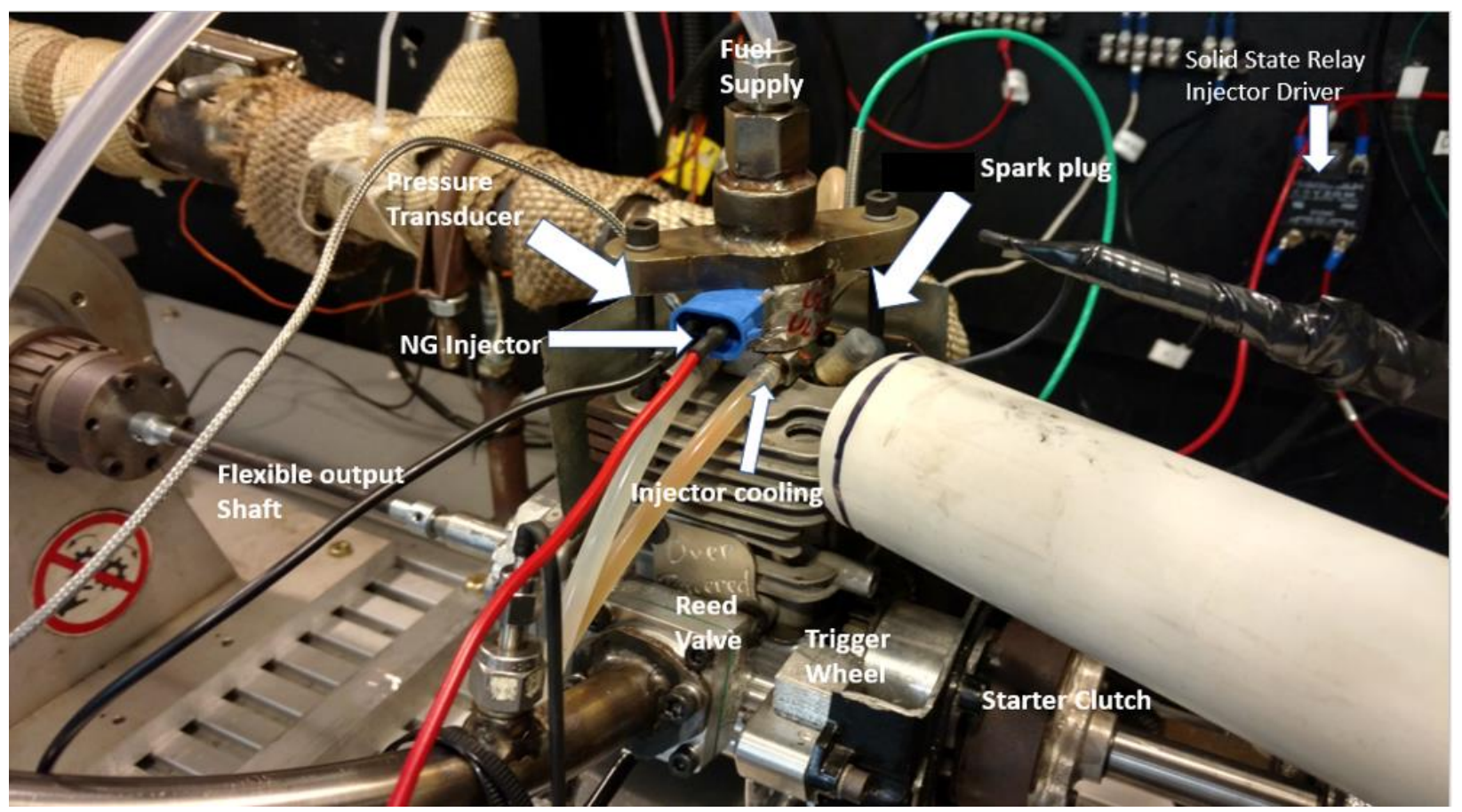

Figure 7 - Laboratory photograph showing the Zenoah research engine outfitted for LPDI operation. Note the white tube entering from the right provided forced cooling air to the cylinder.

The original spark plug location was reamed to 10 millimeters to accommodate central location of the LPDI injector tip. A model 1039 Mercury Optimax air injector was used for the injection of NG. It may be noted, the injector is traditionally used in combination with a fuel injector for mixture injection in marine two-stroke engines. The injector required a custom-made watercooling adapter to avoid overheating from the cylinder and high frequency injector loading. Oil is 
supplied directly into the intake flow prior to the reed valve via a small positive displacement pump.

A CAD model of the engine was required for knowledge of injector, pressure transducer, and spark plug location possibilities. Figure 8 shows a side view schematic of the LPDI setup.

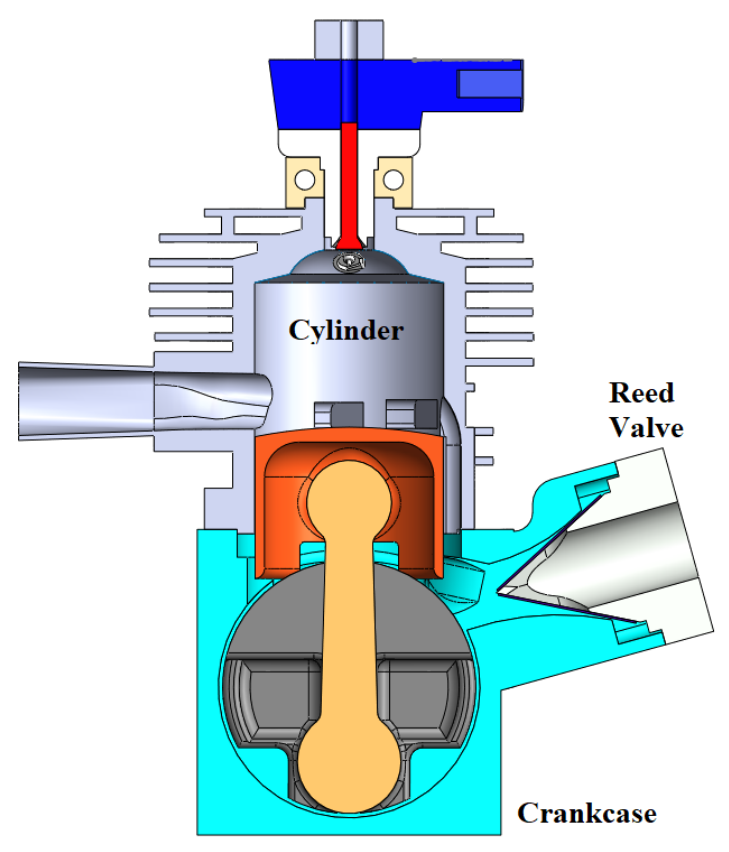

Figure 8 - CAD schematic of LPDI engine setup showing the centrally located injector at the top and center of the combustion chamber [62].

For testing of PI, the original engine spark plug location was used and is shown on the right in Figure 9 [62] . On the left a cross section view of LPDI injector, spark plug location, and pressure transducer location is shown. The pressure transducer port, or crevice, location inside the cylinder was normal to the surface of the combustion dome. The ideal spark plug location for the $6.35 \mathrm{~mm}$ plug would be been located on the dome above the intake port [63]. The scavenge flow loops up to the dome and then down toward the exhaust, making a locally rich pocket which was easier to ignite the mixture for any fueling method. This location however was hardly sufficient in material to tap the required number of threads needed to safely secure the spark plug. For this reason, the spark plug was located on the side of the combustion dome where a fin bridge added extra material to tap. Figure 9 shows differences in the PI and LPDI cylinders, with custom added components for LPDI. 


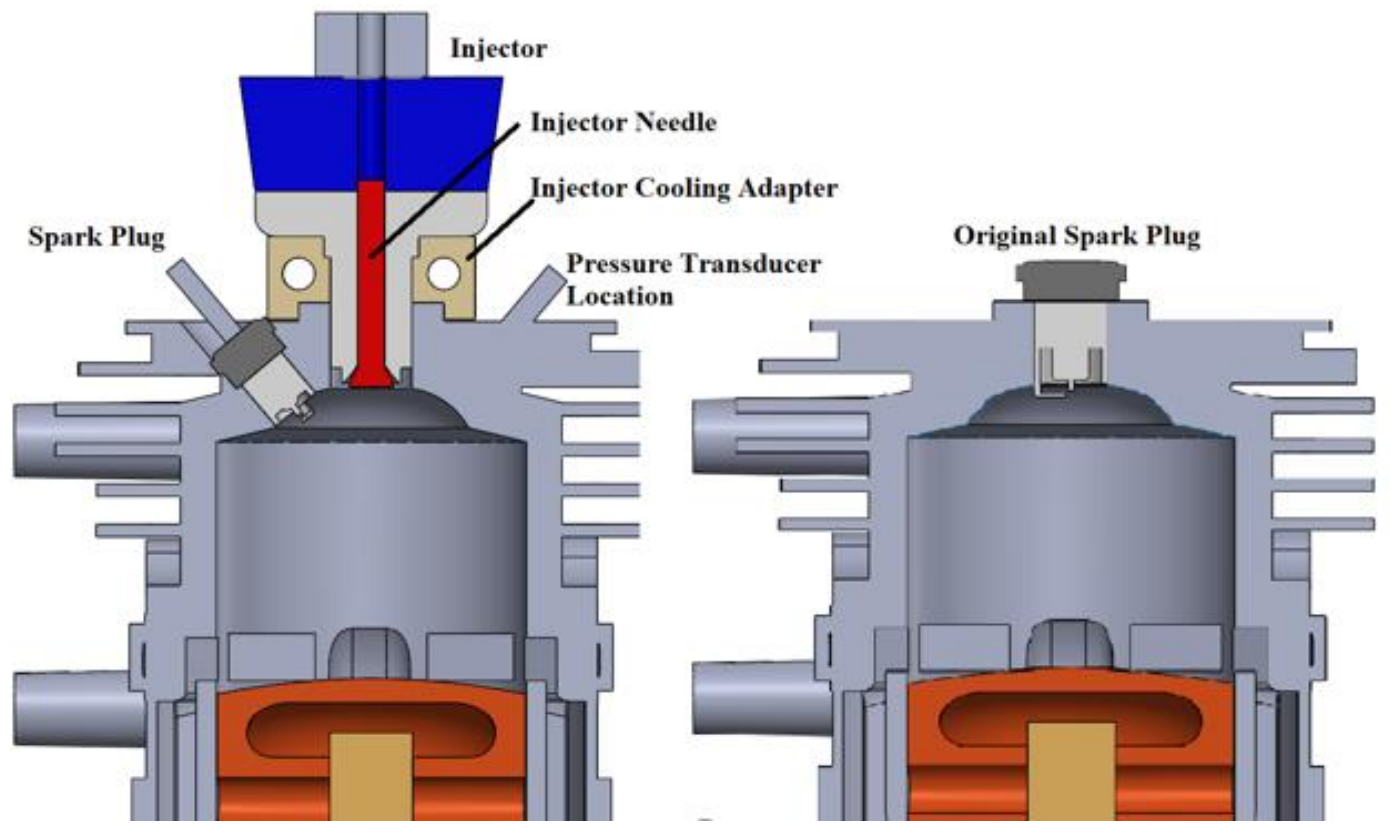

Figure 9 - Cylinder schematics for different fuel delivery methods. LPDI (left), PI (right) showing original spark plug location [62].

The engine porting included four main transfer ports and one rear boost port. The loop scavenge flow motion was primarily caused by the upward facing rear boost port, while the main transfer ports are swirl oriented. The exhaust port was trapezoidal with tapered ends. A schematic of the engine porting is shown below in Figure 10.

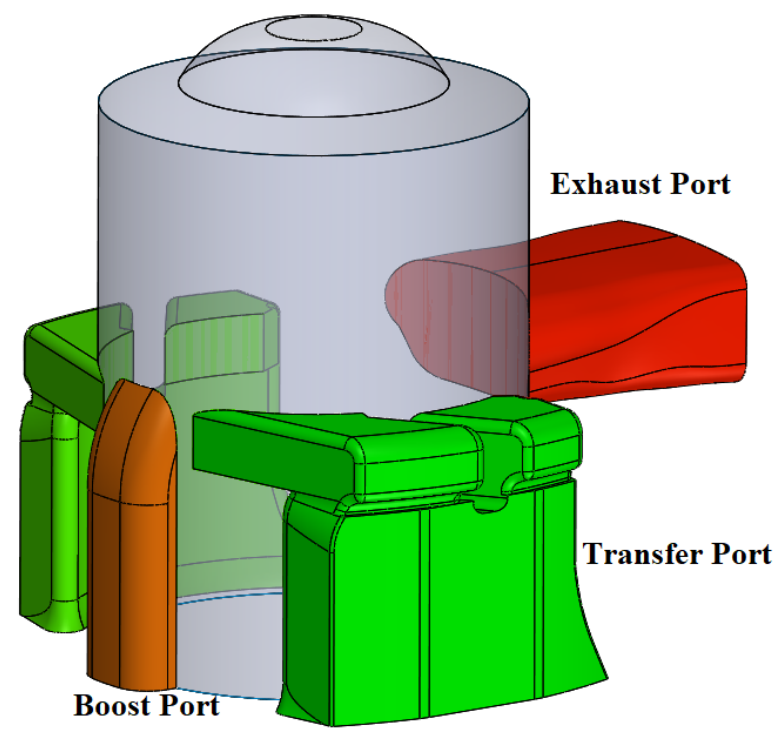

Figure 10 - Porting schematic to highlight the addition of the custom boost port at the rear of the cylinder [62]. 
A preliminary analysis of four different fuel blends found the specific blend listed in Table 3 to be the most efficient under PI and fumigation of a previous engine (CY $29 \mathrm{cc}$ ). For this reason, all subsequent research was conducted using this specific fuel blend with properties listed below. The benefit of this fuel blend comes from high ethane content which reduced ignition delay. The gas blend met pipeline quality standards and was representative of common in-use gas qualities in houses. Notice, the percentages listed are on a volume basis.

Table 3 - Specifications of the natural gas used for these research efforts.

\begin{tabular}{|c|c|}
\hline Component & Value \\
\hline Methane $\left(\mathrm{CH}_{4}\right)$ & 90.5 \\
\hline Ethane & 5.00 \\
\hline Propane & 1.00 \\
\hline Carbon Dioxide $\left(\mathrm{CO}_{2}\right)$ & 1.00 \\
\hline Nitrogen & 2.50 \\
\hline LHV & $46.5[\mathrm{MJ} / \mathrm{kg}]$ \\
\hline MN & $78[--]$ \\
\hline Stoichiometric AFR & $15.87[--]$ \\
\hline Density at STP & $0.734\left[\mathrm{~kg} / \mathrm{m}^{3}\right]$ \\
\hline Wobbe Number & $66.0[\mathrm{MJ} / \mathrm{kg}]$ \\
\hline Molecular Weight & $17.6[\mathrm{~kg} / \mathrm{kmol}]$ \\
\hline
\end{tabular}

For each test configuration the start of injection, ignition timing, intake length, and exhaust length were all held constant. To change AFR, injection duration was used for load control. The general timings are listed below in Table 4 for reference to test conditions. Notice that the injection duration was taken as the average injection duration of the different configurations when sweeping from the rich to lean limits.

Table 4 - List of constant parameters for configuration variations.

\begin{tabular}{|c|c|c|c|c|c|}
\hline & Spark Timing & $\begin{array}{c}\text { Start of } \\
\text { Injection }\end{array}$ & $\begin{array}{c}\text { Average } \\
\text { Injection } \\
\text { Duration }\end{array}$ & $\begin{array}{c}\text { Intake } \\
\text { Length }\end{array}$ & $\begin{array}{c}\text { Exhaust } \\
\text { Length } \\
\text { (L3) }\end{array}$ \\
\hline Configuration & [CAD BTDC] & [CAD BTDC] & [CAD] & [cm] & [cm] \\
\hline PI Beta & 25 & 80 & 64 & 49.5 & 71 \\
\hline LPDI Beta & 29 & 162 & 37 & 49.5 & 81 \\
\hline $\begin{array}{c}\text { LPDI } \\
\text { Optimized }\end{array}$ & 25 & 154 & 27 & 49.5 & 79 \\
\hline
\end{tabular}




\subsection{Designs}

\subsubsection{Injection Strategies}

The determination of fuel mass flow rate is based on a series of calculations involving the density of the specific gas blend and ALICAT MFC volumetric reading. The standard reference temperature and pressure used for MFC corrections are $25^{\circ} \mathrm{C}$ and $101.325 \mathrm{kPa}$.

\subsubsection{Injection Pressure Window}

Studies conducted using high speed imaging of $90^{\circ}$ conical injectors by Sankesh et al. show the turbulent dynamics of the injection pulse. The results of the study show that radial motion of the injected fuel dominated over axial motion down the cylinder [64]. High speed images of the conical injector gaseous fuel delivery flow are shown above in Figure 11. It also shows the formation of two small vortices at the leading corners of the injected plume [64].

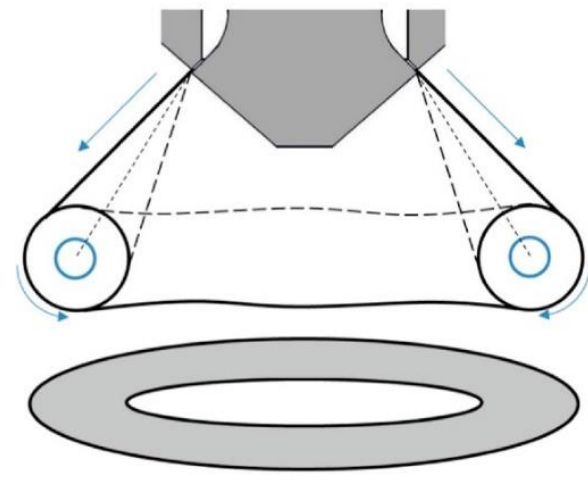

(i)

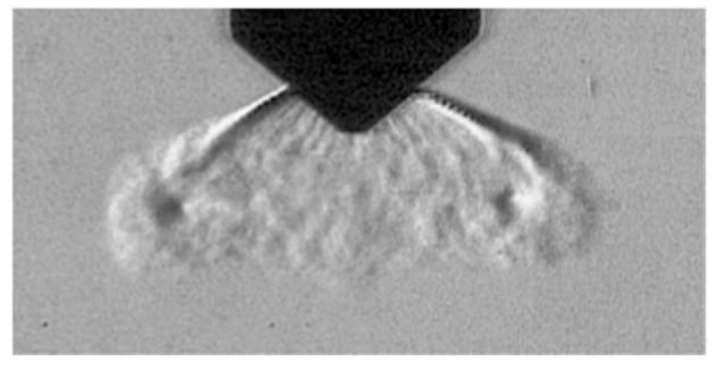

(ii)

Figure 11 - Basic conical injector flow schematic [64].

Based on calculations using Equations 4-6 [52], I found that the ideal injection pressure window to maintain choked (or maximum) injection flow occurred from 180 to 65 CAD BTDC for an injection pressure of $275 \mathrm{kPa}$ gauge. For an injection pressure of $137 \mathrm{kPa}$ gauge this pressure window reduced into 180 to 83.5 CAD BTDC. This injection window must be adjusted to account for injector opening and closing time, both were experimentally determined to be between 16-20 CAD at an operating speed of $90 \mathrm{~Hz}$.

$$
\begin{gathered}
\dot{m}=A_{e f f} \sqrt{2 P_{\text {inj }} \rho} \sqrt{\frac{\gamma}{\gamma-1}\left[P_{\text {crit }}{ }^{\frac{2}{\gamma}}-P_{\text {crit }}{ }^{\frac{\gamma+1}{\gamma}}\right]} \\
P_{\text {crit }}=\frac{P_{c y l}}{P_{\text {inj }}}
\end{gathered}
$$




$$
P_{\text {crit }} \leq\left(\frac{2}{\gamma+1}\right)^{\frac{\gamma}{\gamma-1}} \approx 0.54 \quad\left(\text { for } \gamma_{\mathrm{CH} 4}=1.31\right)
$$

\subsubsection{Port Injection}

Testing of the injection window on PI operation was found to be robust. Due to the travel time down the intake, and pre-mixing in the crankcase prior to being pumped via the transfer ports into the cylinder created a homogenous mixture regardless of injection timing. Fuel injection pressure required for PI was less than 1.5 bar gauge.

\subsubsection{Low Pressure Direct Injection}

LPDI start-of-injection timings from 210 to 155 CAD BTDC were shown to maintain engine operation. Early injection allowed for better mixing but had the negative consequence of higher slipped fuel. Late injections likely resulted in a more stratified charge which appeared as unstable combustion. The injection timing for maximum brake torque was found for all three cases and used for the sweep of AFRs. Injection duration was used as a means of control for the engine. Fuel pressure required for LPDI had a maximum limit of 5 bar, however pressure less than 2.5 bar was found to be sufficient. Note that this lower pressure requirement extended the applicability to NG lines of lower than standard street pressure.

\subsubsection{Thermal Barrier Coating}

To improve overall efficiency by reducing heat losses, a thermal barrier coating (TBC) was applied to the crown of the piston as well as combustion dome of the original CY engine. The product information reported that $\mathrm{CBC} 1$ reduced part temperature by allowing minimal surface heat transfer, resistance to knock, and increased combustion chamber efficiency. Furthermore, the product claimed more efficient fuel oxidation which leads to increased power output [65].

In preparing the parts for TBC application, an initial cleaning occurred with acetone. In order to help the thin film layer of water-based TBC adhere to the parts, etching was next performed with 100 grit aluminum oxide sand via a sand blaster. The purpose was to create a very fine but porous surface for the $0.0254 \mathrm{~mm}$ layer to adhere. After etching, tape was applied to the parts to keep the TBC only in desired areas. The TBC was then carefully applied with an air brush in a fine mist spray under $210 \mathrm{kPa}$ gauge air pressure. The TBC was finally cured onto the parts by baking them in an oven at $150^{\circ} \mathrm{C}$ for one hour. Figure 12 shows the TBC coating applied to the CY 29 cc engine piston and combustion dome. 


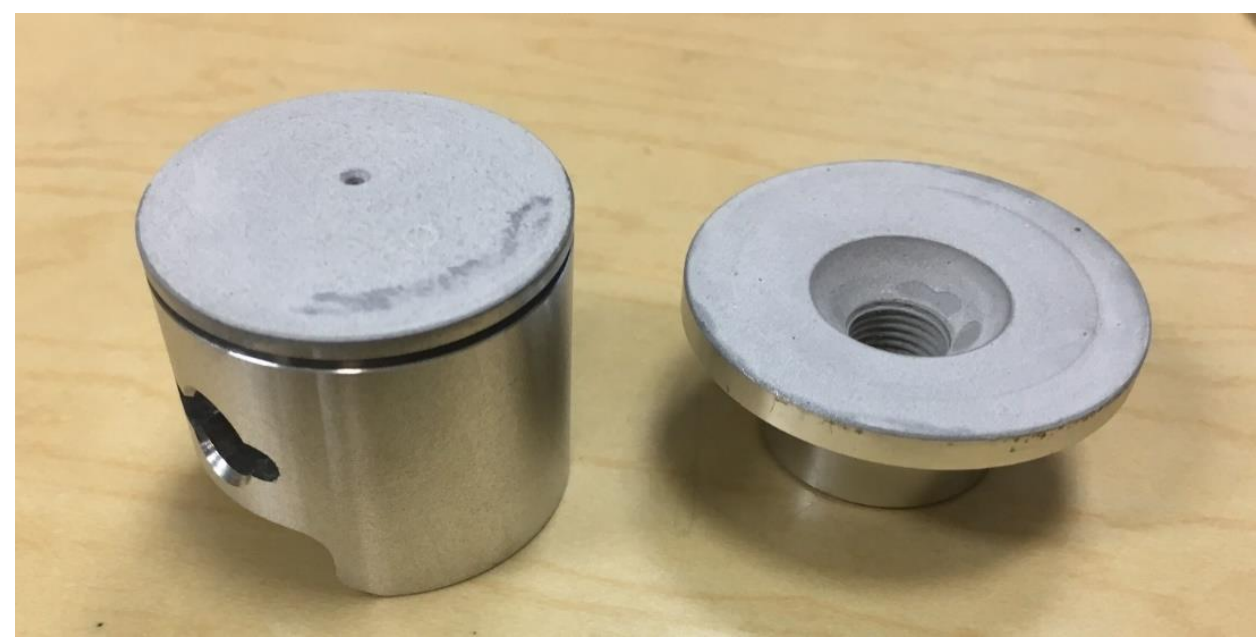

Figure 12 - Ceramic TBC applied to piston and dome of the original CY engine.

Testing of the TBC coating was performed on the original baseline CY $29 \mathrm{cc}$ two-stroke engine fueled by PI of NG. The intake length was swept over the encompassing range of values surrounding the theoretical prediction. All tests were performed with a constant exhaust length and an average lambda of 0.95 . Figure 13 shows the small increase in efficiency of the engine operated with TBC coating applied to the piston and compression dome.

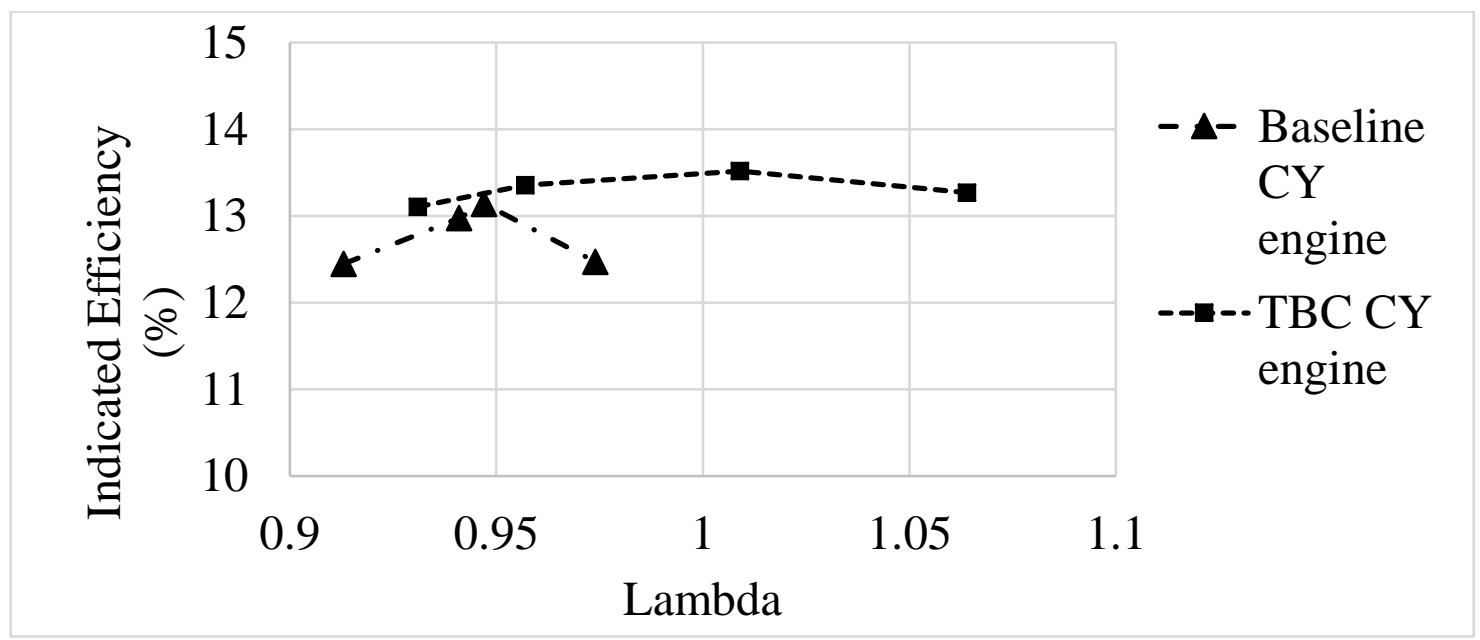

\section{Figure 13 - Effect of TBC coating on indicated efficiency for CY engine at various lambda values.}

The thermal barrier coating led to an approximate $0.4 \%$ increase in peak indicated thermal efficiency (from $13.1 \%$ to $13.5 \%$ ) for the CY 29 Engine. The relative increase in efficiency as compared to the baseline was near 3\%. The increase was less than expected due to the negative charging effects from heating the combustion chamber being dominant. The TBC also weakened 
and became brittle after short periods of use. Future efforts could be shifted to thermal swing barriers. Due to these issues and high cost, TBC coating was not used in further optimization efforts.

\subsubsection{Intake Optimization}

A Helmholtz tuned intake was designed based on Equations (1-3). By simply increasing the intake runner length over a span of lengths known to contain the one predicted by theory an empirical match was produced that closely resembled the one predicted. The calculated length used twice the engine frequency of $90 \mathrm{~Hz}$ for finding a point of maximum power at the operating conditions. Half of the displacement volume as well as complete crankcase volume were both taken into consideration. The process may be iterative if a proper diameter pipe is not chosen on the first attempt. To dampen the effects of flow pulsations upstream of the tuned intake, a pulsation tank was placed between the LFE and tuned intake. The pulsation tank was connected to the tuned intake pipe with flexible hose connectors and an additional slide section for experimental tuning. Based on the tuning calculations, L was determined to be 45.7 centimeter $(\mathrm{cm})$ for a $1.6 \mathrm{~cm}$ diameter intake pipe. The intake was initially constructed at this length, then cut for additional testing of shorter lengths.

The intake tuning theory was validated on the original baseline CY 29 cc engine. The range surrounding the theoretical prediction was swept. It was determined the optimum operational point occurred at a length of $49.5 \mathrm{~cm}$, which corresponded well with theory. The differences in the predicted and experimental values were attributed to error in crankcase volume measurement, as well as using peak efficiency as the tuning criteria. Intake tuning was found to have a $31 \%$ increase in indicated efficiency at the optimum point $49.5 \mathrm{~cm}$ as compared to $\sim 46 \mathrm{~cm}$. The results of intake tuning on indicated efficiency are presented below in Figure 14. All other parameters such as exhaust length, injection timing, and ignition timing were held constant during the rich to lean sweep. 


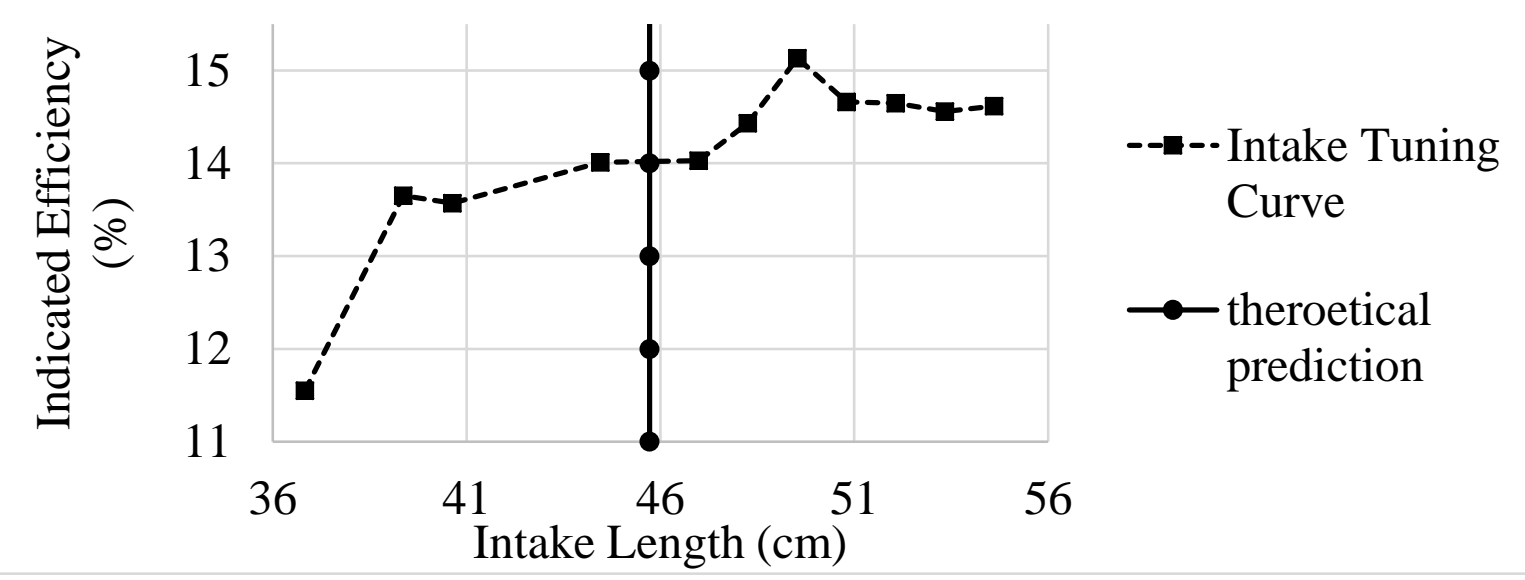

Figure 14 - Effect of intake length on indicated efficiency for CY engine at lambda of 0.95.

\subsubsection{Exhaust Optimization}

\subsubsection{Tuners Handbook: Jennings [12]}

The Tuner's Handbook by Jennings provided empirical formulas for creating an exhaust resonator tailored to a specific engine displacement, speed, and operating exhaust port temperature. The source recommended a constant area ratio of 6.25 be used in determining the diffuser cone angle. It was mentioned that an $8^{\circ}$ diffuser angle is common for most engines. The baffle cone, or convergent cone, should have in general twice the angle of the diffuser cone angle. The largest baffle taper recommended is $20^{\circ}$ and smallest of $14^{\circ}$. The lead in pipe should be $10-15 \%$ greater in area than that of the exhaust port. The guide also states that heavier steel exhaust pipes reduce the vibrations and noise of the ringing exhaust. It mentions that a departure from round pipe to square in the mid-section could benefit engine efficiency. However, it details that overall round pipe sections are the best for noise and vibration reduction.

\subsubsection{Design and Simulation of Two-Stroke Engines: Blair [20]}

A separate set of empirical based exhaust design guidelines were presented by Blair. The design used staged cones with small angles initially to avoid energy destructive shock waves from occurring. A three-section divergent diffuser cone set, and single convergent baffle were recommended. Preliminary calculations following this method showed the total length required of 1.46 meters. While this total length is possible to achieve in a laboratory setup, creating some of the 0.40 meter long cone sections would become too costly. The design guide did offer some other 
helpful suggestions however. One such point was that adding a silencer past the baffle cone had little effect on the gas dynamics inside of the resonator chamber.

\subsubsection{Beta Design}

The beta exhaust was designed using the guidelines presented in Gordon Jennings Two-Stroke Tuner's Handbook [12]. As a general rule prescribed to determine the taper angles a constant area ratio of 6.25 was recommended. The calculations were based on the time required for the pressure wave to travel twice the tuned length. The required input parameters are $\mathrm{N}$ the engine speed in RPM, $V_{s}$ the sonic wave velocity, and $E_{o}$ the exhaust port opening duration in CAD. The source says to use sonic wave speed of 1700 feet per second (fps) which is not far from the calculated and used value of $1592 \mathrm{fps}$.

The beta exhaust design formulas are presented below in Equations (4-17), and follow the schematic layout presented in Figure 15.

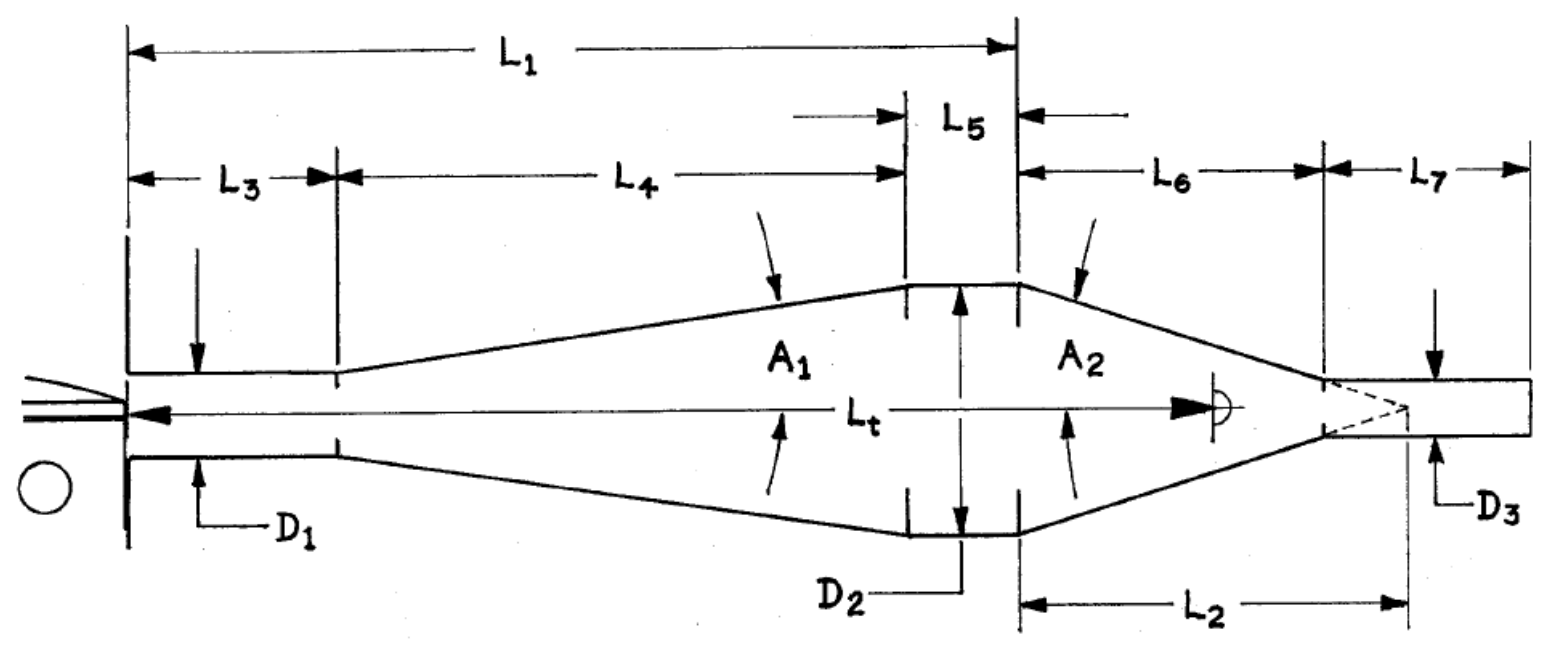

Figure 15 - Tuner's Handbook exhaust design schematic with key dimensions and their naming convention used in experimental designs [12] [66].

$$
\begin{gathered}
L_{T}=\frac{E_{o} V_{s}}{N} \\
L_{1}=L_{T}-\frac{L_{2}}{2} \\
L_{2}=\frac{D_{2}}{2} \cot \left(A_{2}\right)
\end{gathered}
$$




$$
\begin{gathered}
L_{3}=D_{1} \times(6 \text { to } 11) \\
L_{4}=\frac{D_{2}-D_{1}}{2} \cot \left(A_{1}\right) \\
L_{5}=L_{1}-\left(L_{3}+L_{4}\right) \\
L_{6}=\frac{D_{2}-D_{3}}{2} \cot \left(A_{2}\right) \\
L_{7}=D_{3} \times 12 \\
D_{1}=(1.1 \text { to } 1.15) \times A_{\text {port }} \\
D_{2}=\sqrt{6.25 * D_{1}^{2}} \\
D_{3}=D_{1} \times(0.57 \text { to } 0.62) \\
L_{\text {curved }}=r \times 0.01745 \times \theta_{\text {bend }} \\
V_{s}=\sqrt{\gamma R_{i}\left(T_{\text {ex,kelvin }}\right)} * 3.28\left[\frac{\mathrm{ft}}{\mathrm{m}}\right] \\
L_{R}=\frac{L_{e}}{2}
\end{gathered}
$$

The true tuned length considered the mean point of reflection in the baffle come rather than just the baffle cone length. A schematic of this location is presented below in Figure 16. The true tuned length $\left(\mathrm{L}_{\mathrm{T}}\right)$ calculated is the sum of $\mathrm{L}_{1}, \mathrm{~L}_{2}, \mathrm{~L}_{3}$ and $\mathrm{L}_{\mathrm{r}}$.

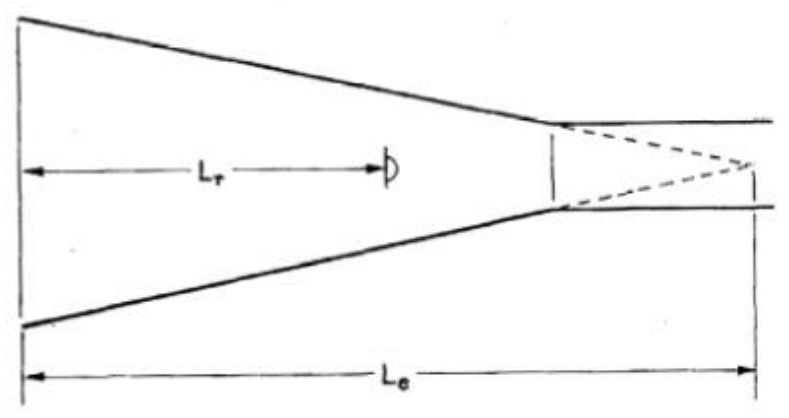

Figure 16 - Actual location of the design length for the reflected wave [12].

$\mathrm{L}_{1}$ should include the port length leading up to the piston. The variation in the coefficient used to determine $\mathrm{L}_{3}$ is mentioned to use 6-8 times the diameter for maximum power tuning, and up to 11 
for broad tuning. The higher power value of 6 was used in designing the beta exhaust. This value was chosen to allow for maximum torque at the required set speed which corresponded to maximum efficiency. The factor selected for $\mathrm{D}_{3}$ was 0.60 . When using larger than 8 times the diameter, the diameter at the further end should be tapered to increase in diameter $\left(2^{\circ}\right.$ taper) due to increased flow resistance [12].

The beta exhaust, shown in Figure 17, was manufactured in house at WVU by me, Mr. Darzi, and Dr. Johnson. The exhaust used off-the-shelf cones which were closest to the design specs in angle, then cut to size. The angle $A_{2}$ was determined to be $10^{\circ}$ in the original design, however $7.5^{\circ}$ was used due to availability. It was manufactured with a sliding section in the middle to adjust the tested tuned length. This allowed for a sweep of all points surrounding the calculated tuned length and for tuning under different engine operating speeds. Final exhaust dimensions used for the beta design are presented in Table 5.

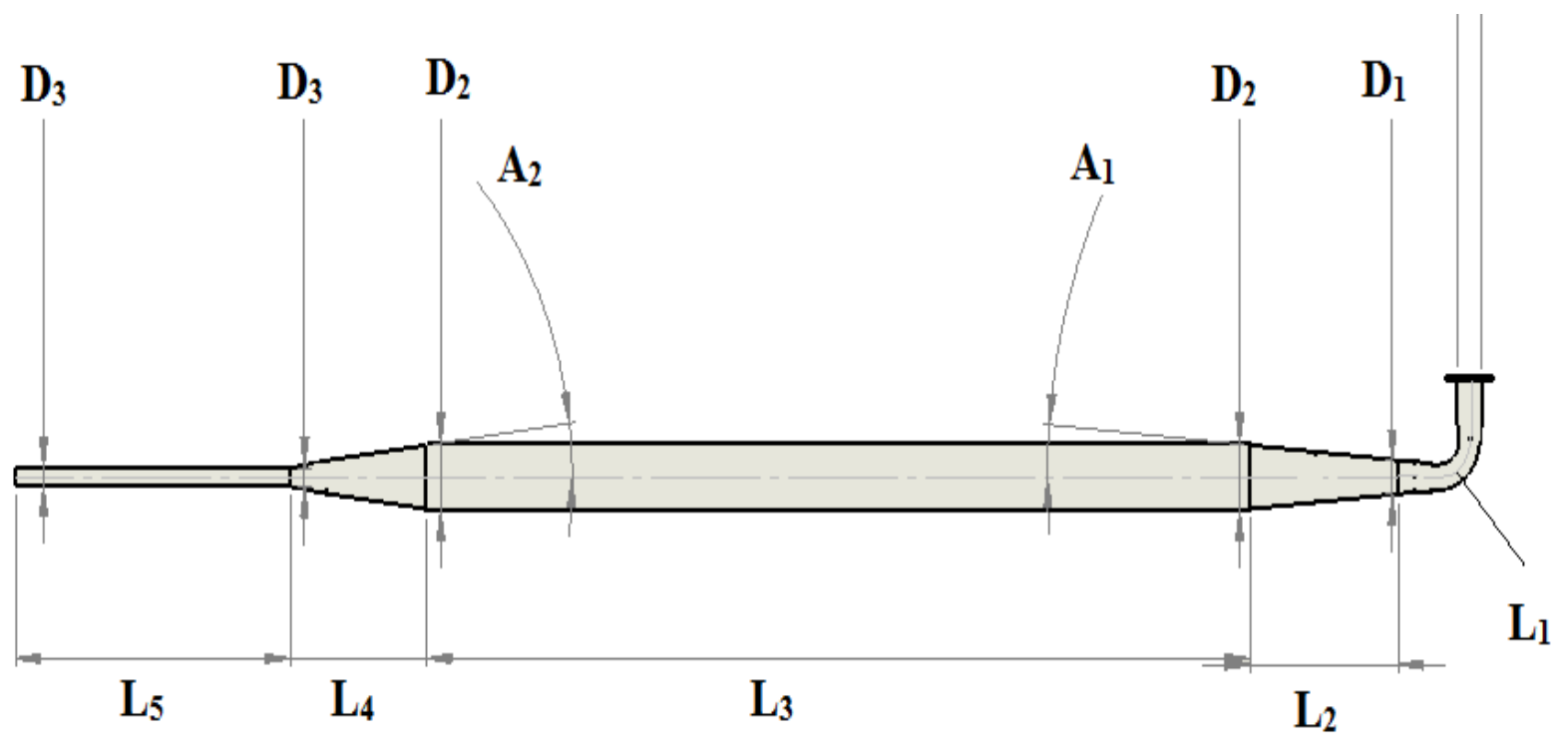

Figure 17 - Beta exhaust schematic using a modified naming convention which starts from the exhaust port on the right and travels to the exhaust tailpipe exit at the left end of L5 [62]. 
Table 5 - Dimensions of the beta exhaust, corresponding with sections of Figure 17.

\begin{tabular}{|c|c|c|c|}
\hline Diameter/Angle & Value & Length & Value [mm] \\
\hline $\mathrm{D}_{1}$ & $18.04[\mathrm{~mm}]$ & $\mathrm{L}_{1}$ & 108.2 \\
\hline $\mathrm{D}_{2}$ & $45.09[\mathrm{~mm}]$ & $\mathrm{L}_{2}$ & 171.7 \\
\hline $\mathrm{D}_{3}$ & $10.82[\mathrm{~mm}]$ & $\mathrm{L}_{3}$ & 899.2 \\
\hline $\mathrm{A}_{1}$ & $4.5\left[^{\circ}\right]$ & $\mathrm{L}_{4}$ & 97.0 \\
\hline $\mathrm{A}_{2}$ & $7.5\left[^{\circ}\right]$ & $\mathrm{L}_{5}$ & 129.8 \\
\hline
\end{tabular}

Figure 18 shows the laboratory setup with the beta exhaust and tuned intake. For testing the influence of individual components on engine power and efficiency, all parameters except the changing variable remained constant.

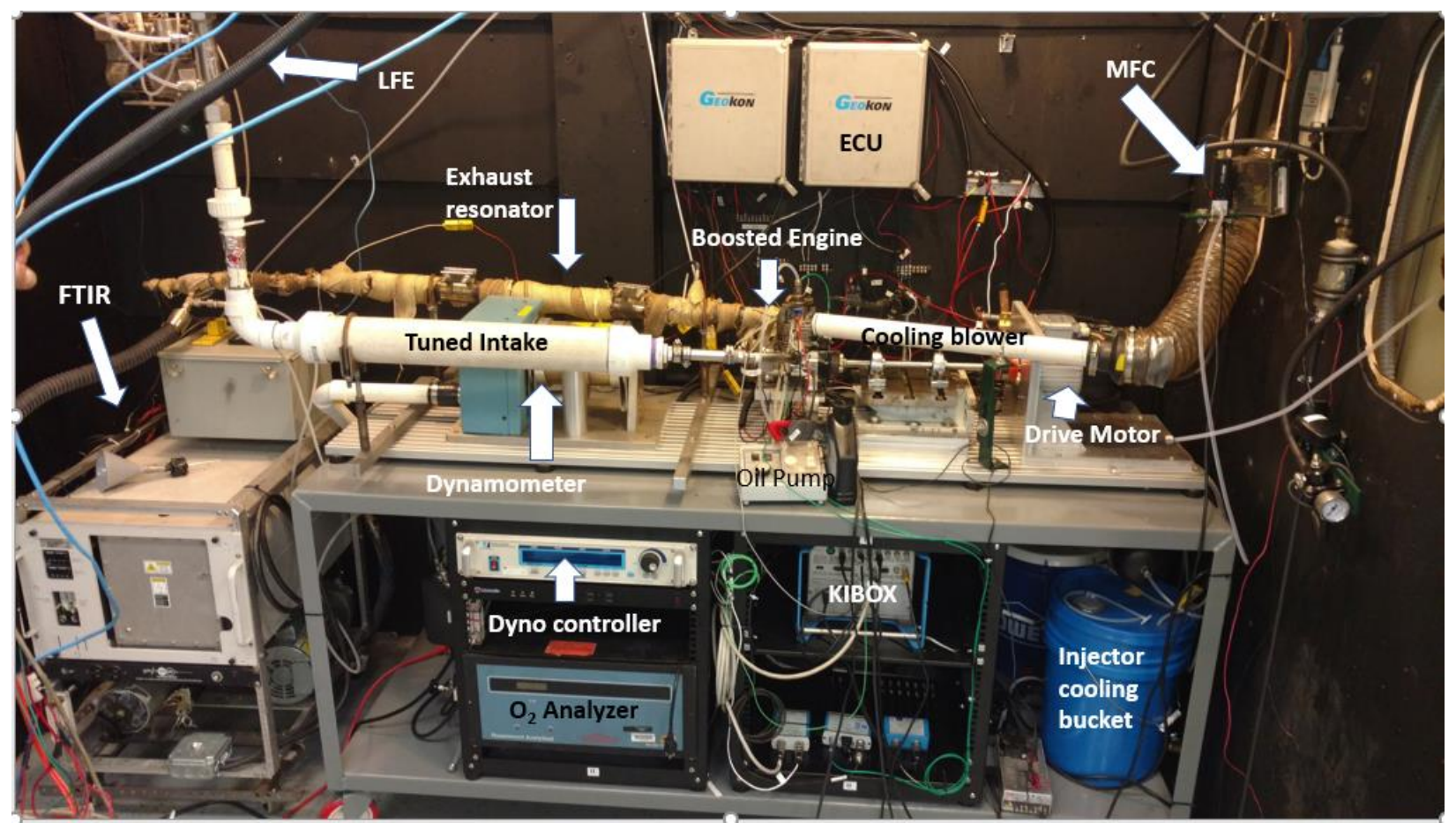

Figure 18 - Photograph of during testing of the beta exhaust with all major measurement and components labeled.

The exhaust tuning method was verified using the original baseline CY $29 \mathrm{cc}$ engine. The predicted tuning length was $89 \mathrm{~cm}$, while my research showed the most efficient point occurred at $76 \mathrm{~cm}$. This deviation is clearer when considering the power curve. Peak power continued to increase past the most efficient operating point, suggesting the empirical formulas are tailored to maximized power and not efficiency. The ability to change the exhaust length by having a slide section proved 
to be invaluable during the tuning process. All other parameters such as intake length, injection timing, and ignition timing were held constant during rich to lean sweeps. The results of exhaust tuning on indicated efficiency are presented below in Figure 19. The indicated power showed an increasing trend toward the design point of $89 \mathrm{~cm}$. However, efficiency was the primary research driver and the efficiency peak was selected as the tuned length for further research. Figure 19 also shows the trend of power with respect to exhaust length, showing that power tuning did not correspond to the most efficient point. While this tuning occurred on the CY 29 cc engine, peak efficiency tuning lengths of the beta exhaust for the $34 \mathrm{cc}$ Zenoah engine are shown Table 5 above.

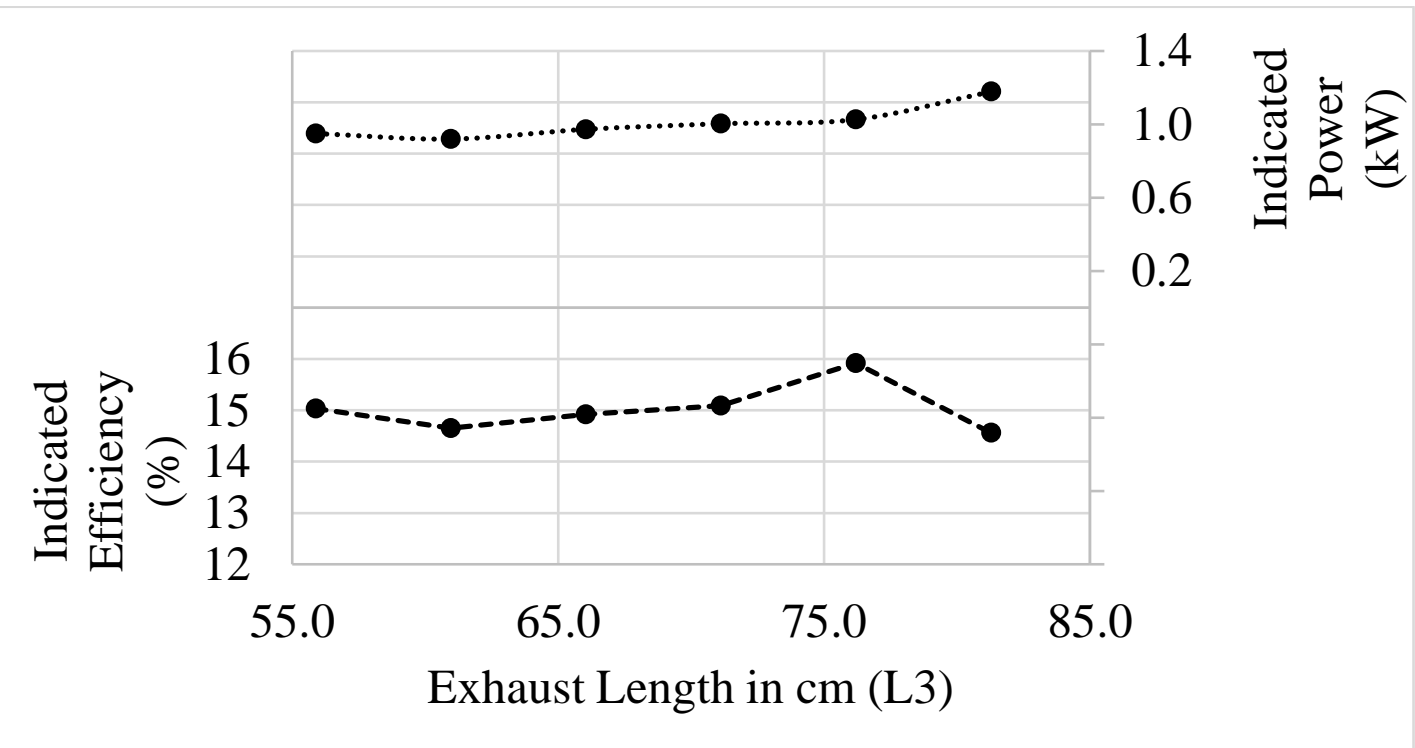

Figure 19 - (Top) Exhaust tuning effect on indicated power of CY engine for constant lambda of 0.95, (Bottom) exhaust tuning effect on indicated efficiency of CY engine for constant lambda of 0.95 .

\subsubsection{Optimized Design}

The optimized exhaust dimensions were determined using GT POWER by Mr. Mahdi Darzi in conjunction with this experimental research. The dimensions used the same general layout as the beta exhaust with small modifications to the dimensions. High level detail was put into the exhaust fabrication using a boring bar and lathe to create custom cones from steel stock. The fabrication of past exhaust systems similar to this have been as costly as $\$ 8000$ per unit. The inside surface was honed for smoothness and an extremely tight fit of the sliding section. All weld splatters were removed for a perfect flow path which reduces exhaust energy losses due to turbulence formation at sharp edges. The material of the cone sections was kept thick for laboratory noise reduction, as 
recommended by Jennings. Finally, the exhaust was insulated to maintain gas temperatures as high as possible for strong pressure wave travel. The final exhaust dimensions are shown in Table 6.

Table 6 - Dimensions of the optimized exhaust, corresponding with sections of Figure 17.

\begin{tabular}{|c|c|c|c|}
\hline Diameter/ Angle & Value & Length & Value [mm] \\
\hline $\mathrm{D}_{1}$ & $17.07[\mathrm{~mm}]$ & $\mathrm{L}_{1}$ & 64 \\
\hline $\mathrm{D}_{2}$ & $50[\mathrm{~mm}]$ & $\mathrm{L}_{2}$ & 220 \\
\hline $\mathrm{D}_{3}$ & $13[\mathrm{~mm}]$ & $\mathrm{L}_{3}$ & 787.4 \\
\hline $\mathrm{A}_{1}$ & $4.28\left[{ }^{\circ}\right]$ & $\mathrm{L}_{4}$ & 134 \\
\hline $\mathrm{A}_{2}$ & $7.86\left[{ }^{\circ}\right]$ & $\mathrm{L}_{5}$ & 267 \\
\hline
\end{tabular}

The exhaust differed from the suggested 6.25 constant ratio (Equation 13) of diameters and was found to be 8.58. The $\mathrm{D}_{3}$ to $\mathrm{D}_{1}$ ratio was outside of the recommended range of 0.57 to 0.62 range, it was found to be 0.76 . These differences are likely due to the low temperature of the exhaust gas and the low flow rate as compared to traditionally tuned engine sizes of $125 \mathrm{cc}$ and above. Also, traditional designs look to optimize power while efficiency was the target in this design. GT Power predicted the engine indicated efficiency with the optimized exhaust to be $30.7 \%$ [63].

\subsection{Data Processing}

\subsubsection{Calculations}

By using the Kistler Kibox, crank angle data were collected uniformly and with no pressure data filtering required. Pressure measurements, position and volume data were logged with this device for further analysis. A Magtrol hysteresis dynamometer determined the brake power produced by the engine. Operational speed and ignition signal are given by a VR sensor linked to the Kibox. The fuel input is recorded and controlled by an Alicat MFC which is adjusted to the methane setting and corrected by an MFC correction factor to the specific blend. Incoming air-flow is monitored and recorded by $2.54 \mathrm{~cm}$ diameter Meriam LFE. Temperature measurements are taken at specific locations to avoid overheating and supply data for future CHP design. Engine oil was externally pumped into the intake at a flow rate of $0.3 \mathrm{ml} / \mathrm{min}$.

The volume as a function of crank angle theta was determined using Equation (17) and known engine geometry. The displacement volume was determined based on Equation (18). 


$$
\begin{gathered}
\frac{V}{V_{c}}=1+\frac{1}{2}\left(r_{c}-1\right)\left[R+1-\cos \theta-\left(R^{2}-\sin ^{\wedge} 2(\theta)\right)^{\wedge}\left(\frac{1}{2}\right)\right] \\
V_{d}=\frac{\pi}{4} B^{2} L
\end{gathered}
$$

From torque measured at the dynamometer, and speed recorded by VR sensors the brake power was determined by Equation (19). Indicated power was calculated by the Kibox using Equation (20).

$$
\begin{gathered}
P_{b}=2 \pi N T \\
P_{i}(k W)=\frac{(I M E P)\left(V_{d}\right)(N)}{6000}
\end{gathered}
$$

The AFR was determined from Equation (21), which used measured mass flow rates recorded by the LFE and MFC. From known fuel mass flow rate and brake power the brake specific fuel consumption was calculated using Equation (22). Brake efficiency was also determined from the mass flow rate of fuel and brake power with the addition of the fuels lower heating value, shown in Equation (23).

$$
\begin{gathered}
A F R=\frac{\dot{m}_{a}}{\dot{m}_{f}}=\frac{M A F_{S L P M} * \rho_{A I R}}{C N G_{S L P M} * \rho_{C N G}} \\
b s f c=\frac{\dot{m}_{f} * 60 * 1000}{P_{b}} \\
\eta_{\text {th,brake }}=\frac{P_{b}}{\dot{m}_{f} L H V}
\end{gathered}
$$

The flow rate of the specific gas blend was corrected to MFC standard gas selection using Equations (24) and (25).

$$
\begin{gathered}
C N G_{S L P M}=k_{E Q} M F C_{S L P M}, k_{E Q}=0.9857 \\
k_{E Q}=\frac{K_{\text {factor }} \text { blend }}{K_{\text {factor }} \text { methane }}
\end{gathered}
$$

Lambda was determined based on Equation (26), which was the ratio of the incoming streams AFR to the required stoichiometric AFR. DR was determined by Equation (27) as the ratio of actual mass delivered to the cylinder per cycle to the theoretical mass which would be supplied. The form of DR used in calculation is shown by Equation (28). 


$$
\begin{gathered}
\text { Lambda }(\lambda)=\frac{A F R}{A F R_{\text {stoich }}} \\
D R=\frac{\text { mass of delivered mixture per cycle }}{\text { displaced volume } * \text { standard air density }} \\
D R=\frac{\frac{\left(M A F_{S L P M} \rho_{\text {air }}+C N G_{S L P M} \rho_{C N G}\right)}{1000 * 60}}{\rho_{\text {air }} V_{d, \text { liters }}}
\end{gathered}
$$

Torque was recorded at the dynamometer, and power was subsequently calculated based on Equation (19), however for proper unit conversion the detailed form is shown in Equation (29). Input energy to the system was calculated from the fuel flow, fuel density, and lower heating value of the fuel as shown in Equation (30). The indicated efficiency of the engine was determined from ratio of the average indicated power over a test cycle to the input energy as shown in Equation (31).

$$
\begin{gathered}
P_{\text {dyno,kW }}=\frac{\left(\text { Torque }_{\text {inlb }} N_{R P M}\right) * 0.745}{12 * 5252} \\
\dot{E}_{\text {in }}=\frac{(L H V)\left(C N G_{S L P M}\right)\left(\rho_{C N G}\right)}{1000 * 60} \\
\text { Efficiency, } \eta_{\text {indicated }}=\frac{P_{i, \text { avg }}}{\dot{E}_{\text {in }}} * 100 \%
\end{gathered}
$$

In all calculations the DR was based on the incoming flows to the cylinder without consideration of scavenging losses. It was difficult to quantify the amount slipped under cycle to cycle variations, therefore keeping this approach for all cases allowed a comparable platform. Lambda was defined by the incoming flows of air and fuel, some of which escaped the combustion chamber. This "lambda" value was consistent during all tests of LPDI but skewed when compared to the well premixed trapped lambda reported under PI testing.

Emission calculations were performed with guidance from Mr. David McKain, using the steady state 1065 graphical user interface program developed at WVU, shown in Figure A1. The program calculated brake specific (BS) emission values, included humidity correction factors and performed a carbon balance. NMHC emissions were determined from the difference between THC and methane contents measured by the FTIR. $\mathrm{NO}_{2}$ and $\mathrm{NO}$ emissions were combined during post processing of the data to produce a single $\mathrm{NO}_{\mathrm{x}}$ value. 
Brake specific emissions were calculated using the ratio of the mass flow rate of the specific emission to the brake power produced. Brake specific $\mathrm{NO}_{\mathrm{x}}, \mathrm{THC}, \mathrm{CO}, \mathrm{CH}_{4}$, and $\mathrm{CO}_{2}$ are determined in this form from Equations (32-36)

$$
\begin{aligned}
b S N O_{X} & =\frac{\dot{m}_{N O_{X}}}{P_{b}} \\
b s T H C & =\frac{\dot{m}_{T H C}}{P_{b}} \\
b S C O & =\frac{\dot{m}_{C O}}{P_{b}} \\
b S C O 2 & =\frac{\dot{m}_{C O 2}}{P_{b}} \\
b S C H 4 & =\frac{\dot{m}_{C H 4}}{P_{b}}
\end{aligned}
$$

The mass flow rate of the emissions were determined from the FTIR measurement in ppm, molar mass of each emission, molar flow rate of exhaust, and correction factor for $\mathrm{NO}_{\mathrm{x}}$. All emissions were measured wet. Equations (37-41) show the relationships used to determine emission mass flow rates.

$$
\begin{aligned}
& \dot{m}_{N O_{X}}=\frac{F T I R_{N O X_{P P M}}}{10^{6}} * 38 \frac{\mathrm{g}}{\mathrm{mol}} * \dot{n}_{\text {exh } \frac{\mathrm{kmol}}{\mathrm{s}}} * \frac{1000 \mathrm{~mol}}{\mathrm{kmol}} * \mathrm{Kh} \\
& \dot{m}_{T H C}=\frac{F T I R T H C_{\%} * 10000}{10^{6}} * 17.60 \frac{\mathrm{g}}{\mathrm{mol}} * \dot{n}_{\text {exh } \frac{\mathrm{kmol}}{\mathrm{s}}} * \frac{1000 \mathrm{~mol}}{\mathrm{kmol}} \\
& \dot{m}_{C O}=\frac{\text { FTIRCO } \% * 10000}{10^{6}} * 28 \frac{\mathrm{g}}{\mathrm{mol}} * \dot{n}_{\text {exh } \frac{\mathrm{kmol}}{\mathrm{s}}} * \frac{1000 \mathrm{~mol}}{\mathrm{kmol}} \\
& \dot{m}_{\mathrm{CO} 2}=\frac{\text { FTIR CO2\% } * 10000}{10^{6}} * 44 \frac{\mathrm{g}}{\mathrm{mol}} * \dot{n}_{\text {exh } \frac{\mathrm{kmol}}{\mathrm{s}}} * \frac{1000 \mathrm{~mol}}{\mathrm{kmol}} \\
& \dot{m}_{C H 4}=\frac{\text { FTIR CH4 } \% * 10000}{10^{6}} * 16.04 \frac{\mathrm{g}}{\mathrm{mol}} * \dot{n}_{\text {exh } \frac{\mathrm{kmol}}{\mathrm{s}}} * \frac{1000 \mathrm{~mol}}{\mathrm{kmol}}
\end{aligned}
$$

The FTIR measured both $\mathrm{NO}$ and $\mathrm{NO}_{2}$ separately, from which the sum formed the $\mathrm{NO}_{\mathrm{x}}$ concentration as shown in Equation (42). The $\mathrm{CO}_{2}$ equivalent was determined from the combination of brake specific $\mathrm{CO}_{2}$ and a weighting factor multiplied by brake specific $\mathrm{CH}_{4}$ as 
shown in Equation (42). Brake specific NMHC is determined from the subtraction of methane from THC in Equation (43).

$$
\begin{gathered}
F T I R_{N O x_{P P M}}=F T I R_{N O_{P P M}}+F T I R_{N O 2_{P P M}} \\
\mathrm{CO}_{2} \text { Equivalent }=b s C O 2+(25 * b s C H 4) \\
b s N M H C=b s T H C-b s C H 4
\end{gathered}
$$




\subsection{Results/Discussion}

\subsection{Port Injection}

For PI testing, all parameters such as exhaust length, intake length, injection timing, and ignition timing were held constant during the rich to lean sweep. PI of CNG showed a smooth decreasing trend in power with respect to lambda. The power curve was narrow in the rich region due to instability with lean mixtures. Figure 20 shows the power curve for PI on beta exhaust. Maximum indicated power of $1.19 \mathrm{~kW}$ was recorded at the rich limit of the sweep. The DR shown also in Figure 20 has a very similar trend to the power curve and indicates better trapping with richer mixtures. The DR under PI is limited by crankcase pumping of a mixture, without pressure assisted fuel injection into the cylinder.

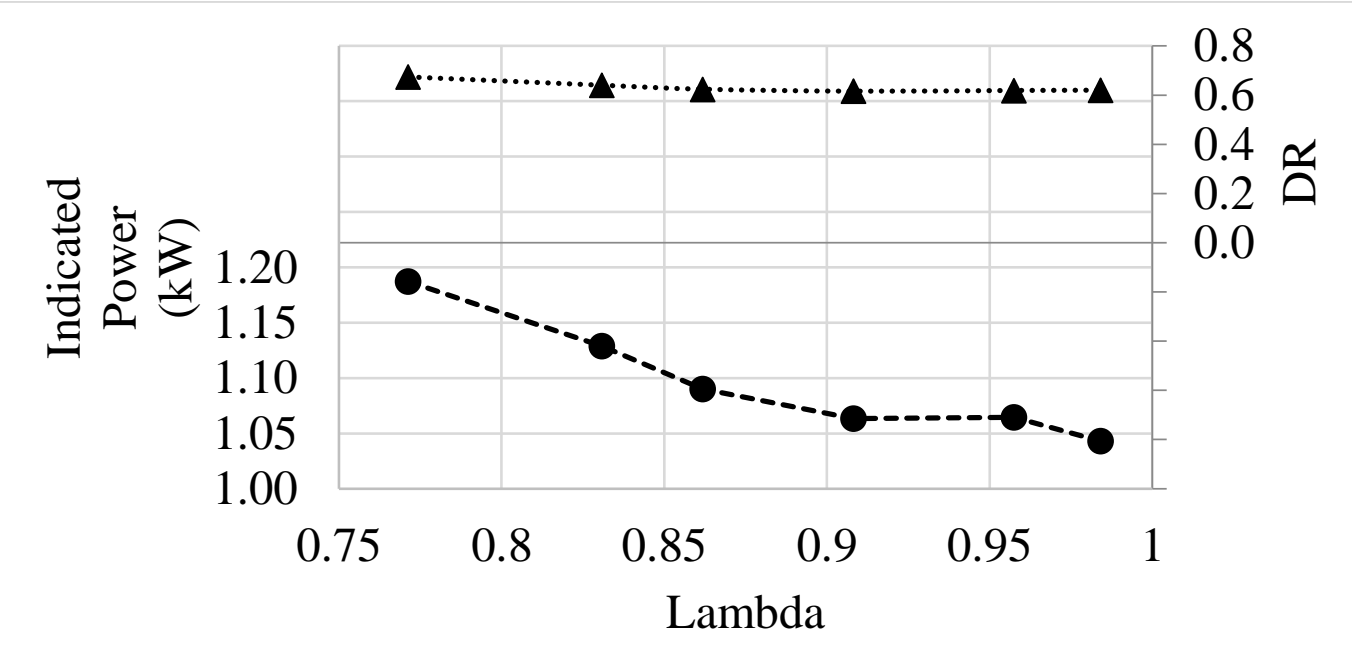

Figure 20 - (Top) DR at various lambda values under PI with the beta exhaust, (Bottom) indicated power at various lambda values under PI with the beta exhaust.

Figure 21 shows that indicated efficiency was modest under PI with the beta exhaust. The efficiency plateaued near the lean limit of operation, which was still rich. Due to instability, stoichiometric and lean mixtures could not be tested under this configuration. High brake specific fuel consumption was observed under PI. This was partly due to higher fuel slip rates under this configuration and was also due to the limitation of rich operation only. This trend is also shown in Figure 21. 


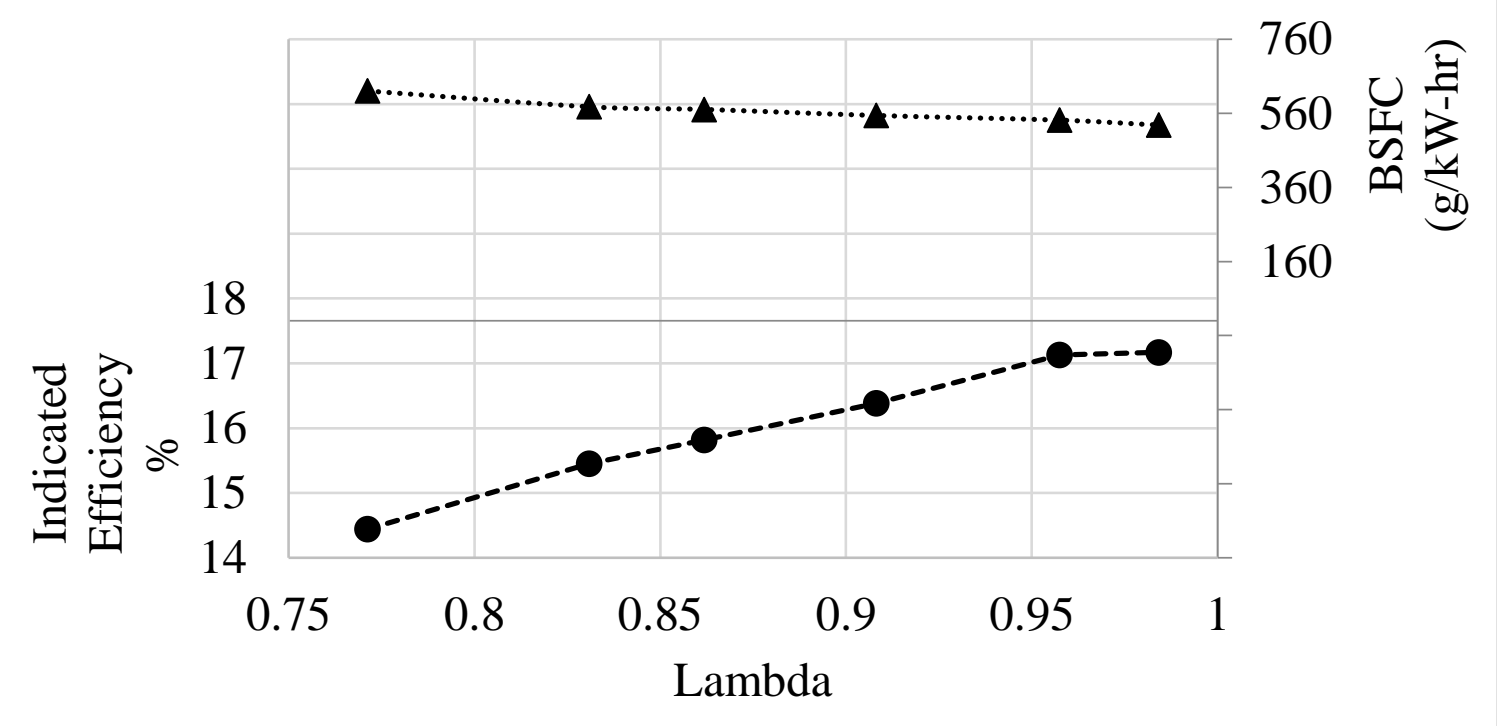

Figure 21 - (Top) BSFC at various lambda values under PI with the beta exhaust, (Bottom) indicated efficiency at various lambda values under PI with the beta exhaust.

Figure 22 below shows the indicated power with respect to input energy. The curve is expected to increase until peak power is reached, at which point power will begin to deteriorate. A small fluctuation in this trend occurred near the lean operation point. The rich limit was not extended far enough to see the turning point in the curve where power decreased.

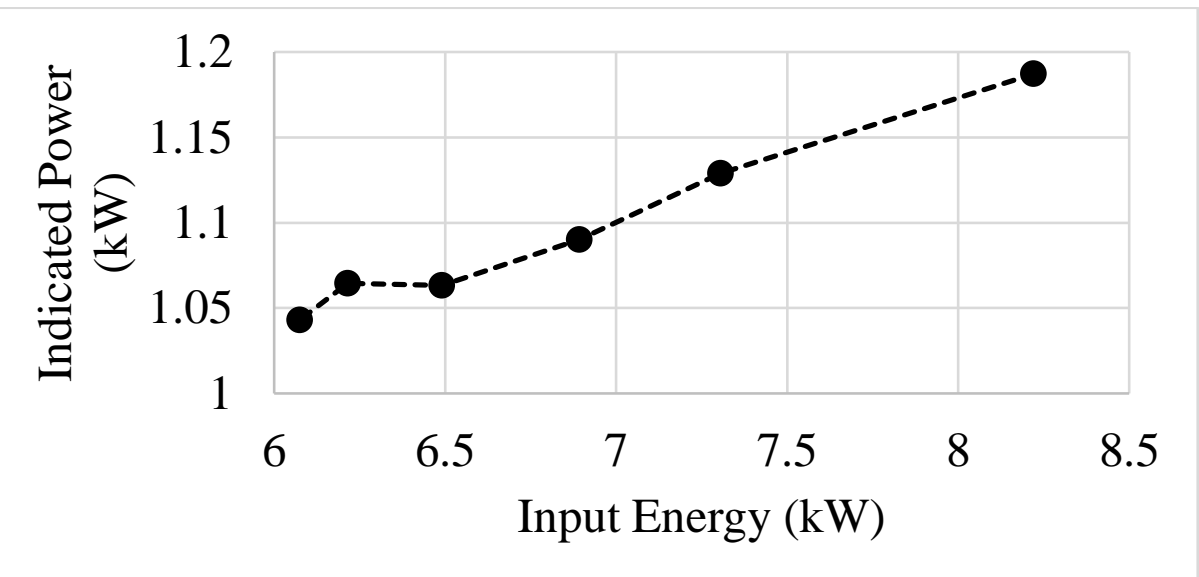

Figure 22 - Indicated power as a function of input energy under PI with the beta exhaust.

$\mathrm{NO}_{\mathrm{x}}$ quantification was reported as brake specific for indication of emission compliance when compared to regulations. The emission trend is presented in Figure 23 without the addition of $\mathrm{NMHC}$ due to the high impact it had on the combined emission level. The $\mathrm{NO}_{\mathrm{x}}$ emissions were relatively low due to the rich operation. While rich operation benefitted $\mathrm{NO}_{\mathrm{x}}$ reductions, $\mathrm{THC}$ and 
proportionally NMHC increased. THC emissions remained high for all tested lambdas due to the consequential slipped fuel during scavenging. The mixture became homogenous within the crankcase, and the cylinder was scavenged with this mixture resulting in fuel short circuiting. Figure 23 also shows peak $\mathrm{NO}_{\mathrm{x}}$ production occurred with lambda of 0.86 , which is in the expected range of equivalence ratio being 1.1 [41].

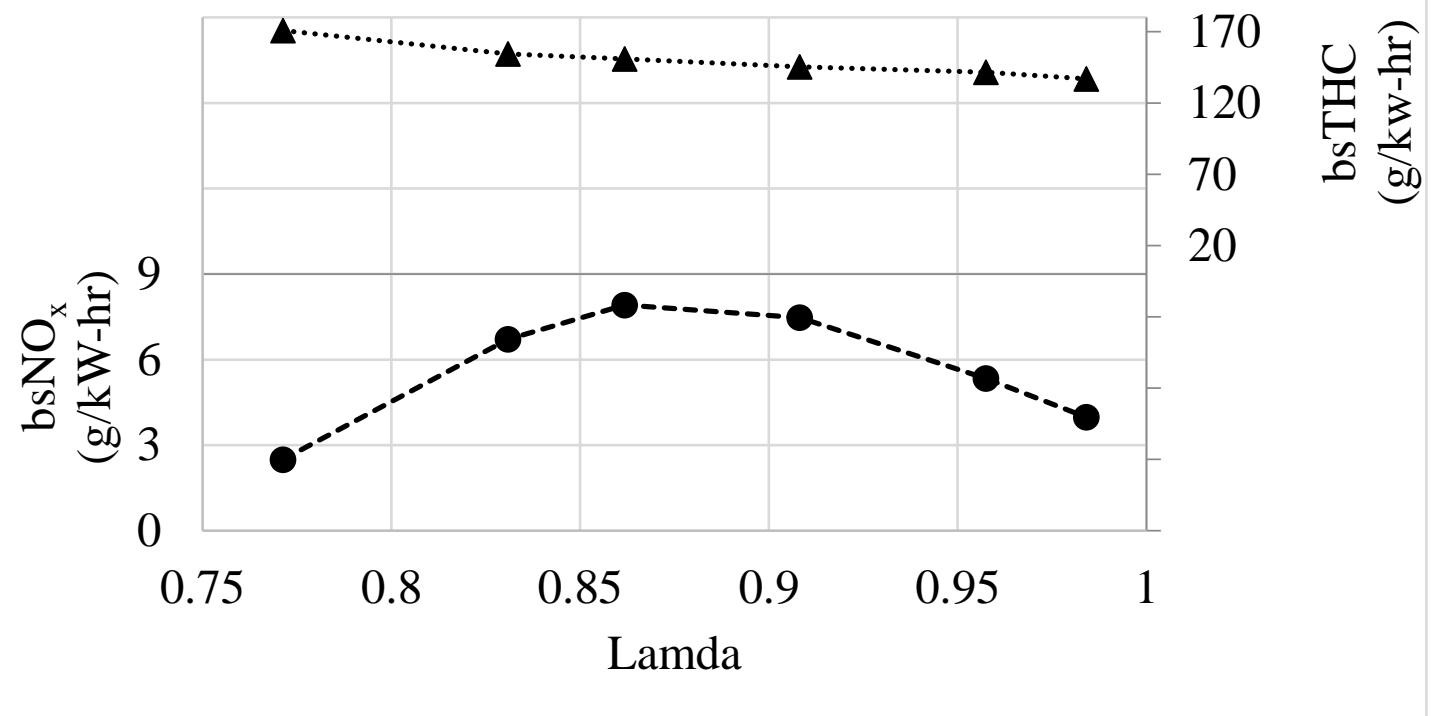

Figure 23 - (Top) bsTHC at various lambda values under PI with beta exhaust, (Bottom) bsNO $O_{x}$ at various lambda values under PI with beta exhaust.

PI data showed a similar trend for $\mathrm{CO}_{2}$ equivalent when compared to brake specific THC. This is due to the dominant contributor being methane. With 25 times the global warming potential (GWP) of $\mathrm{CO}_{2}$, methane's impact outweighed $\mathrm{CO}_{2}$. THC content was primarily consistent of methane with at most $10 \%$ content of ethane and propane combined. Figure 24 shows the reduction in $\mathrm{CO}_{2}$ equivalent as operations became leaner and this was linked to a reduction in fuel slip rate as well as reduced fueling. The CA5-CA90 duration trend was shown to be near constant for all PI data points. This indicated consistent mixture formation produced from crankcase mixing. Fluctuation in combustion duration was minimal under PI, with a maximum change of less than one CAD. Figure 24 also shows the small variations in combustion duration at various lambda values. 


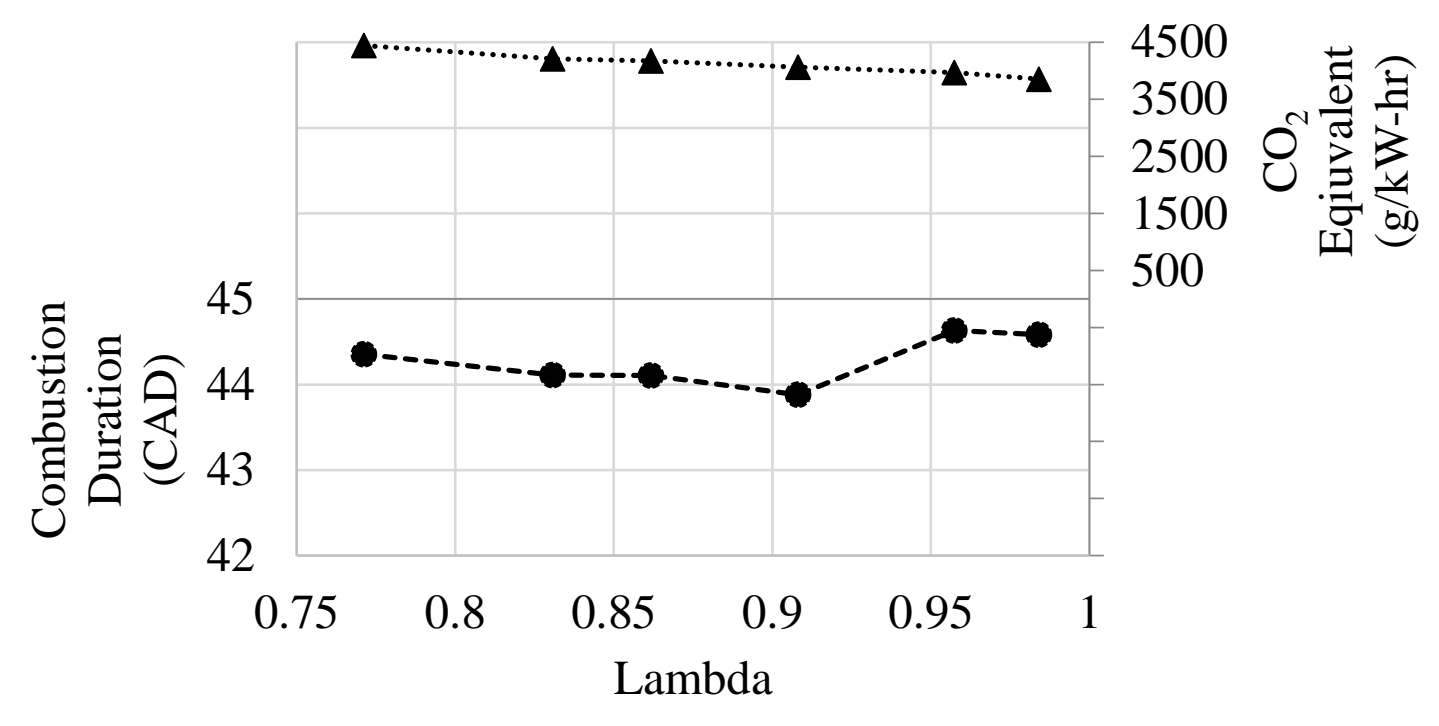

Figure 24 - (Top) $\mathrm{CO}_{2}$ equivalent emissions at various lambda values under PI with the beta exhaust, (Bottom) CA5-CA90 duration at various lambda values under PI with the beta exhaust.

\subsection{LPDI with Beta Exhaust Resonator}

The transition to LPDI allowed for leaner operation and yielded higher power over the entire rich to lean limit sweep. Peak indicated power of $1.51 \mathrm{~kW}$ was achieved at lambda of 1.62. Again, for LPDI testing, all parameters such as exhaust length, intake length, injection timing, and ignition timing were held constant during the rich to lean sweep. Figure 25 shows the increase in indicated power of the LPDI engine using PI as a new baseline. The DR trend deviates from the indicated power trend in the region of lambda between 1.7 and 1.8. Although the DR increased again toward the lean limit, this increase in indicated power was not observed. The DR trend is also shown in Figure 25. 


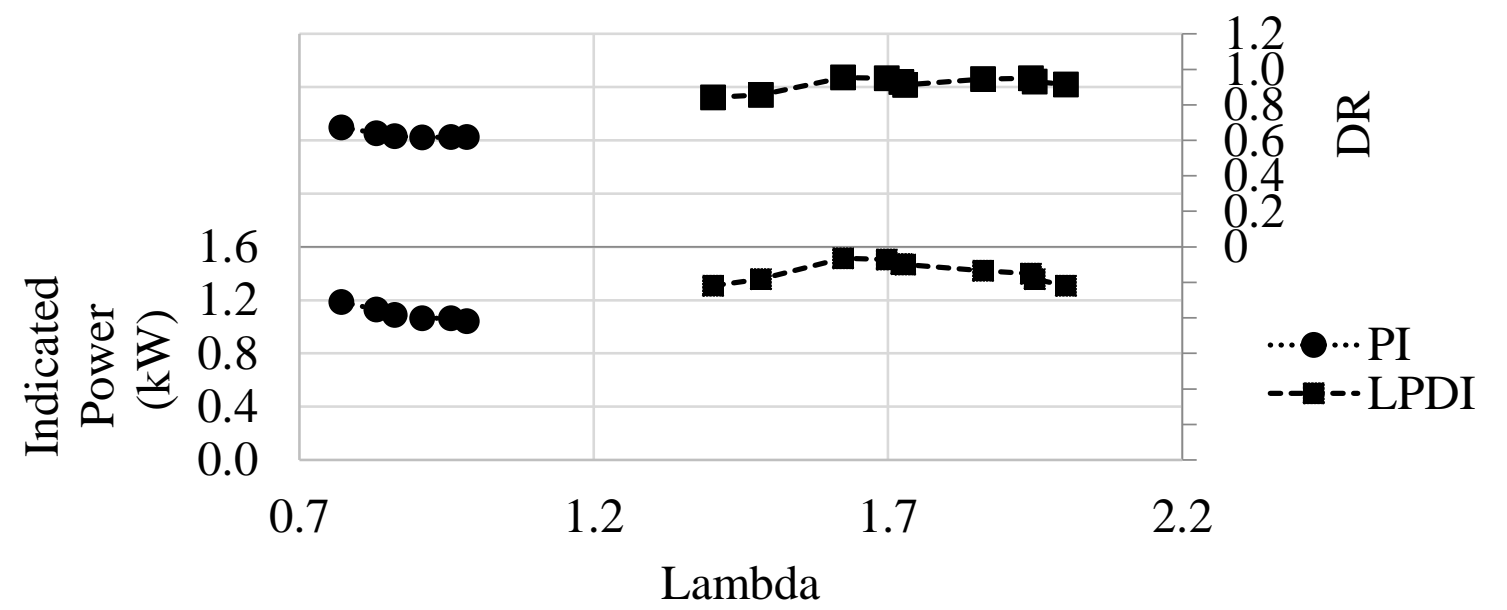

Figure 25 - (Top) DR at various lambda values with the beta exhaust, (Bottom) indicated power at various lambda values with the beta exhaust.

Figure 26 shows indicated efficiency rises continuously from the rich to lean limits under LPDI on the beta exhaust. Peak indicated efficiency of slightly over $29 \%$ occurred at the lean limit. The efficiency remained above $28 \%$ for all lambdas greater than 1.72 . Every point presented showed an increase over PI indicated efficiency. BSFC was also lower at all operating points under LPDI as compared to PI. On average, the BSFC decreased by $177.2 \mathrm{~g} / \mathrm{kW}-\mathrm{hr}$ or $31 \%$ under LPDI as compared to PI. The reduction is shown in Figure 26 as well.

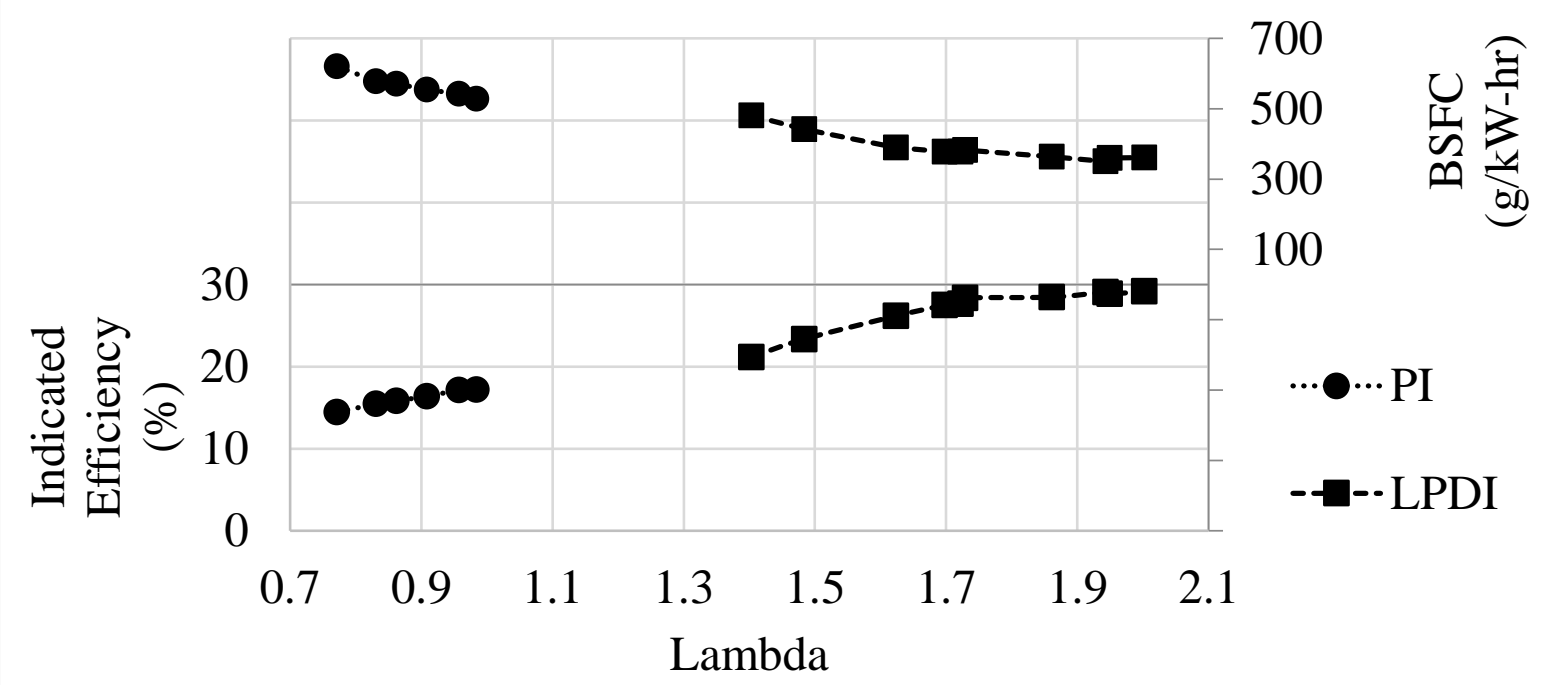

Figure 26 - (Top) BSFC at various lambda values with the beta exhaust, (Bottom) indicated power at various lambda values with the beta exhaust. 
The plot of input energy versus indicated power in Figure 27 shows a sharp drop in power produced as fueling reaches its maximum for LPDI. LPDI operation showed a peak in indicated power followed by a decrease with increased fuel energy input. This peak was likely the point of incylinder trapped mixture stoichiometry which is not indicated by the intake lambda values for LPDI. PI mixture preparation was fixed within the crankcase and the lambda values reported were likely more accurate. For this reason, PI never experienced the decrease in power related to overly rich mixture preparation.

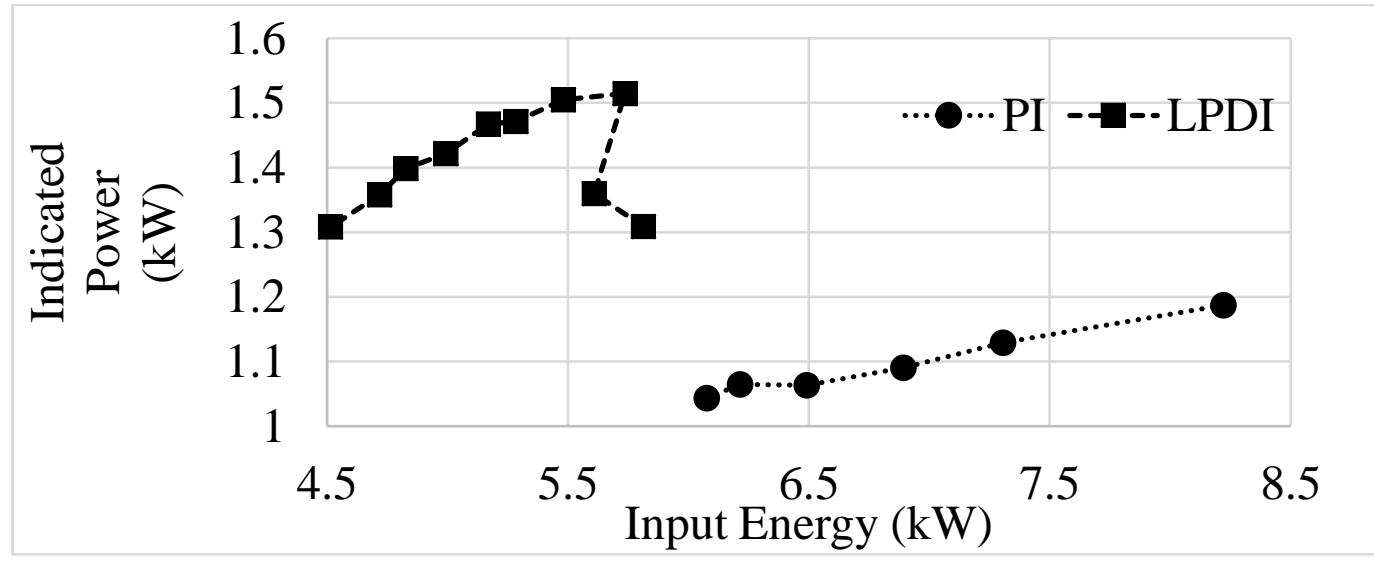

Figure 27 - Indicated power as a function of input energy with the beta exhaust.

Brake specific $\mathrm{NO}_{\mathrm{x}}$ emissions increased for LPDI as compared to PI. While combustion temperatures were higher under PI, the air flow was considerably lower. Also, excess oxygen is present for all LPDI cases resulting in higher $\mathrm{NO}_{\mathrm{x}}$ production. From an emission attainment standpoint, the increase in $\mathrm{NO}_{x}$ production was also coupled to a considerable decrease in NMHC. Figure 28 shows the effect of injection strategy on brake specific $\mathrm{NO}_{\mathrm{x}}$ emissions. Figure 28 also shows brake specific total hydrocarbon emissions decrease under LPDI significantly. The best bsTHC value on PI was observed at $135 \mathrm{~g} / \mathrm{kW}$-hr, while LPDI was able to achieve $25 \mathrm{~g} / \mathrm{kW}$-hr at best. This $81 \%$ reduction greatly reduces the global warming potential or $\mathrm{CO}_{2}$ equivalent. 


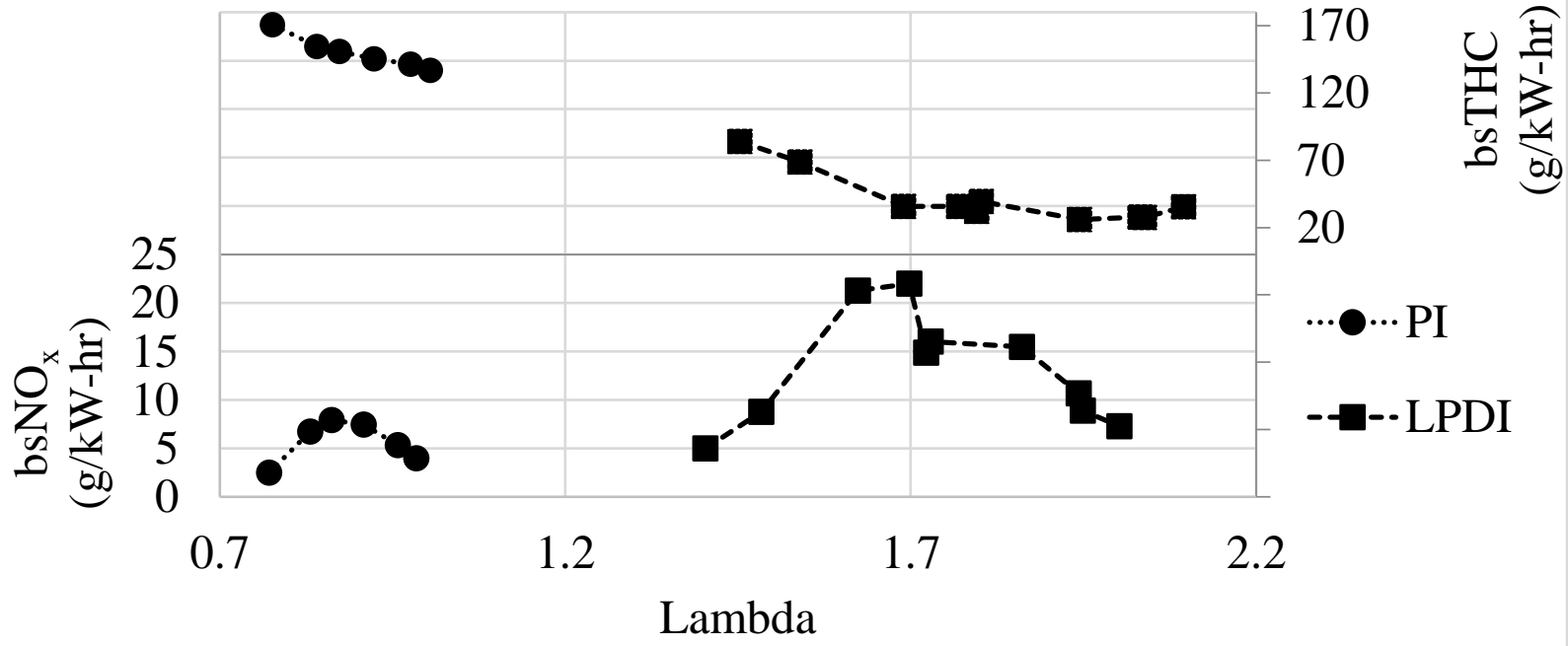

Figure 28 - (Top) bsTHC at various lambda values with the beta exhaust, (Bottom) bsNO $\mathrm{O}_{x}$ at various lambda values with the beta exhaust.

Figure 29 shows that LPDI operation offered significant benefits for reduced $\mathrm{CO}_{2}$ equivalent emissions primarily better fuel trapping (i.e. lower slipped fuel). On average, the shift to LPDI cut the $\mathrm{CO}_{2}$ equivalent in half. Figure 29 also shows that the CA5-CA90 duration increased under LPDI operation as compared to PI with the beta exhaust. The increase in combustion duration indicated better fuel conversion efficiency and was also evident in brake specific THC emission reduction. The combination of longer combustion duration and excess oxygen was also linked to higher in-cylinder temperatures and thus higher levels of $\mathrm{NO}_{\mathrm{x}}$ for LPDI as compared to PI. Longer CA5-CA90 durations led to higher in-cylinder pressures at exhaust port opening, which with the tuned exhaust created a stronger suction wave and also larger reflected pressure wave. With a larger exhaust suction wave, DR increased, however the extent of correlation was not investigated in this study. 


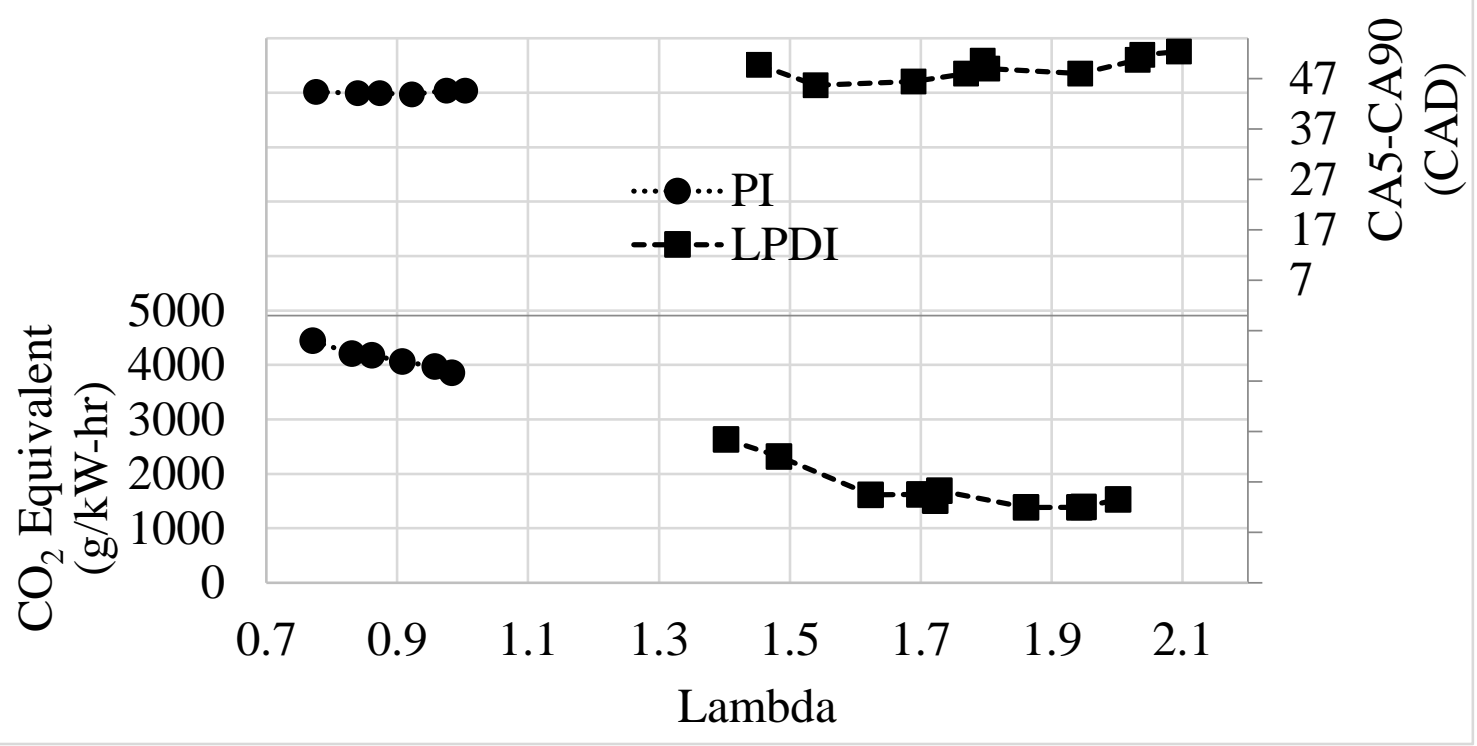

Figure 29 - (Top) CA5-CA90 duration at various lambda values with beta exhaust, (Bottom) $\mathrm{CO}_{2}$ equivalent at various lambda values with beta exhaust.

\subsection{LPDI with Optimized Exhaust Resonator}

Indicated power of the optimized exhaust operating under LPDI was comparable to that of the beta exhaust with LPDI. The optimized exhaust showed a larger range of AFRs which still achieved a near maximum power level. The effect of exhaust optimization on indicated power is shown below in Figure 30. The DR of the optimized exhaust shows a near identical trend with the indicated power and is also presented in Figure 30. Both curves fall in magnitude at lambda of 1.94. The optimized exhaust DR was near constant for all but two points. 


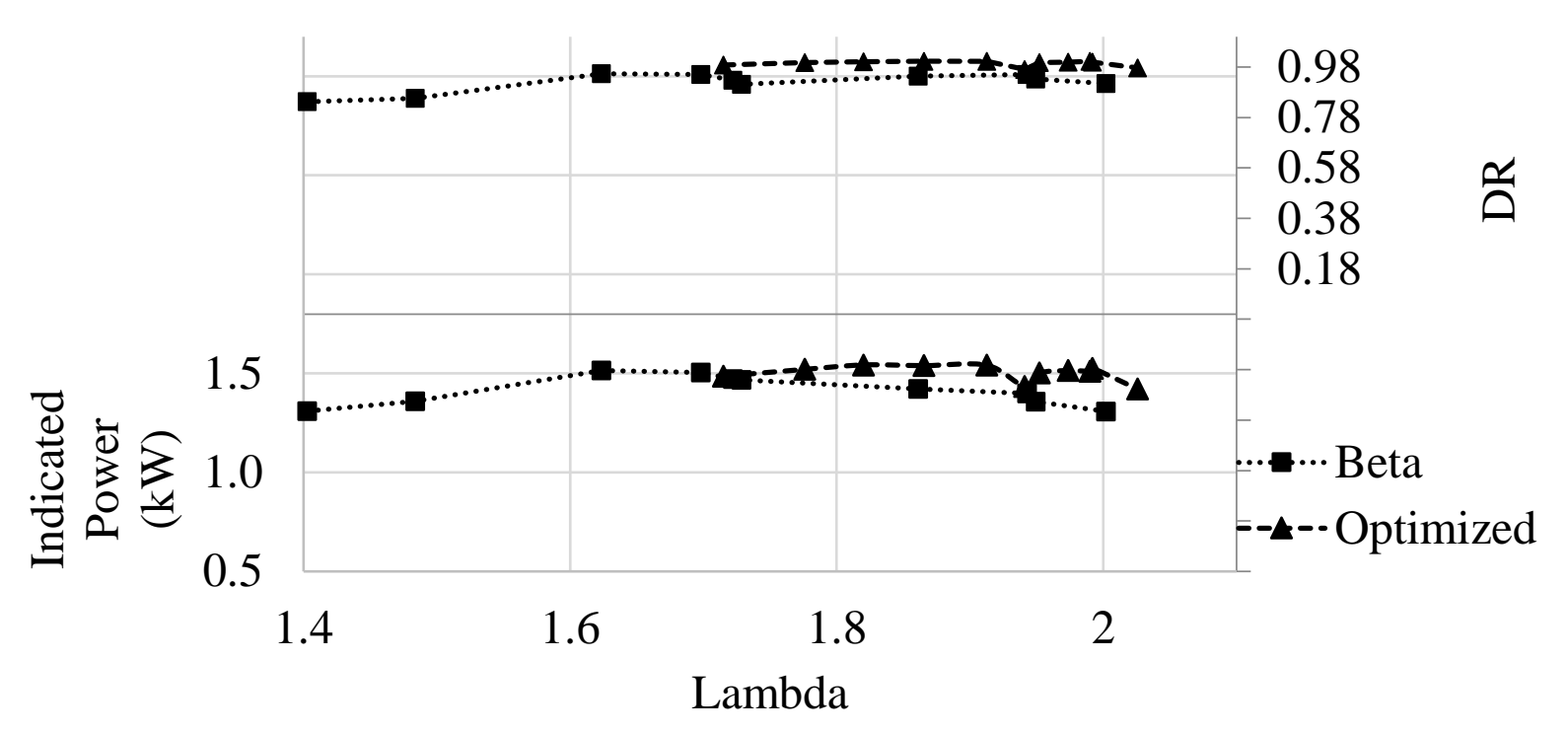

Figure 30 - (Top) DR at various lambda values under LPDI, (Bottom) indicated power at various lambda values under LPDI.

Indicated efficiency, shown in Figure 31, followed a steady increasing trend with decreased fueling. Peak indicated efficiency was reported at $31.2 \%$. This efficiency increase of $2 \%$ (absolute) over the beta exhaust was considered a success. The values recorded experimentally were slightly higher than the simulation predicted value of $30.7 \%$.

Brake specific fuel consumption showed that at a lambda of 1.94 there was a spike in fuel consumption. This corresponded to the same decrease in indicated power and DR as shown above. The minimum BSFC occurred at lambda of 1.97, however it began to increase again as the mixture became continually leaner. The trend is shown in Figure 31. 


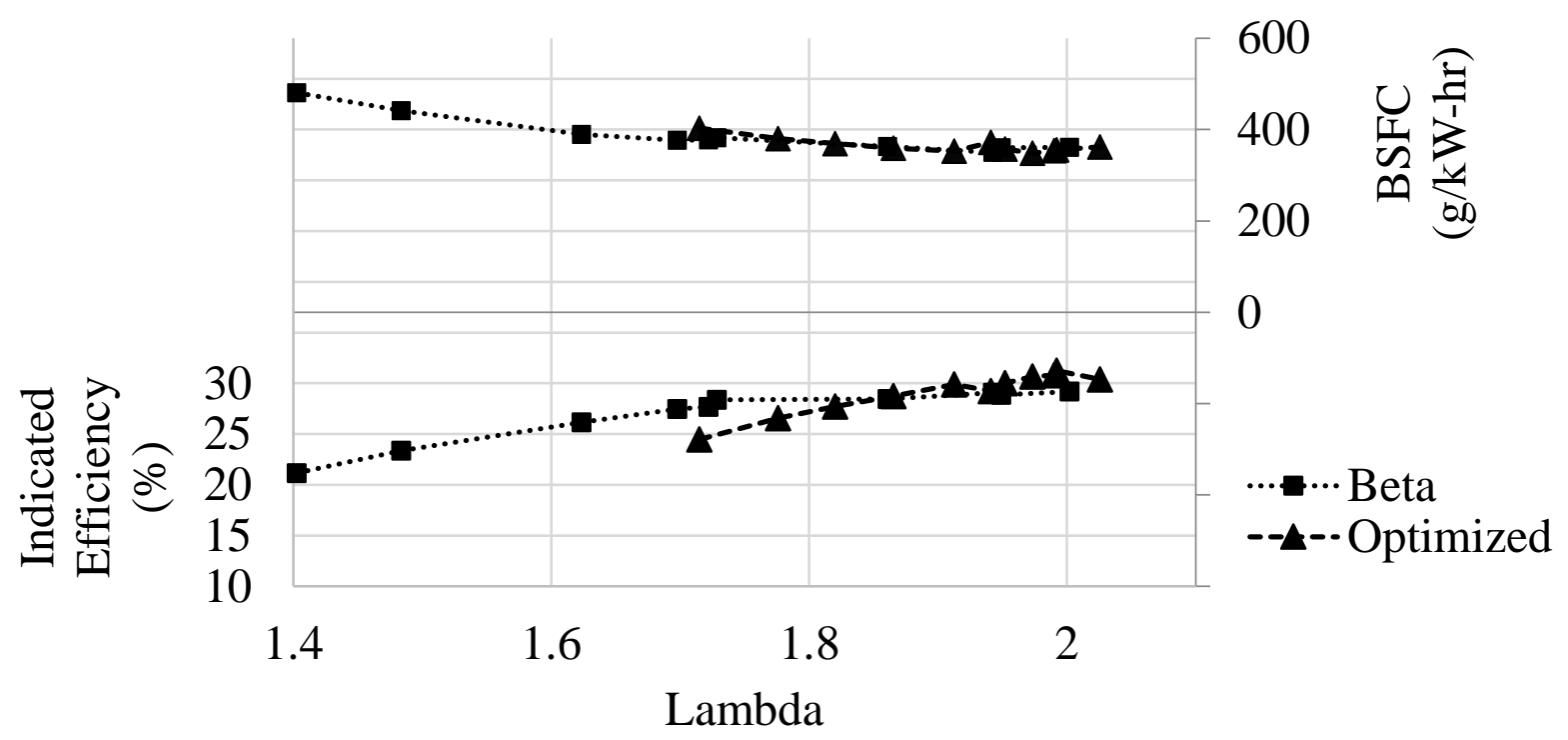

Figure 31 - (Top) BSFC at various lambda values under LPDI, (Bottom) indicated efficiency at various lambda values under LPDI.

In Figure 32, the input energy versus indicated power plot shows one data point for the optimized exhaust that was likely an anomaly. This point corresponded to the lambda of 1.94 which also caused deviation from the trend in indicated power, DR, and BSFC.

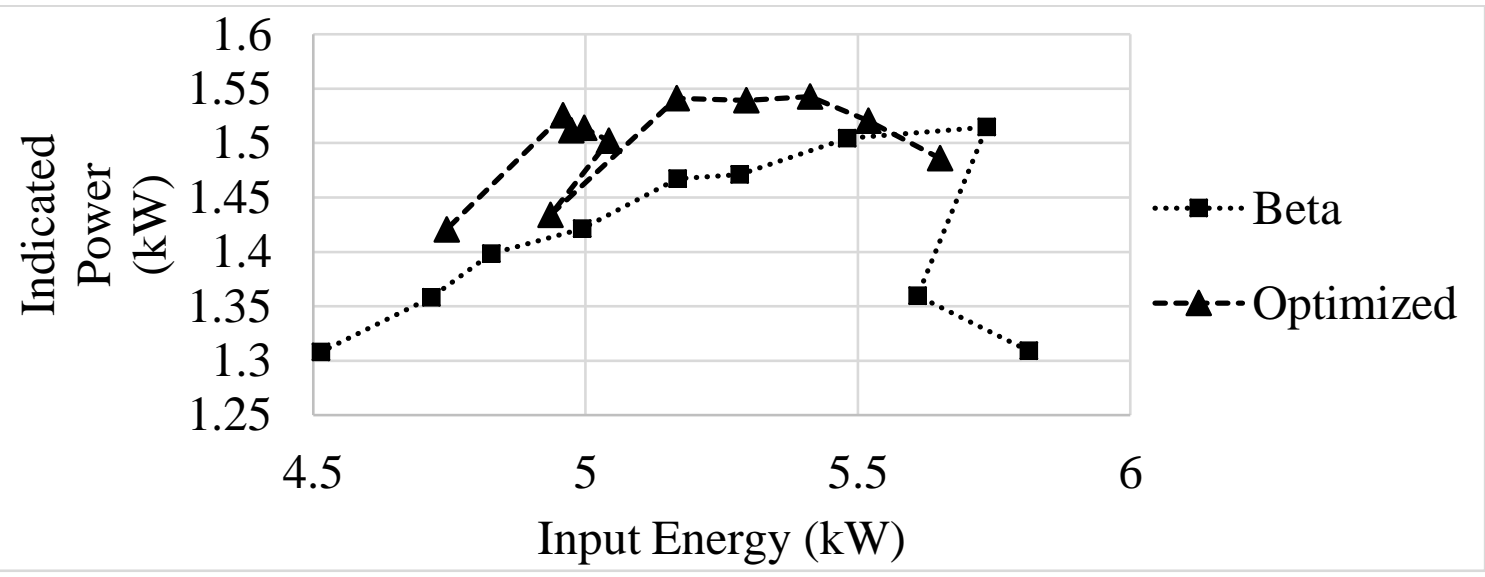

Figure 32 - Indicated power as a function of input energy under LPDI.

Figure 33 shows brake specific $\mathrm{NO}_{\mathrm{x}}$ emissions reduced as compared to LPDI on the beta exhaust. While both LPDI configurations operated under excessively lean conditions allowing for high $\mathrm{NO}_{\mathrm{x}}$ production, the combustion temperatures were lower for the optimized exhaust. Similar $\mathrm{NO}_{\mathrm{x}}$ levels in similar lambda regions coincided with the similar combustion durations of the two exhausts operated under LPDI. Longer combustion durations are often attributed to higher cylinder 
temperature and increased thermal $\mathrm{NO}_{\mathrm{x}}$ formation [41]. Figure 33 shows the effect of exhaust optimization on brake specific THC emissions as well. The trends were similar over the majority of the lambda range except at the rich and lean extremes. At the most efficient point, the optimized exhaust had reduced THC emissions.

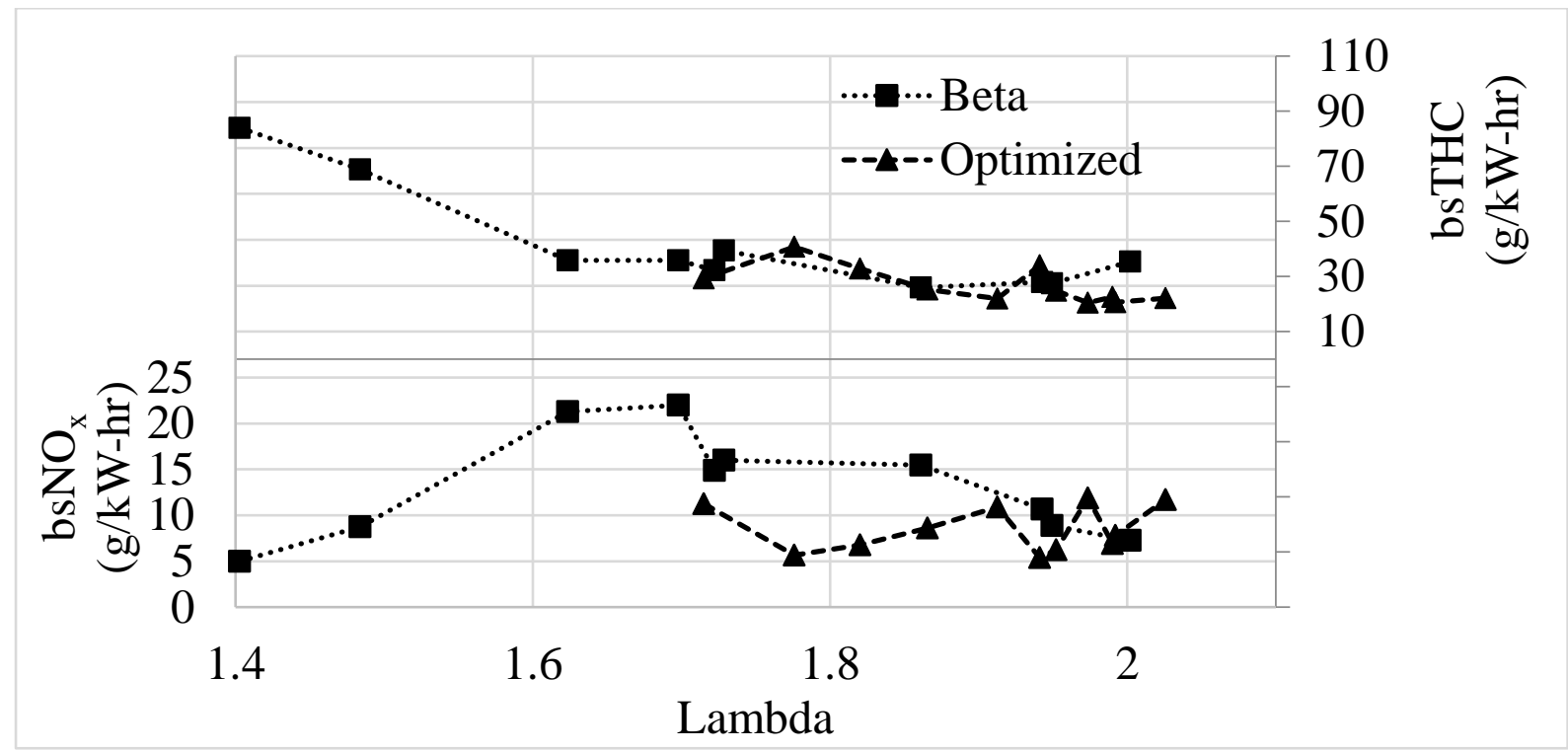

Figure 33 - (Top) bsTHC at various lambda values with under LPDI, (Bottom) bsNO at various lambda values with under LPDI.

Figure 34 shows the impact of exhaust design on the $\mathrm{CO}_{2}$ equivalent emissions. The two exhausts followed similar trends in similar lambda ranges, with a slight reduction under the optimized exhaust. This reduction is proportional to the reduction in THC present in the exhaust. Figure 34 also shows the combustion duration of the optimized exhaust and beta exhaust under LPDI followed similar trends. For this reason, both exhausts had similar THC emissions within the same lambda ranges. Fluctuations in the combustion duration were more pronounced under LPDI as compared to PI. 


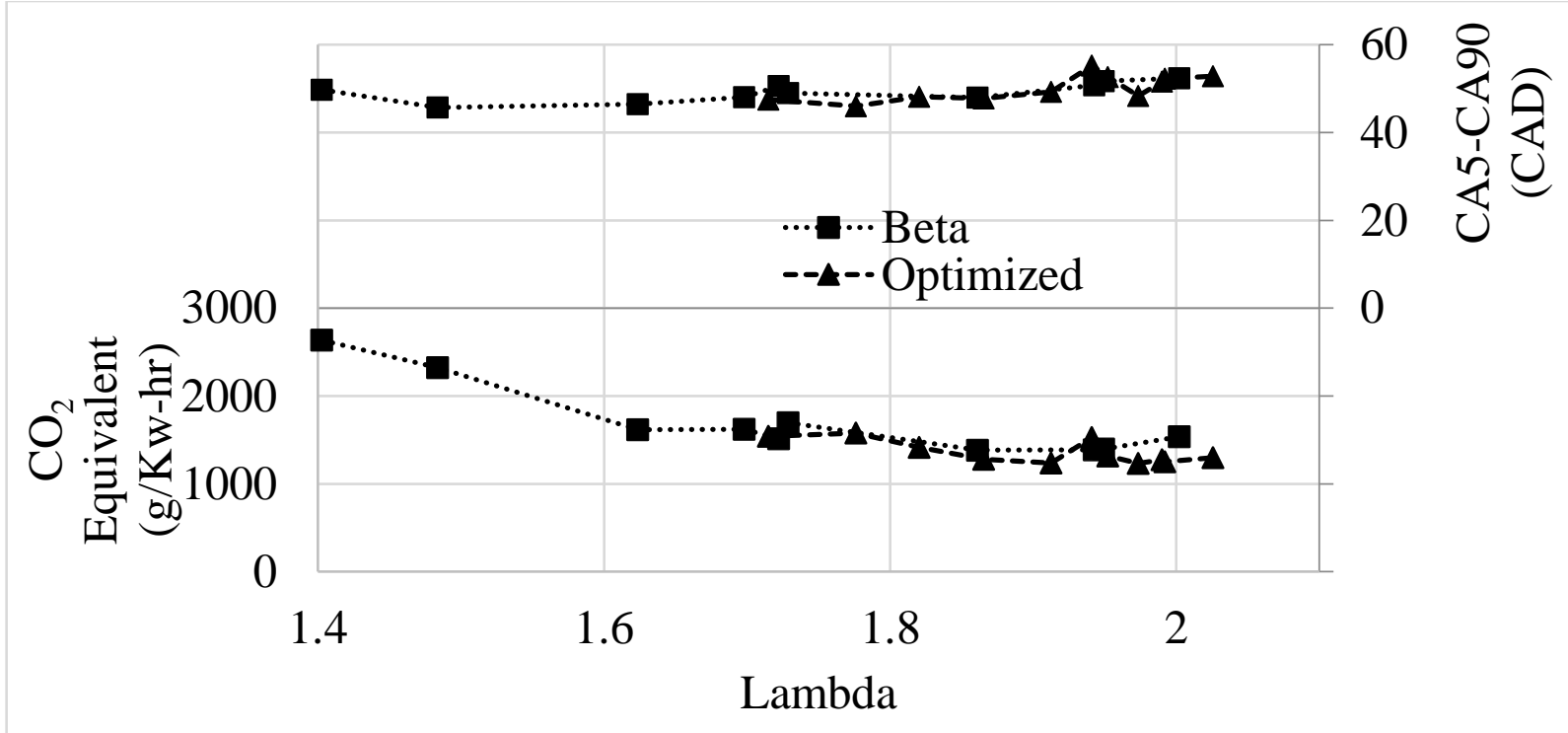

Figure 34 - (Top) CA5-CA90 duration at various lambda values under LPDI, (Bottom) $\mathrm{CO}_{2}$ equivalent at various lambda values with under LPDI.

\subsection{Design Comparison}

A normalized distribution of the data taken at the most efficient point of each engine configuration shown in Figure 35 is used for comparison. PI values were taken as a baseline for relative increases or decreases. The efficiency increased by $81 \%$ and $70 \%$ for the optimized exhaust and beta exhaust on LPDI, respectively. Brake specific fuel consumption decreased by $33 \%$ and $32 \%$, respectively. This was primarily due to less fuel slippage under LPDI versus PI. At their most efficient operation points $\mathrm{NMHC}+\mathrm{NO}_{\mathrm{x}}$ emissions decreased by $46 \%$ for both LPDI configurations as compared to PI, while indicated power increased by $46 \%$ for the optimized LPDI and $25 \%$ for the beta LPDI. Reference to the raw data used for comparisons is presented in Tables A1-A3. 

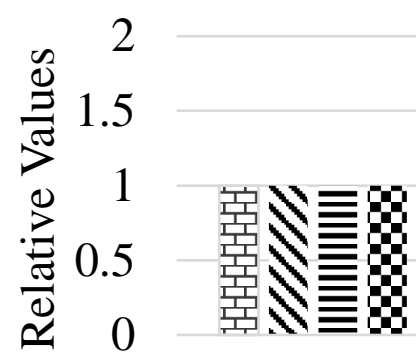

1

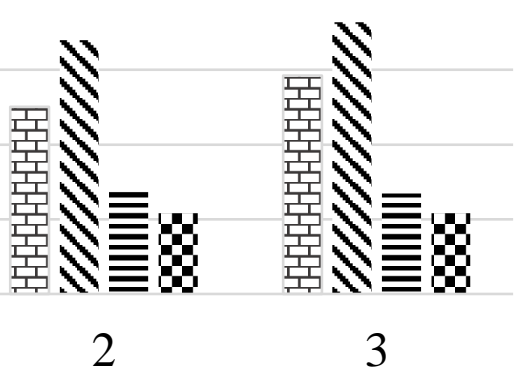

3
호 Indicated Power

s Indicated Efficiency

$\equiv \mathrm{BSFC}$

$\$ \mathrm{NMHC}+\mathrm{NOx}$

\section{1: PI Beta, 2: LPDI Beta, 3:LPDI Optimized}

Figure 35 - Normalized distribution of indicated efficiency, fuel consumption, emissions, and indicated power.

Based on the pressure curves achieved under different configurations, the optimized design with LPDI showed a small increase in peak pressure as well as a delaying shift in the peak location. While the peak pressure was higher under the most efficient point of operation for the optimized design, at richer points the beta exhaust performed better. Both LPDI operations showed significant improvements in peak pressure of about 12 bar. The differences are shown in Figure 36.

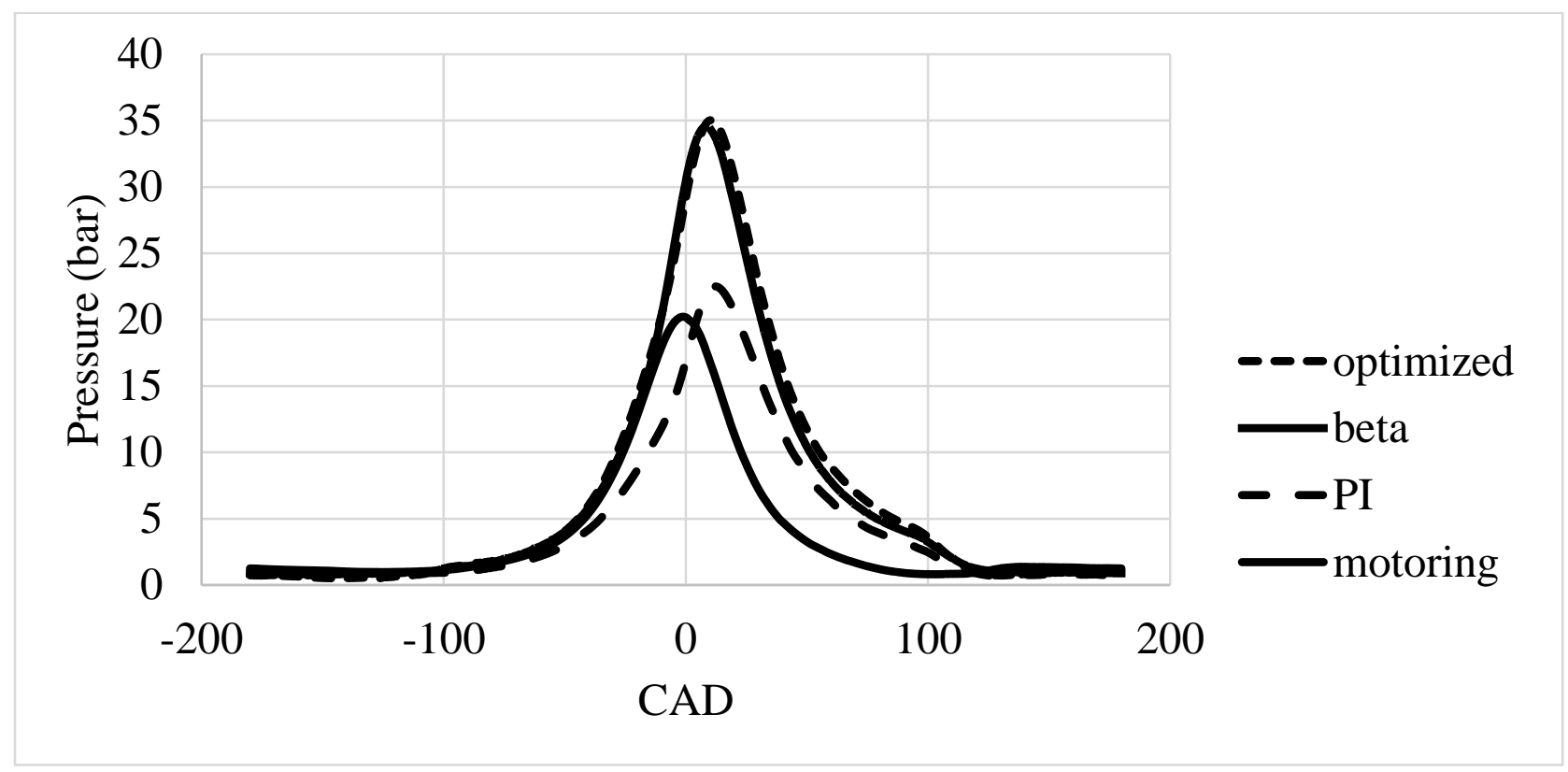

Figure 36 - Average pressure at most efficient point of operation over 200 cycles. 
Table 7 shows combustion statistics for the three different configurations. Peak pressures produced under LPDI are significantly higher than that of PI.

Table 7 - Peak pressure and location for most efficient point (200 cycle average).

\begin{tabular}{|c|c|c|}
\hline Configuration & Peak pressure & Location CAD ATDC \\
\hline PI beta & 22.6 & 12.2 \\
\hline LPDI beta & 34.7 & 8.7 \\
\hline LPDI optimized & 35.2 & 10.8 \\
\hline
\end{tabular}

Based on the maximum cylinder pressures achieved during the rich to lean sweeps of the beta and optimized exhausts under LPDI, the beta exhaust had higher pressures for all lambda values except at the lean limit. This however is the point at which maximum efficiency occurred for both configurations. Between the decreased fuel consumption and increased cylinder pressures, the optimized exhaust showed peak indicated efficiency of $31.2 \%$ near the lean limit of lambda equal to two. The plot also shows that the beta exhaust worked better for a broader tune of AFR's at the specified frequency. Slightly better DR was also related to the increased cylinder pressure of the optimized exhaust. The variations in maximum cylinder pressure with respect to lambda are shown in Figure 37. Figure 37 also shows the required fuel pressure to maintain the desired lambda values. Fuel pressure was increased under LPDI to enable injection into the cylinder under pressure greater than atmospheric. The fuel pressure (gauge) increased for LPDI which also made a shorter injection duration possible. 


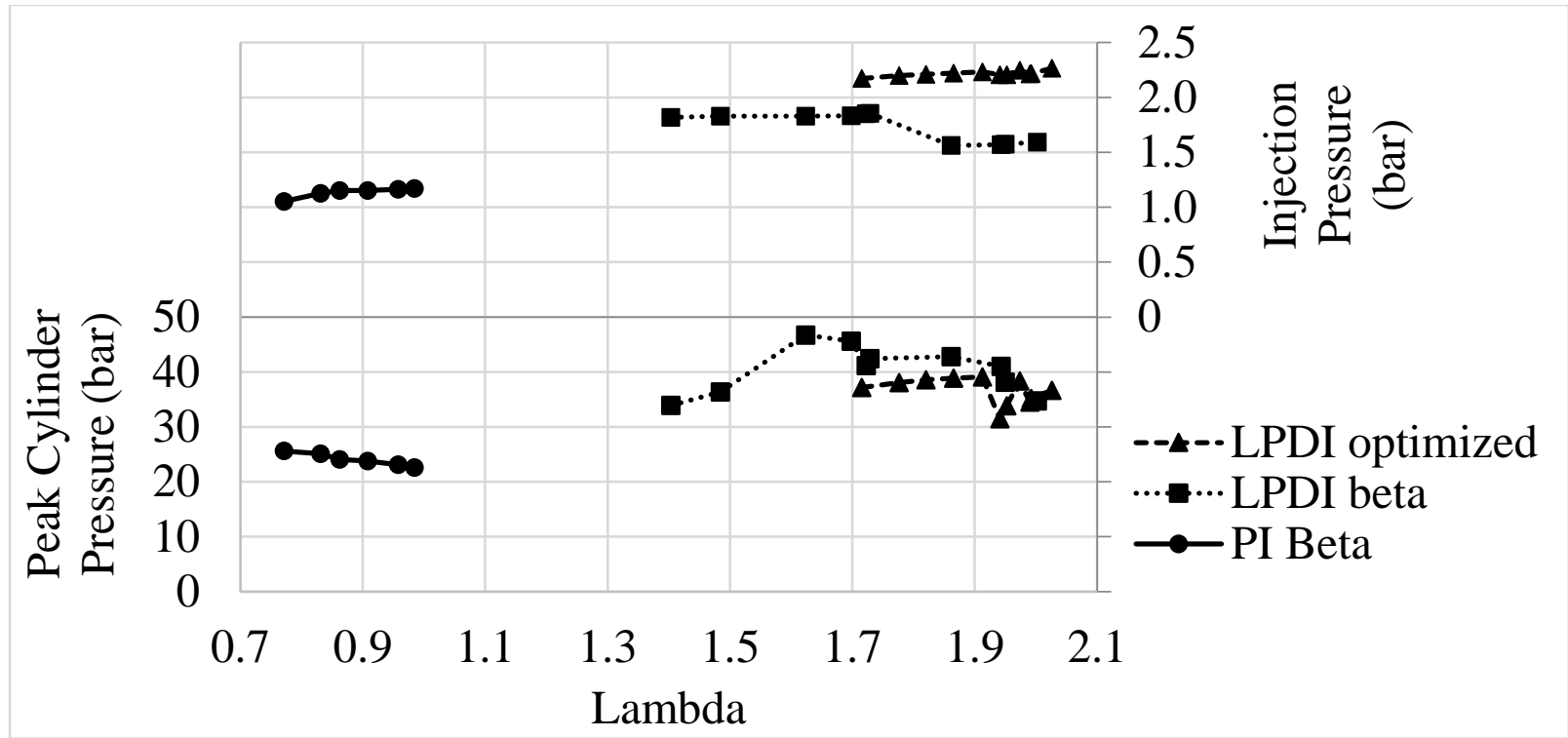

Figure 37 - (Top) injection gauge pressure requirements at various lambda values, (Bottom) average peak cylinder pressures over 200 cycles at various lambda values.

The exhaust pressure waves at the most efficient operating points for the beta and the optimized exhausts respectively are shown in Figure 38. From the plot of the entire engine cycle it is barely visible that the optimized exhaust had stronger sent and received pressure waves. The timing of the return waves was also favorably shifted for the optimized exhaust a few CAD in advance. Magnification of the returning pressure wave allows for a closer examination. The returning pressure wave was larger in magnitude for the optimized exhaust. The duration and initiation of the returning pressure wave was also increased in both respects. The stronger reflection was linked to lower fuel slippage and higher delivery ratios for the optimized exhaust operating under LPDI. 


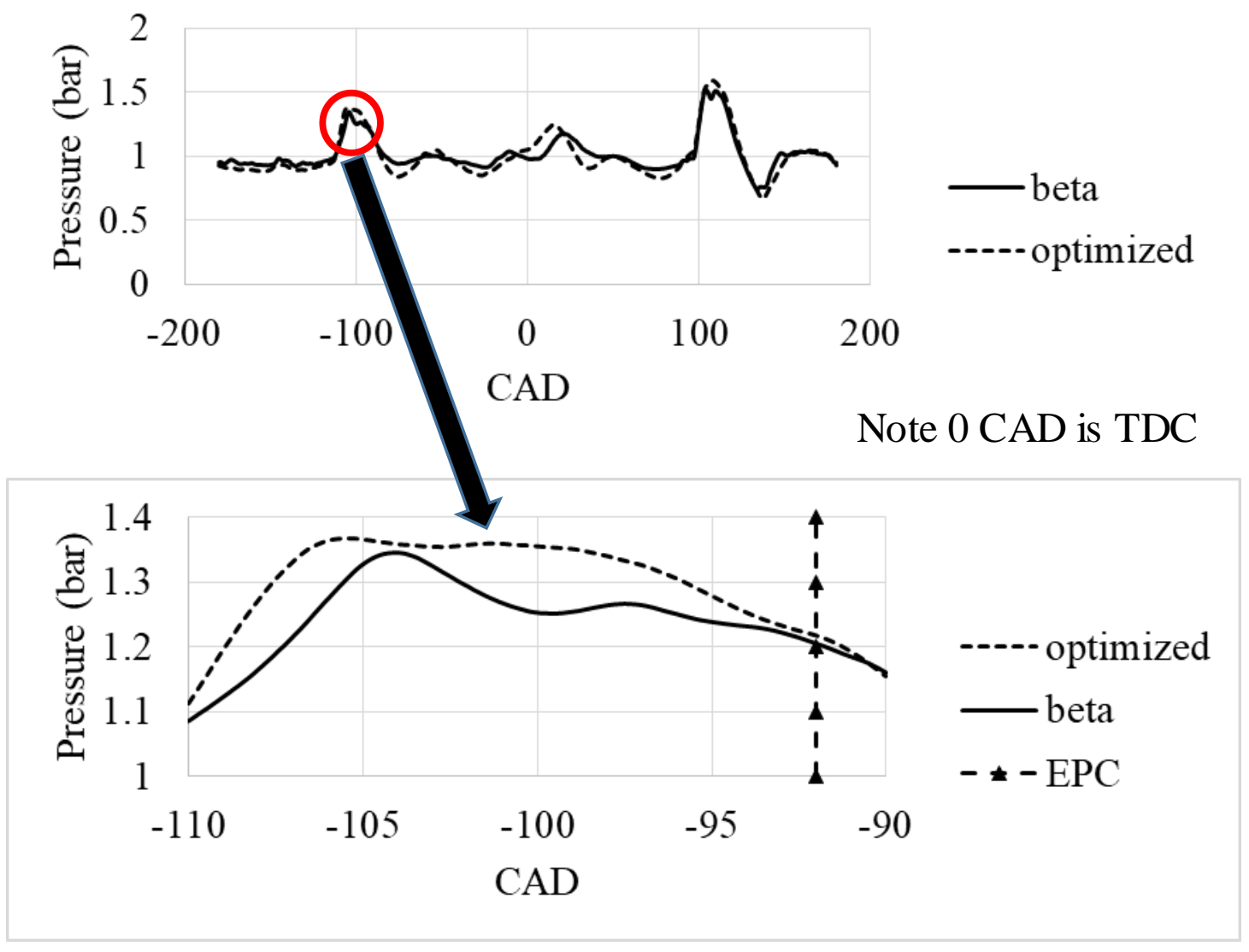

Figure 38 - (Top) average LPDI exhaust pressure with respect to CAD over 200 cycles for different exhausts, (Bottom) average LPDI returning pressure wave near EPC over 200 cycles.

Figure 39 shows the COV of IMEP was within the stable limit for all PI test points. The homogenous pre-mix of air and fuel within the crankcase was attributed to this stable operation, with the penalty of slippage. LPDI operation was shown to be less stable than PI in all operating points for both exhausts. LPDI operation was shown to be increasingly unstable as it approached the rich limit of the sweep. Acceptable stability was achieved under lean operation of both LPDI exhaust configurations [41]. Figure 39 also shows the average heat release per cycle increased under both LPDI exhaust setups. The optimized exhaust was shown to have a higher heat release at leaner points than the beta exhaust. This increased heat release along with decreased fueling allowed for the small gain in efficiency of the optimized exhaust over the beta design. 


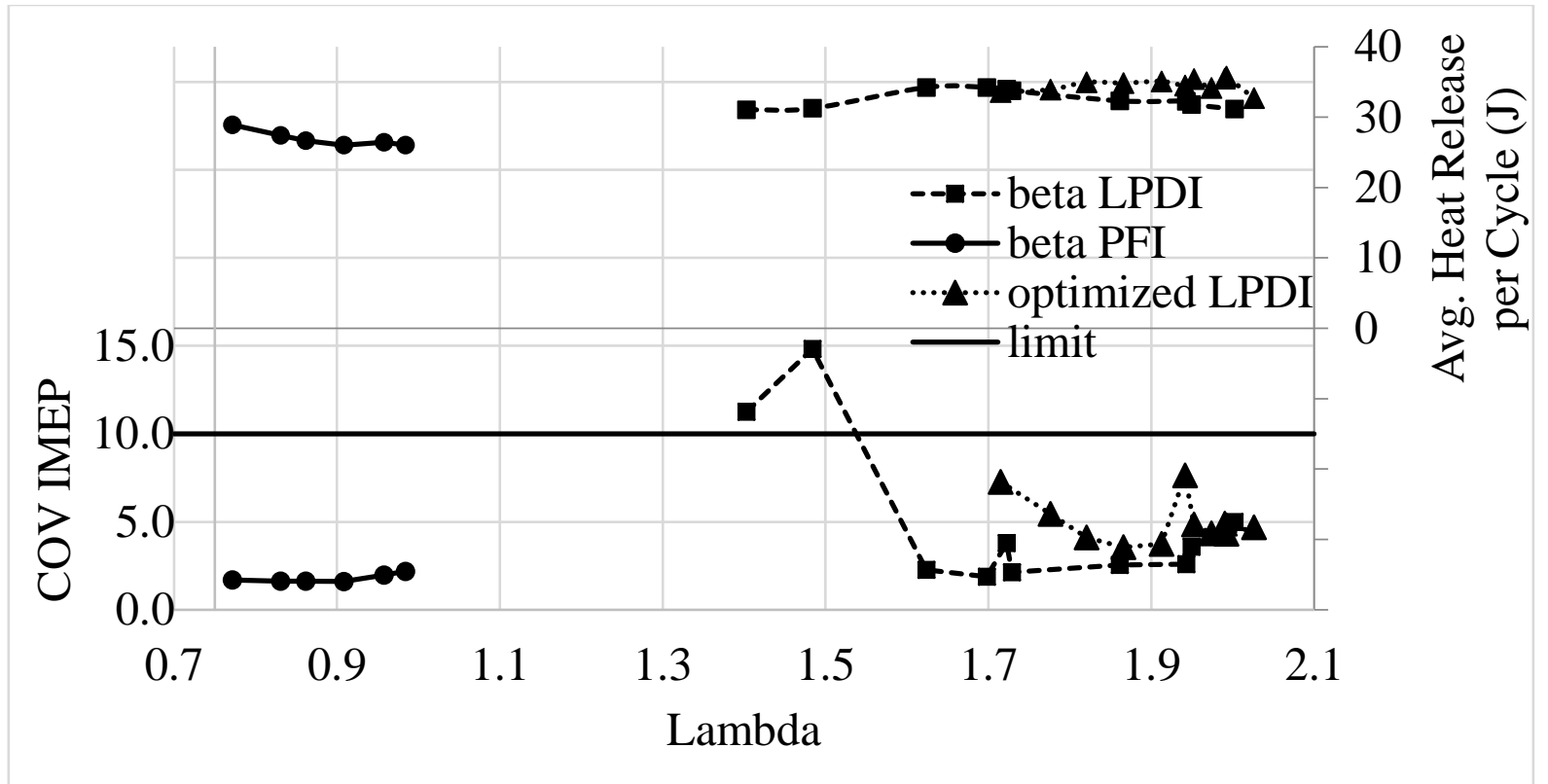

Figure 39 - (Top) average heat release per cycle at various lambda values, (Bottom) COV of IMEP at various lambda values.

Higher net heat release values for the optimized exhaust under LPDI are linked to a higher heat release rate magnitude. The faster heat release was likely due to better mixture preparation or more trapped mixture with the optimized exhaust due to the larger returning pressure wave at exhaust port closure. The inducted wave acted in part to push fuel back into the cylinder. A $30 \%$ increase in peak heat release rate was observed under LPDI operation of the optimized exhaust as compared to the beta exhaust. The heat release rate for each LPDI setup is shown below in Figure 40.

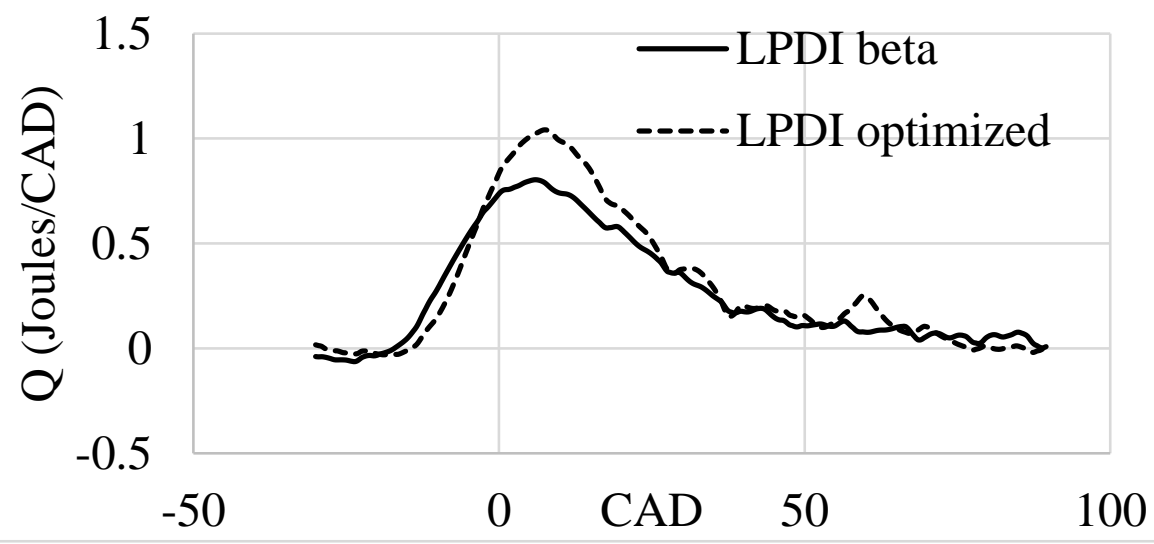

Figure 40 - Heat release rate for LPDI at most efficient lambda. 
Carbon monoxide emissions stayed well below both the California alternative EPA limit of 536 $\mathrm{g} / \mathrm{kW}$-hr and EPA standard $805 \mathrm{~g} / \mathrm{kW}$-hr of for all test cases. The limit was not displayed in Figure 41 due to this reason. The general trend with all three cases showed lower $\mathrm{CO}$ as operation progressively shifted toward leaner mixtures. Lower CO under PI was attributed to a more homogenous mixture likely undergoing a more complete combustion near the stoichiometric mixture ratio. While LPDI configurations increased $\mathrm{CO}$ by a factor of 8.3 for the beta exhaust and 5.7 for the optimized exhaust, the increase was compared to a very low baseline value of 3.81 $\mathrm{g} / \mathrm{kW}$-hr. This baseline CO value only represented $0.5 \%$ of the EPA standard level, while the LPDI beta was at $4.4 \%$ of the standard and the optimized LPDI was at $3.2 \%$ of the standard. The addition of an oxidation catalyst in earlier laboratory testing was shown to reduce $\mathrm{CO}$ emissions by up to $99 \%$.

Non-methane hydrocarbon emission attainment levels were reached for both PI and LPDI. Both injection strategies showed similar emission levels, and all stayed below half of the threshold EPA standard limit of $50 \mathrm{~g} / \mathrm{kW}$-hr. LPDI operation showed a slightly better trend, with average $\mathrm{NMHC}+\mathrm{NO}_{\mathrm{x}}$ emission reductions over the lambda range of $26 \%$ for beta and $52 \%$ for the optimized exhaust. However, at the most efficient point of each LPDI setup the $\mathrm{NMHC}+\mathrm{NO}_{\mathrm{x}}$ emissions were identical. Figure 41 shows the $\mathrm{NMHC}+\mathrm{NO}_{\mathrm{x}}$ emissions of each setup compared to the standard.

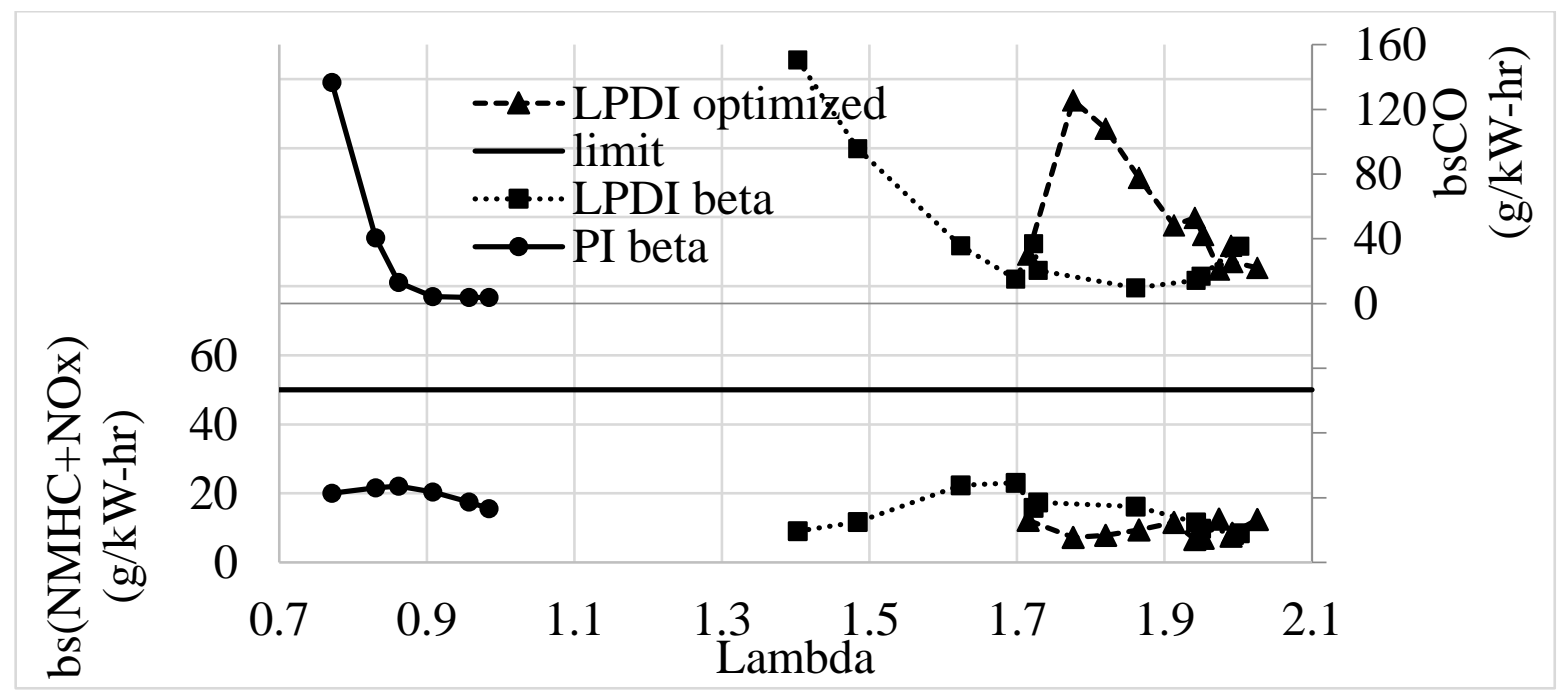

Figure 41 - (Top) Emission attainment plot brake specific CO for different configurations at various lambda values, (Bottom) emission attainment plot of brake specific $\mathrm{NMHC}+\mathrm{NO}_{x}$ for different configurations at various lambda value. 


\subsection{Summary and Conclusions}

Research was conducted as part of the ARPA-E GENSETS project at WVU. The projected focused on designing a $1 \mathrm{~kW}$ residential CHP system fueled by natural gas and operating at a fixed frequency. Research was partitioned into team efforts for designing the various electrical and mechanical sub-systems. The engine or combustion team focused on creating an experimental research engine testing platform, experimental data collection from various engine selections, refinement and validation of efficiency improving technologies, as well as engine simulation.

My research focused on the development of the laboratory setup, conducting research tests, assisting in data processing, validation of intake resonance theory, validation of exhaust resonance theory, experimental validation of a GT Power optimized exhaust design, and evaluation of injection strategies of LPDI over PI.

The results of this work show that NG two-stroke operation could efficiently drive a decentralized CHP system. Significant gains in engine efficiency and emission characteristics were made possible by fixed frequency tuning of the intake and exhaust system. The conversion from PI to LPDI technology allowed for even further gains in efficiency. The small gasoline engine converted to operate on NG was tested under two different fueling methods with two different exhaust resonators. Helmholtz theory was used in designing a tuned resonant intake which remained the same for all tests. Results showed both injection strategies allowed for an emission compliant engine without required after treatment. Peak efficiency and power output was achieved under LPDI with reduced fuel slippage from cylinder scavenging.

The optimized exhaust was shown to increase efficiency by strengthening the reflected pressure wave. This larger return wave corresponded to higher DR, reduced HC slippage, and slightly increased power at their respective most efficient points. Peak indicated efficiency was shown to increase by $2 \%$ (absolute) for the optimized exhaust as compared to the beta exhaust for LPDI. With PI values taken as a baseline for relative effects on key parameters have been compared. The efficiency increased by $81 \%$ and $70 \%$ (relative) for the optimized exhaust and beta exhaust on LPDI respectively. Brake specific fuel consumption decreased by $33 \%$ and $32 \%$ respectively. This was primarily due to less fuel slippage under LPDI versus PI. Indicated power increased by $46 \%$ and $25 \%$, respectively. 
Emission levels below the EPA NMHC+NO standard for small engines were observed for all test configurations. $\mathrm{NMHC}+\mathrm{NO}_{x}$ was reduced by $46 \%$ for both the optimized exhaust and beta exhaust as compared to PI with beta exhaust. All configurations were substantially below the EPA CO emission standard. While LPDI configurations increased by a factor of 8.3 for the beta exhaust and factor of 5.7 for the optimized exhaust, the increase was compared to an extremely low baseline value of $3.81 \mathrm{~g} / \mathrm{kW}-\mathrm{hr}$. The baseline value only represented $0.5 \%$ of the EPA standard level. The engine met emission regulation limits for EPA standards as well as California alternative limits and therefore could be applicable nationwide.

The configuration of NG LPDI operating at a fixed frequency with an optimized tuned resonator exhaust was shown suitable for small scale residential power generation. The target efficiency of $37 \%$ was not achieved, but with further modifications it could be attained at least as an indicated value. Table 8 below shows a summary of relative changes in key engine parameters using PI beta as the baseline. My key conclusions are as follow:

\section{Intake Tuning}

- Intake length tuning shows strong influence on indicated efficiency

- Intake length tuning for peak power and peak efficiency occur at different lengths

- Relies on fixed frequency operation

\section{Exhaust Tuning}

- Exhaust tuning also had a strong impact on indicated efficiency, with peak power and peak efficiency occurring at different lengths

- Traditionally aimed at peak power density, also can be used for peak efficiency

- Efficiency targeting GT Power optimized design increase indicated efficiency by $2 \%$

- Tuned exhaust geometry suitable for stationary fixed frequency operation

\section{LPDI}

- Higher indicated efficiency and indicated power with lower BSFC

- Emissions remain within EPA regulated limits

- $46 \%$ decrease in $\mathrm{NMHC}+\mathrm{NO}_{\mathrm{x}}$ as compared to PI at most efficient point

- Reduced $\mathrm{CO}_{2}$ equivalent by over $60 \%$ 
Table 8 - Change in key parameters at most efficiency point compared to PI baseline.

\begin{tabular}{|c|c|c|}
\hline \multirow{2}{*}{ Variable } & Beta, LPDI & Optimized, LPDI \\
\hline & $\%$ change & $\%$ change \\
\hline Indicated Power & 25.40 & 46.25 \\
\hline Delivery Ratio & 47.59 & 61.26 \\
\hline Indicated Efficiency & 69.94 & 81.94 \\
\hline BSFC & -31.72 & -32.69 \\
\hline Input Energy & -25.70 & -18.38 \\
\hline Combustion Duration & 17.46 & 17.31 \\
\hline NOx & 82.79 & 95.68 \\
\hline THC & -74.09 & -84.88 \\
\hline $\mathrm{CH} 4$ & -72.63 & -84.02 \\
\hline $\mathrm{NMHC}+\mathrm{NOX}$ & -45.78 & -45.70 \\
\hline CO2 EQ. & -60.21 & -67.52 \\
\hline $\mathrm{CO}$ & 832.67 & 572.50 \\
\hline Pmax & 53.69 & 55.75 \\
\hline $\mathrm{AP} \max$ & -29.12 & -11.91 \\
\hline IMEP & 25.54 & 46.33 \\
\hline IMEP COV & 128.00 & 97.73 \\
\hline Fuel Pressure & 35.96 & 89.57 \\
\hline HRL per Cycle Kibox & 19.61 & 37.29 \\
\hline MAF & 54.42 & 68.79 \\
\hline $\mathrm{FC}$ & -22.26 & -14.60 \\
\hline Brake Torque & 13.99 & 26.95 \\
\hline Brake Power & 13.86 & 26.88 \\
\hline Brake Efficiency & 53.23 & 55.45 \\
\hline
\end{tabular}




\subsection{Recommendations}

Further research should investigate the durability of the LPDI engine and determine the functional lifespan. The effects of piston ring wear on emissions should be explored. The $6.35 \mathrm{~mm}$ small spark plug required for the setup should also be adequately tested for durability. A control mechanism to detect injector failure and seize fueling should be explored. The addition of an adiabatic coated cylinder head and piston crown will be tested on the Zenoah $34 \mathrm{cc}$ engine under LPDI to determine if possible improvements can be made on efficiency. Catalyst testing of the LPDI optimized exhaust is required to determine the lowest possible emission levels attainable. A analysis of the emission mass produced by annual usage of the engine in a CHP system compared to emission mass produced by the equivalent large scale electrical production should be conducted. Water-cooling of the engine should be explored as an alternative to air-cooling in order to utilize wasted heat energy in a heat exchanger for CHP applications. The engine should also be tested using minimum pipeline quality NG to determine performance and emission differences in fuel with lower methane content than the research blends already tested. 


\subsection{References}

[1] "GENSETS," ARPA-E, 18 June 2015. [Online]. Available: https://arpae.energy.gov/?q=arpa-e-programs/gensets. [Accessed 30 Nov 2018].

[2] J. K. Ausserer, M. D. Polanka, J. Baranski, K. Grinstead and P. Litke, "Measurement of Loss Pathways in Small, Two-Stroke Internal Combustion Engines," SAE International, vol. 10, no. 2; 2017-01-9276, 2017.

[3] M. Foss, J. Wardzinski and F. Delano, "Interstate Natural Gas - Quality Specifications \& Interchangeability," Center for Energy Economics, Austin Texas, 2004.

[4] "Gases- Explosion and Flammability Concentration Limits," The Engineering ToolBox, 2003. [Online]. Available: https://www.engineeringtoolbox.com/explosive-concentrationlimits-d_423.html. [Accessed 20 Sept. 2018].

[5] J. Lui and C. Dumitrescu, "Flame development analysis in a diesel optical engine converted to spark ignition natural gas operation," Applied Energy, vol. 230, no. doi:10.1016/2018.09.059, pp. 1205-1217, 2018.

[6] J. Heywood and E. Sher, The Two-Stroke Cycle Engine : Its Development, Operation, and Design, New York: Taylor \& Francis Group, LLC, 1999.

[7] "ARPA-E : MOVE," 12 July 2012. [Online]. Available: https://arpa-e.energy.gov/?q=arpae-programs/move. [Accessed 3 May 2018].

[8] K. Tsai and N. Ameen, "Today in Energy: EIA expects 2018 and 1029 natural gas prices to remain relatively flat," U.S. Energy Information Administration, 25 Jan 2018. [Online]. Available: https://www.eia.gov/todayinenergy/detail.php?id=34672. [Accessed 22 Oct 2018].

[9] T. Hodge, "Today In Energy," U.S.. Energy Information Administration , 22 January 2018. [Online]. Available: https://www.eia.gov/todayinenergy/detail.php?id=34612. [Accessed 6 June 2018].

[10] "How much carbon dioxide is produced when different fuels are burned?," U.S. Energy Information Administration , 8 June 2018. [Online]. Available: https://www.eia.gov/tools/faqs/faq.php?id=73\&t=11. [Accessed 13 June 2018].

[11] "Natural Gas Expalined: Use of Natural Gas," U.S. Energy Information Administration, 26 Oct. 2017. [Online]. Available: https://www.eia.gov/energyexplained/index.php?page=natural_gas_use. [Accessed 29 May 2018]. 
[12] G. Jennings, Tuner's Handbook, H.P. Books, 1973.

[13] E. G. Groff, "Automotive Two-Stroke-Cycle Engine Development in the 1980-1990's," SAE Technical Paper 2016-01-0177, vol. 2016, no. doi:10.4271/2016-01-0177, 2016.

[14] A. Boretti and J. Scalzo, "A Novel Valve-Less Superchraged Small Two Stroke Engine of Top Brake Efficiency above 36\% and Power Density Above 100kW/Liter," SAE International, 2013.

[15] V. Pradeep, S. Bakshi and A. Ramesh, "Direct Injection of gaseous LPG in a two-stroke SI engine for improved performance," Applied Thermal Engineering, vol. 89, no. https://doi.org/10.1016/j.applthermaleng.2015.06.049., pp. 738-747, 2015.

[16] Q. Xiong, Y. Moriyoshi, K. Morikawa and Y. Takahashi, "Improvement in Thermal Efficiency of Lean Burn Pre-Chamber Natural Gas Engine by Optimization of Combustion System," SAE International, 2017.

[17] M. Nuti, "Emissions from Two-Stroke Engines", Warrendale, PA: Society of Automotive Engineers, Inc., 1998.

[18] C. Arcoumanis and T. Kamimoto, Flow and Combustion in Reciprocating Engines, Berlin: Springer, 2009.

[19] G. P. Blair, Basic Design of Two-Stroke Engines, Warrendale, P.A.: Society of Automotive Engineers, Inc., 1996.

[20] G. Blair, Design and Simulation of Two-Stroke Engines, Warrendale, P.A.: Society of Automotive Engineers, Inc., 1996.

[21] A. Trattner, S. Schmidt, R. Kirchberger and e. al, "Future Engine Technology in HandHeld Power Tools," SAE International, no. doi:10.4271/2012-32-0111, 2012.

[22] N. Baijal, "Basic Info of Marine Engineering," 2015. [Online]. [Accessed 15 April 2017].

[23] "Cooperative Patent Classification," USPTO, January 2018. [Online]. Available: https://www.uspto.gov/web/patents/classification/cpc/html/cpc-F02D.html. [Accessed 9 January 2018].

[24] P. Piecha, P. Bruckner, S. Schmidt and R. Kirchberger, "Investigations and Analysis of Working Processes of Two-Stroke Engines with the Focus on Wall Heat Flux," SAE international Journal: Engnes, no. 2016-32-0028, 2016.

[25] J. Li, M. Parkes and T. Jacobs, "A Study on the Effects of Cetane Number on the Energy Balance between Differently Sized Engines," SAE Technical Papers, no. 2017-01-0805, 2017. 
[26] S. K. Pathak, V. Sood, Singh and Yograj, "Impact of "Break In" Running on Exhaust Emissions and Fuel Consumption of a Portable Genset," SAE International, 2017.

[27] A. Trattner, F. Kupelwieser and P. Pertl, "Thermodynamic Limits of Efficiency Enhancement of Small Displacement Single-Cylinder Engines," SAE Technical Paper, no. 2015-32-0817, 2015.

[28] M. Bergman and J. Berneklev, "A Novel Method of Tuning a Stratified Scavenged TwoStroke Engine," SAE, 2006.

[29] M. Bergman, M. Bergwall, T. Elm, S. Louring and L. Nielsen, "Advanced Low Friction Engine Coating Applied to a 70cc High Performance Chainsaw," SAE International, no. doi:10.4271/2014-32-0115, 2014.

[30] H. Koga and T. Kiura, "A Study of Controlled Auto-Ignition in Small Natural Gas Engines," SAE International, no. doi:10.4271/2013-32-9098, 2013.

[31] "ISL G Near Zero," Cummins Westport, [Online]. Available: http://www.cumminswestport.com/models/isl-g-near-zero. [Accessed 13 June 2018].

[32] Y. Wakisaka, M. Inayoshi and K. Fukui, "Reduction of Heat Loss and Improvement in Thermal Efficiency by Application of "Thermal Swing" /insulation to Direct-Injection Diesel Engines," SAE International, pp. 1449-1459, 2016.

[33] J. Theurkauf, Interviewee, Plating Expert. [Interview]. 18 March 2017.

[34] B. A. Jawad, A. L. Lounsbery and J. P. Hoste, "Evolution of Intake Design for a Small Engine Formula Vehicle," SAE Technical Paper Series, p. 7, 2001.

[35] D. Johnson, M. Darzi and C. Ulishney, "Methods to Improve Combustion Stability, Efficiency, and Power Density of a Small, Port-Injected, Spark-Ignited, Two-Stroke Natural Gas Engine," ICEF, vol. 2, 2017.

[36] S. Potul, R. Nachnolkar and S. Bhave, "Analysis of Change in Intake Manifold Length and Development of Variable Intake System," International Journal of Scientific \& Technology Research, vol. 3, no. 5, pp. 223-228, 2014.

[37] W. Mitianiec, "Improvements of Crankcase Delivery Ratio in Two-Stroke Engines with Volume Intake System," SAE Technical Paper Series, p. 13, 1999.

[38] V. Mariucci and S. a. Miazgowicz, "Effect of Primary Intake Runner Tapers and Bellmouths on the Performance of a Single Cylinder Engine," SAE Technical Paper Series, p. 16, 2007.

[39] G. P. Blair, Design and Simulation of Two-Stroke Engines, Warrendale, P.A.: SAE, 1996a. 
[40] G. Zsiga, R. Kerres and M. Bach, "Potential of Expansion Chamber Exhaust Pipes for Two-Stroke Powered Tools," SAE, no. DOI:10.4271/2010-32-0011, 2010.

[41] J. B. Heywood, Internal Combustion Engine Fundamentals- Indian Edition, New Delhi : McGraw Hill, 1988.

[42] D. Johnson, M. Darzi, C. Ulishney and e. al, "Baseline Evaluation of Ignition Timing and Compression Ratio Configurations on Efficiency and Combustion Stability of a SmallBore, Natural Gas Engine," IMECE: International Mechanical Engineering Congress and Exposition (Tampa, Florida), vol. 6, no. DOI:10.1115/IMECE2017-70078, 2017.

[43] L. Romani, G. Vichi, G. Ferrara and F. Balduzzi, "Development of a Low Pressure Direct Injection System for a Small 2S Engine. Part II- Experimental Analysis of the Engine Performance and Pollutant Emissions," SAE International, no. doi:10.4271/2015-01-1730, 2015.

[44] S. Prabhukumar and G. Kumarappa, "Improving the Performance of Two Stroke Spark Igntion Engine by Direct Electronic CNG Injection," JJMIE, vol. 2, no. ISSN 1995-6665, pp. 169-174, 2008.

[45] M. Araki, H. Kishimoto and K. Nakajima, "A CNG Two Stroke Cycle S.I. Engine Using Intermittent Low Pressure Fuel Injection from Scavenging Ports," SAE, no. 2008-28-004, 2008.

[46] N. Goddard, "Popular Mechanics," HEARST, 27 June 2017. [Online]. Available: https:/www.popularmechanics.com/cars/motorcycles/a27046/ktm-two-stroke-transferport-injection-tpi/. [Accessed 6 June 2018].

[47] C. Fleming, "Los Angeles Times," Los Angeles Times, 18 December 2017. [Online]. Available: http://www.latimes.com/business/autos/la-fi-hy-husqvarna-2-stroke-20171213story.html. [Accessed 6 June 2018].

[48] Y. Tan, H. Gitano and A. Khalil, "Development of a Transfer Port Injection System for Two-Stroke Engines," SAE International, no. doi:10.4271/2012-32-0115, 2012.

[49] C. Hu and S. Hou, "Investigations on Combustion Process of Low-pressure CNG Compound Direct Injection Spark-ignited Engines," SAE, no. https://doi.org/10.4271/201032-0052., 2010.

[50] S. Hatakeyama, S. Y., T. Murayama, S. Nakai, T. Sako and H. Tsunemoto, "A study on InCylinder Injection of Low Pressure Natural Gas for Performance Improvement of Small Sized Two-Stroke SI Engines," SAE, no. https://doi.org/10.4271/2001-01-1959, 2001. 
[51] S. Krimplstatter, F. Winkler, R. Oswald and R. Kirchberger, "Air Cooled 50 cc Scooter Euro 4 Application of the Two-Stroke LPDI Technology," SAE International, no. doi:10.4271/2014-32-0008, 2014.

[52] D. Seboldt, D. Lejsek and M. Bargende, "Injection strategies for low HC raw emissions and SI engines with CHG direct injection," Automotive and Engine Technology, vol. 1, no. 1-4, pp. 81-91, 2016.

[53] A. Dube and R. A, "Influence of Injection Parameters on the Performance and Emissions of a Direct Injection Two Stroke SI Engine," SAE International , no. doi:10.4271/2016-01$1052,2016$.

[54] "LP Gas, Propane Gas, \& Natural Gas Pressures \& Pressure Settings," Google, [Online]. Available: https://inspectapedia.com/plumbing/Gas_Pressures.php. [Accessed 23 Aug. 2018].

[55] "Electronic Code of Federal Regulations," e-CFR, 5 January 2018. [Online]. Available: https://www.ecfr.gov/cgi-bin/text$\mathrm{idx}$ ?SID=fc799a21d4ca6f413913715af7c09e88\&mc=true \&node=pt40.36.1054\&rgn=div5. [Accessed 9 January 2018].

[56] "Small Nonroad Spark-Ignition Engines (<19 kiloWatts): Family Naming Conventions," EPA, 26 December 2017. [Online]. Available: https://www.epa.gov/vehicle-and-enginecertification/small-nonroad-spark-ignition-engines. [Accessed 9 January 2018].

[57] "Ground-level Ozone Basics," US EPA, 31 Oct. 2018. [Online]. Available: https://www.epa.gov/ground-level-ozone-pollution/ground-level-ozone-basics\#formation. [Accessed 8 Aug. 2018].

[58] "Technical Overview of Volatile Organic Compounds," US EPA, 12 April 2017. [Online]. Available: https://www.epa.gov/indoor-air-quality-iaq/technical-overview-volatile-organiccompounds. [Accessed 8 August 2018].

[59] "NAAQS Table," US EPA, 20 Dec 2016. [Online]. Available: https://www.epa.gov/criteria-air-pollutants/naaqs-table. [Accessed 8 Aug 2018].

[60] M. Darzi, D. Johnson and C. Ulishney, "Gaseous Fuels Variation Effects on First and Second Law Analyses of a Small Direct Injection Engine for Micro-CHP Systems," Energy Conversion and Management, 2018 (pending publication).

[61] M. Feist, M. Landau and E. Harte, "The Effect of Fuel Composition on Performance and Emissions of a Variety of Natural Gas Engines," SAE International, no. 2010-01-1476, 2010 . 
[62] M. Darzi, Lab Setup Schematic, Morgantown: Elsevier Applied Energy (submission), 2018.

[63] M. Darzi, GT-Power Simulation Results, Morgantown, 2018.

[64] D. Snakesh, P. Petersen and P. Lappas, "Flow chracteristics of natural-gas from an outward-opening nozzle for direct injection engines," Elsevier : ScienceDirect, vol. 218, pp. 188-202, 2018.

[65] PowerKote- Tech Line Coatings, "Metallic Ceramic Thermal Barrier Part \# CBC1," [Online]. [Accessed 3 April 2017].

[66] R. Tumpej and T. Gerecnik, "TOMOS: project website," TOMOS, 2012. [Online]. Available: http://tomos.odklopi.se/english/index.html. [Accessed 4 June 2018]. 


\subsection{Appendix}

Table A1 - PI beta exhaust data

\begin{tabular}{|c|c|c|c|c|c|c|c|}
\hline \multicolumn{8}{|c|}{ Port injection Beta Exhaust } \\
\hline Time series & {$[-]$} & 489 & 490 & 491 & 492 & 493 & 494 \\
\hline Lambda & {$[-]$} & 0.77 & 0.83 & 0.86 & 0.91 & 0.96 & 0.98 \\
\hline Indicated Power & {$[\mathrm{kW}]$} & 1.19 & 1.13 & 1.09 & 1.06 & 1.06 & 1.04 \\
\hline Delivery Ratio & {$[-]$} & 0.67 & 0.64 & 0.62 & 0.62 & 0.62 & 0.62 \\
\hline Indicated Efficiency & {$[\%]$} & 14.4 & 15.5 & 15.8 & 16.4 & 17.1 & 17.2 \\
\hline BSFC & [g/kW-hr] & 620 & 578 & 571 & 554 & 542 & 528 \\
\hline Input Energy & {$[\mathrm{kW}]$} & 8.2 & 7.3 & 6.9 & 6.5 & 6.2 & 6.1 \\
\hline Combustion Duration & {$[\mathrm{CA}]$} & 44.4 & 44.1 & 44.1 & 43.9 & 44.6 & 44.6 \\
\hline NOx & [g/kW-hr] & 2.49 & 6.72 & 7.91 & 7.47 & 5.34 & 3.98 \\
\hline THC & {$[\mathrm{g} / \mathrm{kW}-\mathrm{hr}]$} & 171 & 154 & 151 & 145 & 142 & 137 \\
\hline $\mathrm{CH} 4$ & [g/kW-hr] & 153 & 140 & 137 & 132 & 129 & 125 \\
\hline $\mathrm{NMHC}+\mathrm{NOX}$ & [g/kW-hr] & 20.1 & 21.6 & 22.1 & 20.4 & 17.5 & 15.6 \\
\hline $\mathrm{CO} 2 \mathrm{EQ}$. & {$[\mathrm{g} / \mathrm{kW}-\mathrm{hr}]$} & 4443 & 4208 & 4176 & 4065 & 3972 & 3855 \\
\hline $\mathrm{CO}$ & [g/kW-hr] & 137 & 40.6 & 13.2 & 4.2 & 3.7 & 3.8 \\
\hline Pmax & [bar] & 25.6 & 25.1 & 24.0 & 23.7 & 23.1 & 22.6 \\
\hline $\mathrm{AP} \max$ & [CAD ATDC] & 11.9 & 11.3 & 11.4 & 11.6 & 12.0 & 12.2 \\
\hline IMEP & [bar] & 3.82 & 3.63 & 3.51 & 3.42 & 3.42 & 3.35 \\
\hline IMEP COV & {$[\%]$} & 1.69 & 1.63 & 1.62 & 1.61 & 1.98 & 2.19 \\
\hline Fuel Pressure & [bar] & 1.05 & 1.12 & 1.15 & 1.15 & 1.16 & 1.17 \\
\hline HRL per Cycle Kibox & {$[\mathrm{J}]$} & 28.9 & 27.4 & 26.6 & 26.0 & 26.4 & 26.0 \\
\hline Dyno Speed & {$[\mathrm{rpm}]$} & 5412 & 5410 & 5411 & 5411 & 5409 & 5411 \\
\hline MAF & [slpm] & 110 & 105 & 103 & 102 & 103 & 104 \\
\hline $\mathrm{FC}$ & [slpm] & 14.1 & 12.5 & 11.8 & 11.1 & 10.7 & 10.4 \\
\hline Brake Torque & [in-lb] & 16.8 & 16.0 & 15.3 & 14.8 & 14.5 & 14.6 \\
\hline Brake Power & {$[\mathrm{kW}]$} & 1.07 & 1.02 & 0.98 & 0.95 & 0.93 & 0.93 \\
\hline AFR & {$[-]$} & 11.7 & 12.6 & 13.1 & 13.8 & 14.5 & 14.9 \\
\hline Brake Efficiency & {$[\%]$} & 13.1 & 14.0 & 14.2 & 14.6 & 15.0 & 15.3 \\
\hline Relative Humidity & {$[\%]$} & 55.8 & 55.4 & 55.6 & 56.0 & 56.5 & 56.1 \\
\hline T Exh Port & {$[\mathrm{C}]$} & 398 & 420 & 425 & 418 & 409 & 405 \\
\hline $\mathrm{T}$ tail & {$[\mathrm{C}]$} & 242 & 282 & 298 & 307 & 307 & 304 \\
\hline T Cyl Head & {$[\mathrm{C}]$} & 190 & 204 & 203 & 196 & 186 & 180 \\
\hline $\mathrm{T}$ room & {$[\mathrm{F}]$} & 79.0 & 79.3 & 79.0 & 78.7 & 78.6 & 78.7 \\
\hline
\end{tabular}


Table A2 - LPDI beta exhaust data.

\begin{tabular}{|c|c|c|c|c|c|c|c|c|c|c|c|}
\hline \multicolumn{12}{|c|}{ Low Pressure Direct Injection Beta Exhaust } \\
\hline Time series & {$[-]$} & 911 & 912 & 916 & 915 & 913 & 914 & 920 & 919 & 918 & 917 \\
\hline Lambda & {$[-]$} & 1.40 & 1.48 & 1.62 & 1.70 & 1.72 & 1.73 & 1.86 & 1.94 & 1.95 & 2.00 \\
\hline Indicated Power & {$[\mathrm{kW}]$} & 1.31 & 1.36 & 1.51 & 1.50 & 1.47 & 1.47 & 1.42 & 1.40 & 1.36 & 1.31 \\
\hline Delivery Ratio & {$[-]$} & 0.84 & 0.86 & 0.95 & 0.95 & 0.93 & 0.91 & 0.94 & 0.95 & 0.93 & 0.91 \\
\hline Indicated Efficiency & {$[\%]$} & 21.2 & 23.4 & 26.2 & 27.5 & 27.7 & 28.4 & 28.5 & 29.1 & 28.9 & 29.2 \\
\hline BSFC & [g/kW-hr] & 481 & 442 & 389 & 377 & 378 & 382 & 363 & 350 & 360 & 361 \\
\hline Input Energy & {$[\mathrm{kW}]$} & 5.8 & 5.6 & 5.7 & 5.5 & 5.3 & 5.2 & 5.0 & 4.8 & 4.7 & 4.5 \\
\hline $\begin{array}{l}\text { Combustion } \\
\text { Duration } \\
\end{array}$ & {$[\mathrm{CA}]$} & 49.7 & 45.7 & 46.4 & 48.0 & 50.5 & 49.0 & 48.0 & 50.8 & 51.7 & 52.4 \\
\hline $\mathrm{NOx}$ & {$[\mathrm{g} / \mathrm{kW}-\mathrm{hr}]$} & 5.0 & 8.8 & 21.3 & 22.0 & 14.9 & 16.0 & 15.5 & 10.7 & 8.9 & 7.3 \\
\hline THC & [g/kW-hr] & 84.0 & 68.8 & 35.9 & 35.9 & 32.3 & 39.5 & 26.0 & 28.0 & 27.5 & 35.5 \\
\hline $\mathrm{CH} 4$ & {$[\mathrm{~g} / \mathrm{kW}-\mathrm{hr}]$} & 79.9 & 65.8 & 34.8 & 34.9 & 31.4 & 38.2 & 25.3 & 27.1 & 26.6 & 34.3 \\
\hline $\mathrm{NMHC}+\mathrm{NOX}$ & {$[\mathrm{g} / \mathrm{kW}-\mathrm{hr}]$} & 9.1 & 11.8 & 22.3 & 23.1 & 15.8 & 17.3 & 16.2 & 11.5 & 9.7 & 8.5 \\
\hline $\mathrm{CO} 2 \mathrm{EQ}$. & [g/kW-hr] & 2634 & 2322 & 1617 & 1621 & 1511 & 1695 & 1383 & 1386 & 1394 & 1534 \\
\hline $\mathrm{CO}$ & {$[\mathrm{g} / \mathrm{kW}-\mathrm{hr}]$} & 151 & 95.8 & 35.6 & 15.1 & 36.9 & 20.6 & 9.7 & 14.3 & 16.9 & 35.5 \\
\hline Pmax & [bar] & 33.9 & 36.4 & 46.7 & 45.6 & 41.2 & 42.4 & 42.8 & 41.0 & 38.1 & 34.7 \\
\hline $\mathrm{AP} \max$ & $\begin{array}{l}{[\text { CAD }} \\
\text { ATDC }]\end{array}$ & 8.9 & 8.6 & 5.8 & 6.4 & 7.7 & 7.4 & 7.0 & 7.4 & 8.0 & 8.7 \\
\hline IMEP & [bar] & 4.21 & 4.38 & 4.88 & 4.85 & 4.74 & 4.73 & 4.58 & 4.50 & 4.37 & 4.21 \\
\hline IMEP COV & {$[\%]$} & 11.26 & 14.83 & 2.28 & 1.88 & 3.80 & 2.14 & 2.54 & 2.60 & 3.59 & 5.00 \\
\hline Fuel Pressure & [bar] & 1.82 & 1.83 & 1.83 & 1.83 & 1.85 & 1.86 & 1.56 & 1.57 & 1.57 & 1.59 \\
\hline $\begin{array}{l}\text { HRL per Cycle } \\
\text { Kibox }\end{array}$ & {$[\mathrm{J}]$} & 31.1 & 31.3 & 34.2 & 34.2 & 34.0 & 33.8 & 32.3 & 32.3 & 31.8 & 31.1 \\
\hline Dyno Speed & {$[\mathrm{rpm}]$} & 5406 & 5404 & 5404 & 5404 & 5406 & 5401 & 5405 & 5404 & 5404 & 5405 \\
\hline MAF & [slpm] & 144 & 147 & 165 & 165 & 161 & 158 & 165 & 166 & 163 & 160 \\
\hline $\mathrm{FC}$ & [slpm] & 10.4 & 10.1 & 10.3 & 9.8 & 9.5 & 9.3 & 9.0 & 8.7 & 8.5 & 8.1 \\
\hline Brake Torque & [in-lb] & 16.0 & 16.8 & 19.6 & 19.3 & 18.6 & 17.9 & 18.2 & 18.3 & 17.4 & 16.6 \\
\hline Brake Power & {$[\mathrm{kW}]$} & 1.02 & 1.08 & 1.25 & 1.23 & 1.19 & 1.15 & 1.17 & 1.17 & 1.11 & 1.06 \\
\hline AFR & {$[-]$} & 22.3 & 23.5 & 25.8 & 26.9 & 27.3 & 27.4 & 29.5 & 30.8 & 30.9 & 31.8 \\
\hline Brake Efficiency & {$[\%]$} & 17.6 & 19.2 & 21.8 & 22.5 & 22.4 & 22.2 & 23.3 & 24.2 & 23.5 & 23.5 \\
\hline Relative Humidity & {$[\%]$} & 73.8 & 73.3 & 70.8 & 71.3 & 72.9 & 72.1 & 71.0 & 71.5 & 71.9 & 72.2 \\
\hline T Exh Port & {$[\mathrm{C}]$} & 364 & 376 & 396 & 386 & 387 & 384 & 374 & 372 & 373 & 374 \\
\hline $\mathrm{T}$ tail & {$[\mathrm{C}]$} & 183 & 220 & 324 & 308 & 257 & 289 & 302 & 289 & 276 & 257 \\
\hline T Cyl Head & {$[\mathrm{C}]$} & 73.3 & 77.3 & 92.7 & 89.3 & 82.8 & 84.6 & 86.6 & 83.7 & 80.7 & 77.1 \\
\hline $\mathrm{T}$ room & {$[\mathrm{F}]$} & 75.3 & 75.5 & 76.7 & 76.4 & 75.7 & 76.0 & 76.7 & 76.5 & 76.3 & 76.1 \\
\hline
\end{tabular}


Table A3 - LPDI optimized exhaust data.

\begin{tabular}{|c|c|c|c|c|c|c|c|c|c|c|c|c|}
\hline \multicolumn{13}{|c|}{ Low Pressure Direct Injection Optimized Exhaust } \\
\hline Time series & {$[-]$} & 977 & 978 & 979 & 980 & 981 & 973 & 974 & 983 & 975 & 976 & 984 \\
\hline Lambda & {$[-]$} & 1.72 & 1.78 & 1.82 & 1.87 & 1.91 & 1.94 & 1.95 & 1.97 & 1.99 & 1.99 & 2.03 \\
\hline Indicated Power & {$[\mathrm{kW}]$} & 1.49 & 1.52 & 1.54 & 1.54 & 1.54 & 1.43 & 1.50 & 1.51 & 1.51 & 1.53 & 1.42 \\
\hline Delivery Ratio & {$[-]$} & 0.99 & 1.00 & 1.00 & 1.00 & 1.00 & 0.97 & 1.00 & 1.00 & 1.00 & 1.00 & 0.98 \\
\hline $\begin{array}{l}\text { Indicated } \\
\text { Efficiency }\end{array}$ & [\%] & 24.5 & 26.6 & 27.7 & 28.7 & 29.9 & 29.2 & 30.0 & 30.7 & 30.8 & 31.2 & 30.4 \\
\hline BSFC & [g/kW-hr] & 403 & 380 & 369 & 359 & 353 & 372 & 358 & 348 & 354 & 356 & 362 \\
\hline Input Energy & {$[\mathrm{kW}]$} & 5.7 & 5.5 & 5.4 & 5.3 & 5.2 & 4.9 & 5.0 & 5.0 & 5.0 & 5.0 & 4.7 \\
\hline $\begin{array}{l}\text { Combustion } \\
\text { Duration }\end{array}$ & {$[\mathrm{CA}]$} & 47.5 & 46.0 & 48.2 & 47.8 & 49.3 & 55.2 & 52.6 & 48.3 & 51.6 & 52.3 & 52.8 \\
\hline NOx & [g/kW-hr] & 11.3 & 5.7 & 6.8 & 8.6 & 10.9 & 5.4 & 6.2 & 11.9 & 6.9 & 7.8 & 11.7 \\
\hline THC & [g/kW-hr] & 29.3 & 40.8 & 32.8 & 25.3 & 22.0 & 34.0 & 24.8 & 20.5 & 22.6 & 20.7 & 22.1 \\
\hline $\mathrm{CH} 4$ & [g/kW-hr] & 28.3 & 39.2 & 31.7 & 24.5 & 21.3 & 32.7 & 24.0 & 19.8 & 21.9 & 20.0 & 21.3 \\
\hline $\mathrm{NMHC}+\mathrm{NOX}$ & [g/kW-hr] & 12.2 & 7.2 & 7.9 & 9.5 & 11.6 & 6.7 & 7.0 & 12.6 & 7.6 & 8.5 & 12.4 \\
\hline $\mathrm{CO} 2 \mathrm{EQ}$. & [g/kW-hr] & 1543 & 1577 & 1412 & 1278 & 1238 & 1529 & 1317 & 1233 & 1276 & 1252 & 1298 \\
\hline $\mathrm{CO}$ & [g/kW-hr] & 30.4 & 126 & 108 & 77.6 & 48.3 & 53.0 & 42.4 & 21.1 & 35.7 & 25.6 & 22.0 \\
\hline Pmax & [bar] & 37.2 & 38.0 & 38.6 & 38.9 & 39.1 & 31.4 & 33.9 & 38.4 & 34.5 & 35.2 & 36.7 \\
\hline $\mathrm{AP} \max$ & [CAD ATDC] & 9.2 & 9.3 & 9.4 & 9.1 & 9.0 & 10.7 & 11.0 & 9.0 & 10.8 & 10.8 & 8.7 \\
\hline IMEP & [bar] & 4.78 & 4.89 & 4.97 & 4.96 & 4.96 & 4.62 & 4.84 & 4.87 & 4.87 & 4.91 & 4.59 \\
\hline IMEP COV & {$[\%]$} & 7.27 & 5.46 & 4.11 & 3.55 & 3.76 & 7.65 & 4.86 & 4.34 & 4.89 & 4.33 & 4.68 \\
\hline Fuel Pressure & [bar] & 2.17 & 2.20 & 2.21 & 2.22 & 2.23 & 2.20 & 2.21 & 2.25 & 2.21 & 2.22 & 2.26 \\
\hline $\begin{array}{l}\text { HRL per Cycle } \\
\text { Kibox }\end{array}$ & {$[\mathrm{J}]$} & 33.6 & 33.9 & 35.0 & 34.9 & 35.1 & 34.5 & 35.4 & 34.2 & 35.5 & 35.7 & 32.7 \\
\hline Dyno Speed & [rpm] & 5406 & 5406 & 5406 & 5406 & 5406 & 5407 & 5406 & 5406 & 5406 & 5408 & 5385 \\
\hline MAF & [slpm] & 172 & 174 & 175 & 175 & 175 & 170 & 174 & 175 & 175 & 175 & 170 \\
\hline $\mathrm{FC}$ & [slpm] & 10.1 & 9.9 & 9.7 & 9.5 & 9.3 & 8.9 & 9.0 & 9.0 & 8.9 & 8.9 & 8.5 \\
\hline Brake Torque & [in-lb] & 18.6 & 19.3 & 19.4 & 19.5 & 19.4 & 17.6 & 18.7 & 19.0 & 18.6 & 18.5 & 17.5 \\
\hline Brake Power & {$[\mathrm{kW}]$} & 1.19 & 1.23 & 1.24 & 1.25 & 1.24 & 1.12 & 1.20 & 1.22 & 1.19 & 1.18 & 1.11 \\
\hline AFR & {$[-]$} & 27.2 & 28.2 & 28.9 & 29.6 & 30.4 & 30.8 & 31.0 & 31.3 & 31.6 & 31.6 & 32.2 \\
\hline Brake Efficiency & [\%] & 21.0 & 22.3 & 23.0 & 23.6 & 24.0 & 22.8 & 23.7 & 24.3 & 24.0 & 23.8 & 23.4 \\
\hline Relative Humidity & [\%] & 65.3 & 65.3 & 65.0 & 64.7 & 64.5 & 70.0 & 69.4 & 63.1 & 68.9 & 68.0 & 62.7 \\
\hline T Exh Port & {$[\mathrm{C}]$} & 358 & 365 & 369 & 371 & 369 & 373 & 376 & 365 & 375 & 374 & 355 \\
\hline $\mathrm{T}$ tail & {$[\mathrm{C}]$} & 302 & 307 & 311 & 314 & 316 & 277 & 297 & 318 & 305 & 314 & 313 \\
\hline T Cyl Head & {$[\mathrm{C}]$} & 110 & 114 & 115 & 116 & 116 & 103 & 108 & 115 & 108 & 108 & 110 \\
\hline $\mathrm{T}$ room & {$[\mathrm{F}]$} & 74.7 & 74.7 & 74.7 & 74.7 & 74.8 & 74.1 & 74.3 & 74.8 & 74.3 & 74.5 & 74.8 \\
\hline
\end{tabular}




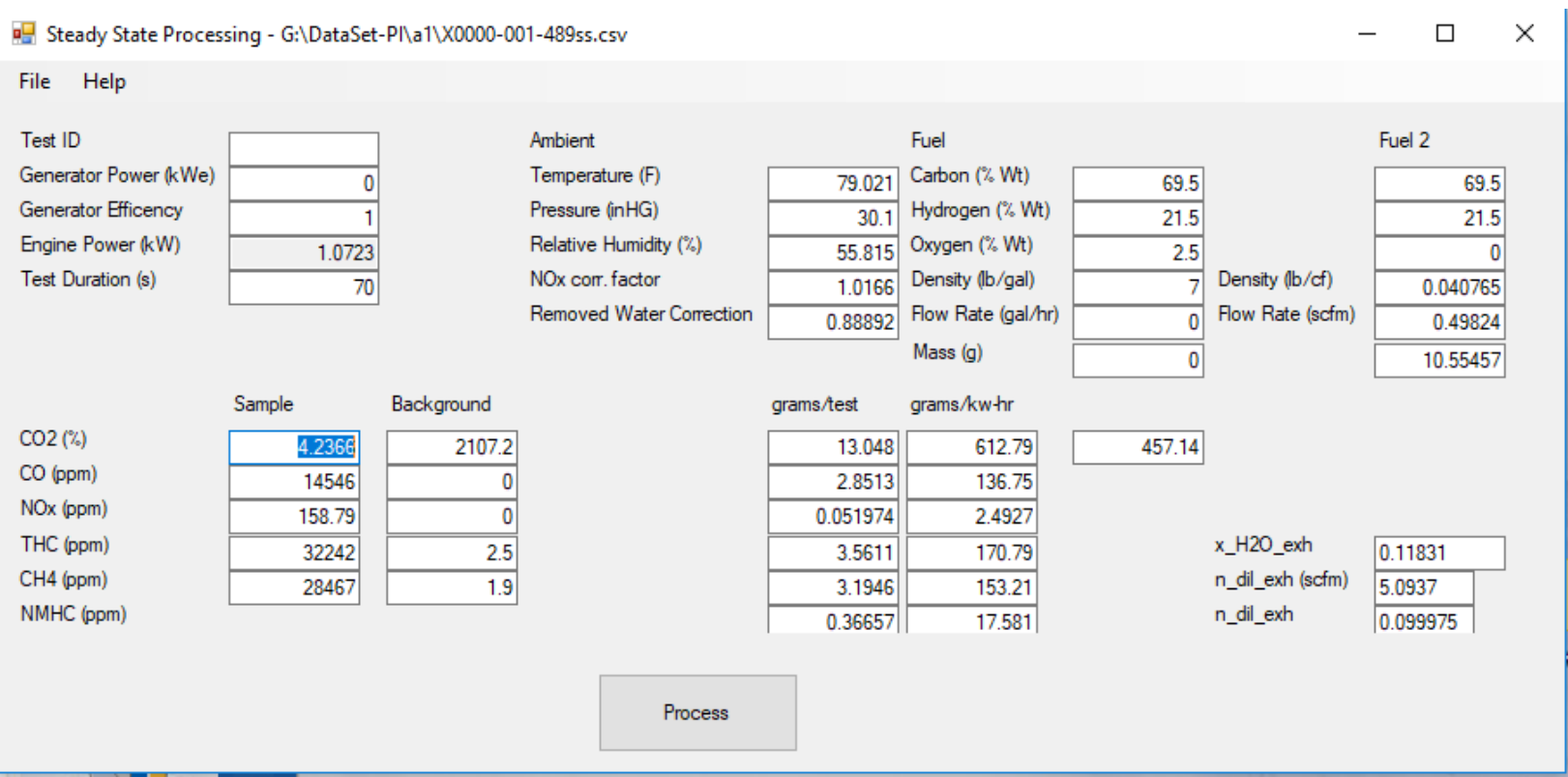

Figure A1 - Example of CFR 1065 program used for emissions processing.

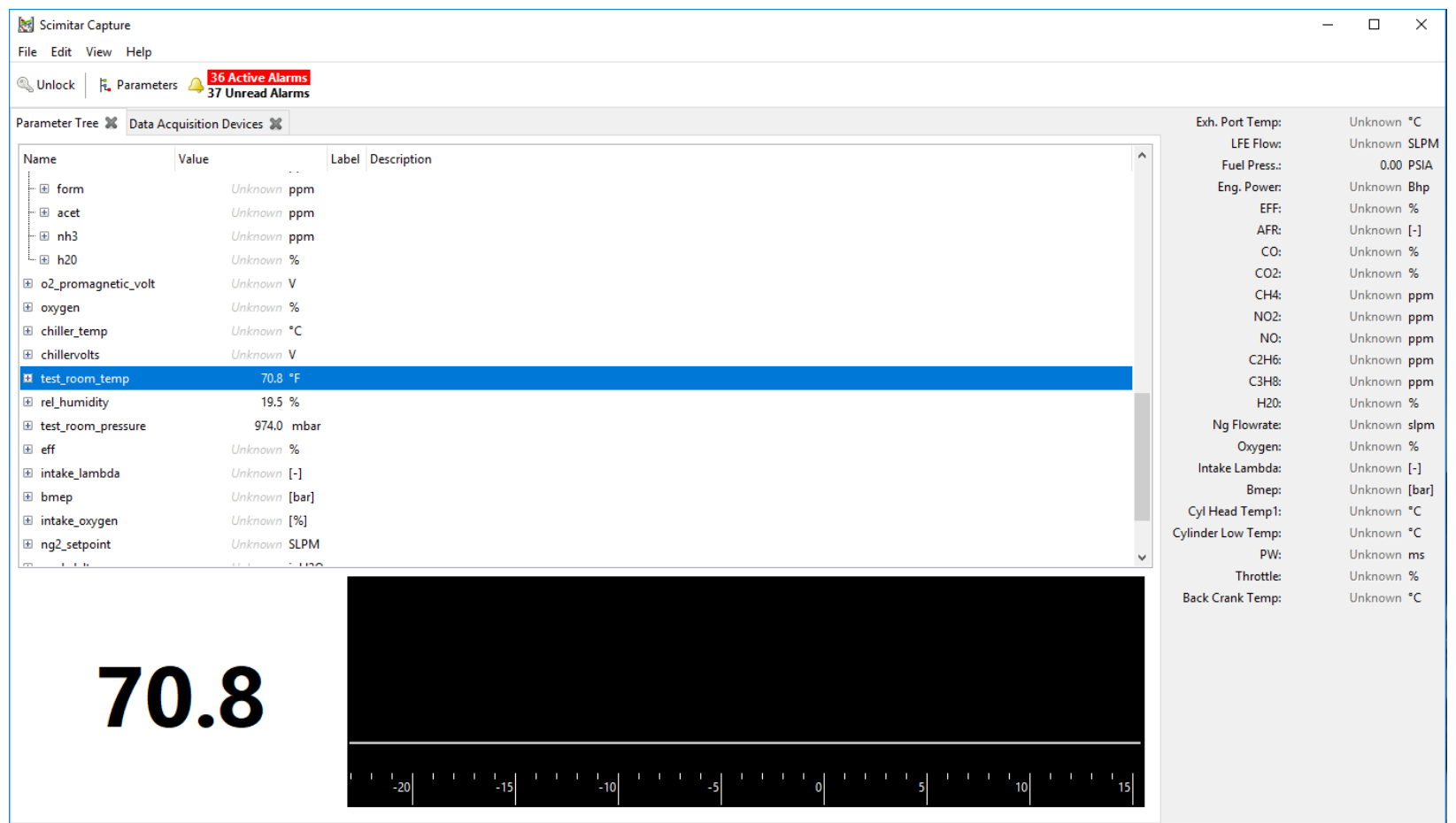

Figure A2 - Example of Scimitar software used for data acquisition. 
[1] KiBoxCockpit - BoostedEngine_Nov2018.kip *

File Edit View Measure KiBox Tools Help

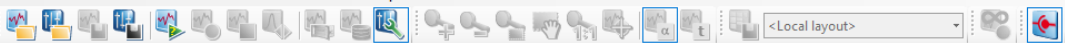

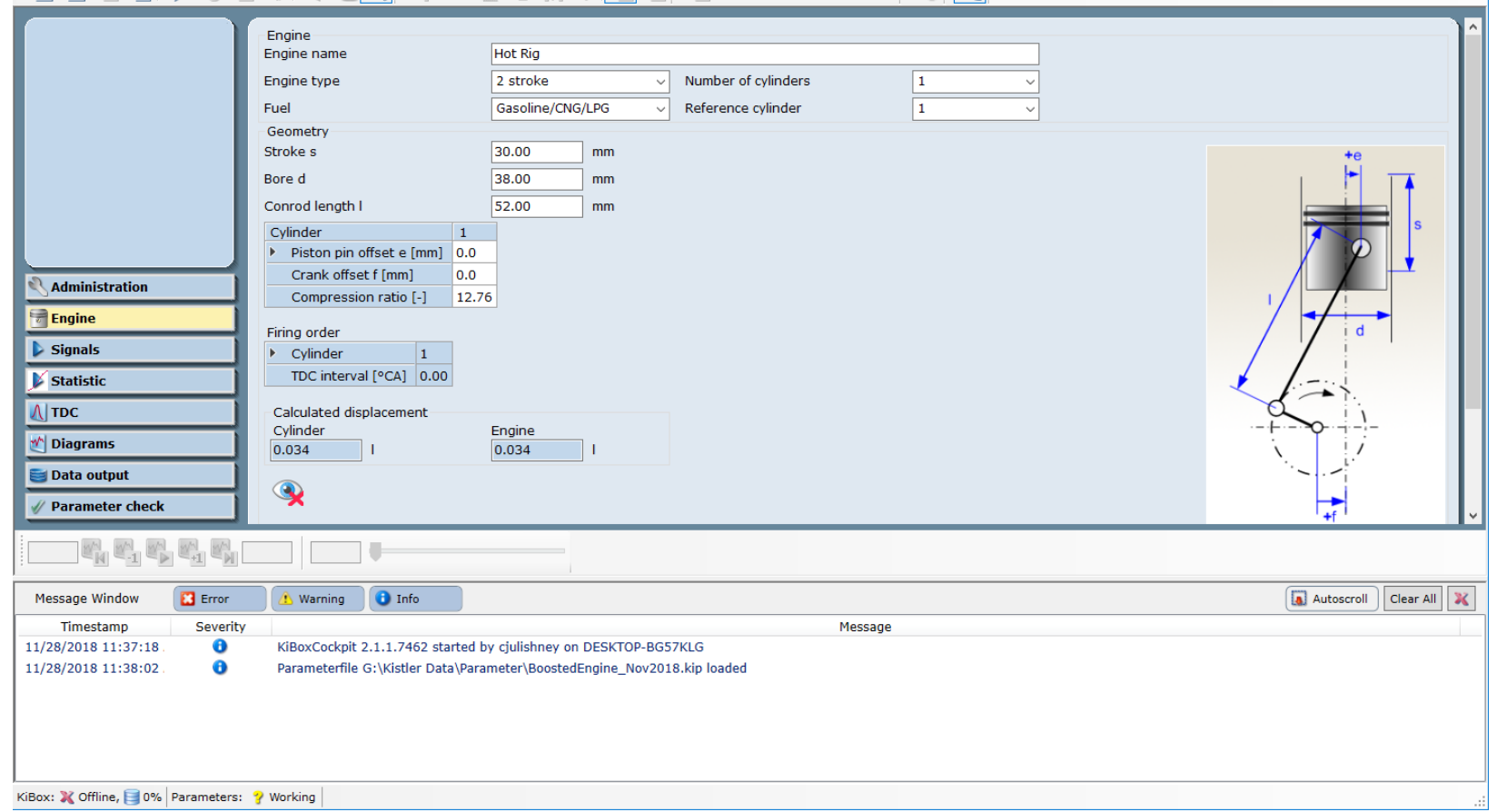

Figure A3 - Example of Kibox software used for combustion data and analysis. 